\title{
Suicide rates/trends and antidepressant prescribing in Italy and Ticino Canton, Switzerland
}

Citation for published version (APA):

Guaiana, G. (2012). Suicide rates/trends and antidepressant prescribing in Italy and Ticino Canton, Switzerland. [Doctoral Thesis, Maastricht University]. Maastricht University.

https://doi.org/10.26481/dis.20121025gg

Document status and date:

Published: 01/01/2012

DOI:

10.26481/dis.20121025gg

Document Version:

Publisher's PDF, also known as Version of record

\section{Please check the document version of this publication:}

- A submitted manuscript is the version of the article upon submission and before peer-review. There can be important differences between the submitted version and the official published version of record.

People interested in the research are advised to contact the author for the final version of the publication, or visit the DOI to the publisher's website.

- The final author version and the galley proof are versions of the publication after peer review.

- The final published version features the final layout of the paper including the volume, issue and page numbers.

Link to publication

\footnotetext{
General rights rights.

- You may freely distribute the URL identifying the publication in the public portal. please follow below link for the End User Agreement:

www.umlib.nl/taverne-license

Take down policy

If you believe that this document breaches copyright please contact us at:

repository@maastrichtuniversity.nl

providing details and we will investigate your claim.
}

Copyright and moral rights for the publications made accessible in the public portal are retained by the authors and/or other copyright owners and it is a condition of accessing publications that users recognise and abide by the legal requirements associated with these

- Users may download and print one copy of any publication from the public portal for the purpose of private study or research.

- You may not further distribute the material or use it for any profit-making activity or commercial gain

If the publication is distributed under the terms of Article $25 \mathrm{fa}$ of the Dutch Copyright Act, indicated by the "Taverne" license above, 
Suicide trends and antidepressant prescribing in Italy and Ticino Canton, Switzerland

Giuseppe Guaiana

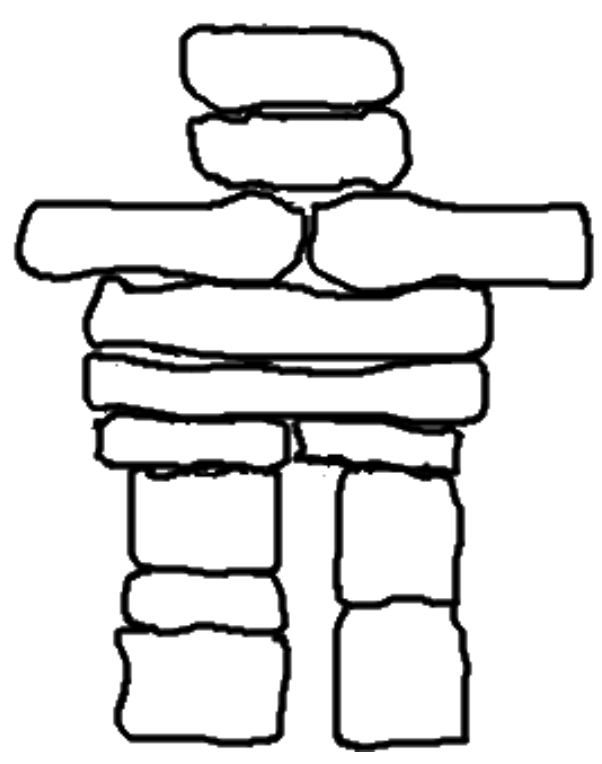




\section{Suicide trends and}

\section{antidepressant prescribing in}

Italy and Ticino Canton,

Switzerland 
Printed by: Smikhouse

Design: Giuseppe Guaiana 


\section{Suicide rates and antidepressant prescribing in Italy and Ticino Canton, Switzerland}

\section{DISSERTATION}

to obtain the degree of DOCTOR at Maastricht University on the authority of the Rector Magnificus, Prof. L.L.G. Soete in accordance with the decision of the Board of Deans to be defended in public on Thursday the $25^{\text {th }}$ of October 2012, at 14:00 hours

by

GIUSEPPE GUAIANA 


\section{Supervisor:}

Prof. dr. E.J.L. Griez

\section{Assessment committee:}

Prof. Dr. I. Germeys (chairman)

Prof. Dr. Marc Ansseau (Liege, Belgium)

Prof. Dr. P. Delespaul

Dr. F. Peeters

Dr. K. Schruers 
To Loen: THE shining lighthouse in my life 


\section{Contents}

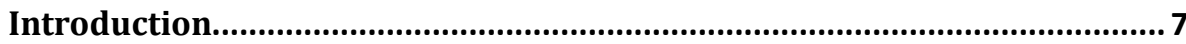

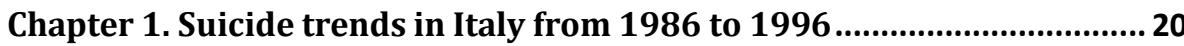

Chapter 2. Suicide in Italian adolescents: mortality trends among people aged 15-19 from 1972 to 2008 ........................................................................... 37

Chapter 3. Suicide and antidepressant prescribing in Italy, 1955-2000 ... 56

Chapter 4. Antidepressant drugs prescribing and suicide in EmiliaRomagna region (Italy), 1999-2008

Chapter 5. Antidepressant prescribing, suicide and hospital admissions for depression in Veneto region (Italy), 2000-2005

Chapter 6. Admissions for Personality Disorders in Italy and suicide. Are Personality Disorders a determinant of suicide?

Part 1. Admissions for Personality Disorders in Italy from 1988 to 1998 122

Part 2. Note: are personality disorders a determinant of suicide? 132

Chapter 7. An epidemiological investigation of suicides in Ticino Canton (Switzerland) compared to neighboring areas, 1999-2007

Conclusion 167

Nederlanse Samenvatting …..................................................................... 176

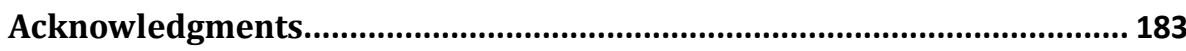

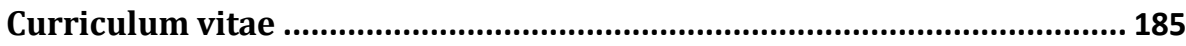

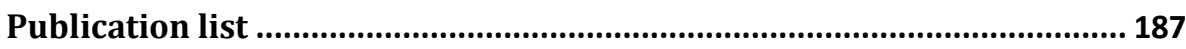




\section{Introduction}


Psychiatric Epidemiology has been recently gaining more and more importance in mental health research (Prince et al, 2003). An important application of Psychiatric Epidemiology is the epidemiology of suicide. Social and epidemiological aspects of suicide were first systematically investigated by the French sociologist Emile Durkheim in a seminal book published at the end of the eighteenth century (Durkheim, 1951). He found that there was a relationship between religion and suicide. He explored suicide rates in 13 Prussian provinces and noticed that area with a Protestant background yielded more suicide rates than areas where the majority of the population was catholic. Many studies with different methods have been employed to explore suicides and suicide rates in the general population. Descriptive methods and psychological autopsies have been used among others (Prince et al, 2003). Data for descriptive studies are usually taken from official statistics and coroners' reports (Prince et al, 2003). There has understandably been some interest in suicide research, as suicidal behavior is a very important public health problem. Suicide is the tenth leading cause of death worldwide (Hawton et al, 2009), with approximately one million people dying by suicide worldwide (Nock et al, 2008). Many cases may be underreported (Hawton et al, 2009). Concerns have been raised on the incidence of suicide, which led the World Health Organization to call for an expansion of data collection on prevalence and risk factors (Nock et al, 2008). Data collection on suicide has been considered vitally 
important, as patterns may emerge in suicide and suicidal behavior (Nock et al, 2008, Hawton et al, 2009). For example, there are clear ethnic patterns. In the United States, Hispanic Americans and African Americans commit suicide less often than European American (Hawton et al, 2009). In other countries, ethnic minorities, such as Inuit and Métis in Canada, show higher suicide rates (Hawton et al, 2009). Methods to commit suicide include more violent ones (for example shooting or hanging) and less violent ones (for example self-poisoning). In general, men chooses more violent means, whilst women chose less violent ones (Hawton et al, 2009). Suicide rates also show geographical variations: very high suicide rates (in excess of 70 deaths per 100,000 population per year) are found in the Baltic Republics, whilst very low rates are found in Latin American countries (around 10 deaths per 100,000 population per year; Gunnell, 2000). There is also some variation in rates according to socioeconomic status and employment situation (Hawton et al, 2009), with high risk of suicide identified in poor and/or unemployed people. Several risk factors for suicide have been identified. Studies consistently show that suicide risk is a combination of genetic and environmental factors (Hawton et al, 2009). Variables identified include (Nock et al, 2008; Hawton et al 2009):

1. Genetic loading

2. Personality characteristics

3. Perinatal circumstances 
4. Early traumatic life events

5. Recent stressful life events

6. Neurobiological disturbances

7. Psychiatric disorders

8. Physical disorders

9. Psychosocial problems

10. Availability of means

11. Exposure to models

Among these above factors, the presence of a psychiatric disorder is one of the strongest predictor of suicide risk (Nock et al, 2008). Psychological autopsy studies have shown that about 90 per cent of people who died by suicide had a mental disorder at the time of suicide (Nock et al, 2008), although the percentage is lower in some countries like China (Nock et al, 2008). Among psychiatric disorders, major depressive episode, borderline personality disorder and substance dependence show the strongest association with suicide (Cheng et al, 2000). However, even anxiety disorders and panic can be independent risk factors for suicide (Katz et al, 2011). It is evident that psychiatric disorder, particularly the one linked to impulsivity and mood, can indeed increase the risk for suicide. It has been argued that early detection and treatment of psychiatric disorder may lead to a lower suicide rate (Isaccson et al, 2010). In particular, prompt treatment of major depression with antidepressants has been associated with lower suicide rates (Isacsson et al, 2008; Isacsson 
at al, 2010). Several methods can be employed to explore the association between medication prescribing and a certain event. These methods are the object of study of Pharmacoepidemiology. Pharmacoepidemiology is the branch of epidemiology that studies the use and effects of drugs in a large number of people (Strom, 2005).

Pharmacoepidemiological approaches can be very useful in several domains, such as systematic definition of medication needs, assessment of patterns of drug utilization, explanations for poor compliance, quantification of incidence and severity of side effects (Avorn, 2004). It has been argued that pharmacoepidemiology can be a very helpful tool which complements the Randomized Controlled Trial and stimulates innovation, as it assesses the situation in real life and can provide policymakers and clinicians with precious information on appropriate drug use, underutilization or overuse of certain drugs (Avorn, 2004). A Randomized Controlled Trial is necessarily based on a small sample, whilst an epidemiological study can potentially capture in entire population. Often, large differences exist between Randomized Controlled trials results and field assessment of medication use (Verdoux et al, 2004). The pharmacoepidemiological approach has been applied to the investigation of the use of psychotropic medication at the population level in several studies (Verdoux et al, 2004). Pharmacoepidemiology has moved beyond the mere counting of 
prescribed drugs (Vitiello, 2005) and offered some interesting insights into real efficacy of medication. For example, pharmacoepidemiological studies were responsible for the dramatic increase in the number of randomized controlled trials exploring the efficacy of psychotropic medication in children (Vitiello, 2005).

One area of psychiatry where a pharmacoepidemiological approach has been instrumental in shading some light over a controversial issue is the relationship between antidepressant prescription and suicide. This topic has been the subject of a hot debate in the mid-2000s. There have been reports that antidepressants, especially SSRIs, can cause an increase in suicidality. One of the most relevant contributor to this debate is David Healy, who argued that Selective Serotonin Reuptake Inhibitors antidepressants (SSRIs) can increase the likelihood of committing suicide in depressed people (Healy et al, 2003). His claims were based on several case reports of intense suicidal preoccupation after starting treatment with fluoxetine (Teicher et al, 1990). Other case reports followed, which described the same event after treatment with fluoxetine and other SSRIs (Healy et al, 2003). The debate has been quite controversial. Many studies have accumulated over the years. The tentative conclusions are that a minority of patients experience suicidal ideation on antidepressants and need to be carefully monitored. (Pompili et al, 2010). The data quality is variable. Many studies are ecological 
and therefore subject to bias and confounding factors (Pompili et al, 2010). Therefore, the issue remains open.

The papers presented in this thesis offer a contribution to the use of an epidemiological and pharmacoepidemiological approach to suicide and prescription of antidepressants. The overall aim of the thesis is to outline the trends in suicide rates in Italy and Ticino Canton, Switzerland, and to explore relationship between suicide and prescription of antidepressants. The first Chapter (Chapter 1) sets the scene. It is an exploration of suicide in Italy between 1986 and 1996. The study is descriptive and uses the national database from the Italian National statistical office (ISTAT). The study has been carried out to investigate suicide trends in Italy, as some worrying data were published which showed an increase in suicide rates in Italy from 1975 to 1987 . Usually, suicide rates are not necessarily uniform across age ranges. Chapter 2 of the thesis explores the issue of suicide among children and adolescents, to see whether a different pattern can be observed. Using data from the same database of Chapter 1, the study in Chapter 2 focuses on suicide among people aged 15 to 19 in Italy from 1972 to 2008. Different explanation have been generated for trends in suicide rates in Italy and elsewhere. One of the most debated issue on suicide causality is the relationship between antidepressant prescribing and suicide. As reported above, this topic has generated a heated debate among researchers and is discussed in the study presented in Chapter 3. This paper presents data on 
antidepressant prescribing and suicide in Italy. It covers quite a long time period. Suicides are examined from 1955 to 2000, whilst antidepressant prescribing has been explored from 1987 to 2000 . The database used for suicide is the same for the studies in Chapter 1 and 2, whilst the database on antidepressant prescribing has been obtained from IMS Health, a private organization. Hospital admissions for depression were also explored using, again, the Italian National Statistical Office (ISTAT) database. A complete analysis of suicide rates, should also consider regional variations. Italy is a country with marked regional differences. Suicide rates can change from region to region (ISTAT, 2005), as well as antidepressant prescribing. The exploration of similarities and differences among regions can offer some insight on possible causes of suicide events. A regional analysis of suicide rates and antidepressant prescribing has been presented in Chapter 4 and 5 for the Italian regions EmiliaRomagna and for the Veneto region. Data on Chapter 4 have been extracted from local databases from region Emilia-Romagna, and cover years from 1999 to 2008. Unlike Chapter 1, 2, 3, where a purely descriptive approach was employed, in Chapter 4 data were analyzed using a simple linear regression model. The same model has been used for data in Chapter 5. Again, antidepressant prescribing has been analyzed in Veneto region and associated with suicide rates, covering a six-year span (from 2000 to 2005). The paper in Chapter 5 offer more details on antidepressant 
prescribing compared to Chapter 3 or 4, as data are divided by age and sex. Antidepressant prescribing was analyzed in people aged 0-14, 15-64 and over 65. This gives some advantage, as antidepressant use varies by age, as well as suicide rates. Admissions for depression were also explored. One of the hypotheses of this study is that if admissions for depression have declined, it means that there are less severe cases of depression, as severity as we considered admissions for depression an important proxy data for depression severity. Depression and other Axis I disorders are certainly an important determinant of suicide. However, personality disorders are also a quite significant causal factor. Chapter 6 explores this issue. It is divided into two sections: Chapter 6, part 1 explores admissions rates for personality disorders in the whole of Italy from 1988 to 1998, as well as first admissions for personality disorders in the same period. Data were collected from the National Institute of Statistics of Italy (ISTAT). A descriptive approach has been employed. As for depression, hospital admissions for personality disorders can be considered a proxy for severity. Chapter 6, part 2 enhances the findings of Chapter 6, part 1, by reviewing the evidence available on the link between suicide and personality disorders. Chapter 6, part 2 is a review on the topic. So far, the various chapters have talked about mental health problems and their relationship with suicide. Whilst this is a very important cause of suicide, one should not forget that there are other 
determinants. Culture is one of these. In the final chapter of this thesis, Chapter 7, suicides rates in Ticino Canton, Switzerland have been shown and compared to bordering Italian Provinces. Ticino Canton is an Italian-speaking canton of Switzerland. It shares elements of Italian and Swiss culture. This last chapter explores possible determinants of suicide through the lens of cultural and systems variations.

In summary, this thesis attempts to provide some tentative answers to the questions on how to assess and reduce suicides using an epidemiological perspective. Several factors that are linked to suicide have been analyzed, from mental problems to pharmacological treatments, including also cultural and systemic aspects of suicide. 


\section{References}

Avorn J. The Role of Pharmacoepidemiology and Pharmacoeconomics in Promoting Access and Stimulating Innovation. Pharmacoeconomics, 2004; 22(Suppl 2): 81-86.

Cheng ATA, Chen THH, Chen CC, Jenkins R. Psychosocial risk factors for suicide. Case-control psychological autopsy study. British Journal of Psychiatry, 2000; 177: 360-365.

Durkheim E. Suicide: a study in sociology. The Free Press, 1951 reprint.

Gunnell DJ. Epidemiology of suicide. International Review of Psychiatry, 2000; 12: 21-26.

Hawton K, Van Heeringen K. Suicide. The Lancet, 2009; 373: 13721381.

Healy D, Whitaker C. Antidepressants and suicide: risk-benefit conundrums. Review Psychiatry and Neuroscience,2003; 28: 331337. 
Isacsson G, Rich C. Antidepressant medication prevents suicide: a review of ecological studies. European Psychiatric Review, 2008, 1: 24-26.

Isacsson G, Rich C, Jureidin J, Raven M. The increased use of antidepressants has contributed to the worldwide reduction in suicide rates. British Journal of Psychiatry, 2010; 196: 429-433.

ISTAT: Annuario Statistico Italiano. Rome: ISTAT; 2000-2005.

Katz C, Yaseen ZS, Mojtabai R, Cohen LJ, Galynker II. Panic as an independent risk factor for suicide attempt in depressive illness: findings from the National Epidemiological Survey on Alcohol and related conditions. Journal of Clinical Psychiatry, 2011; 72: 16281635.

Nock MK, Borges G, Bromet EJ, Cha CB, Kessler RC, Lee S. Suicide and suicidal behavior. Epidemiologic Reviews, 2008; 30: 133-154.

Pompili M, Serafini GL, Innamorati M, Ambrosi E, Giordano G, Girardi P, Tatarelli R, Lester D. Antidepressants and Suicide Risk: A Comprehensive Overview. Pharmaceuticals, 2010; 3: 28612883. 
Prince M, Stewart R, Ford T, Hotopf M (Eds). Practical Psychiatric Epidemiology. Oxford: Oxford University Press, 2003.

Strom BL (Ed). Pharmacoepidemiology, $4^{\text {th }}$ edition. Chichester: Wiley, 2005.

Teicher MH, Glod C, Cole JO. Emergence of intense suicidal preoccupation during fluoxetine treatment. American Journal of Psychiatry, 1990; 147: 207-210.

Verdoux H, Begaud B. Pharmaco-epidemiology: what do (and don't) we know about utilisation and impact of psychotropic medications in real-life conditions? British Journal of Psychiatry, 2004; 185: 93-94.

Vitiello B. Pharmacoepidemiology and Pediatric Psychopharmacology Research. Journal of Child and Adolescent Psychopharmacology, 2005; 15: 10-11. 


\section{Chapter 1. Suicide trends in Italy from 1986 to 1996}

Published as: Guaiana G, D’Avanzo B, Barbui C. Update of suicide trends in Italy from 1986 to 1996. Social Psychiatry and Psychiatric Epidemiology, 2002, 37: 267-270. 


\section{Summary}

Background. In some Western countries increasing suicide rates have been observed among males, especially young men, with a decline of female suicides. The present study analysed age-specific and age-standardised suicide rates in Italy. Method. From 1986 to 1996 national statistics on numbers of suicides in each sex and age group were examined. Results. Overall, suicides have remained substantially stable from 1986 to 1996 . Among males over 45 years of age rates progressively decreased, and among subjects below 15 years rates remained stable. In the 15-24 and 25-44 age groups rates progressively rose: an overall increase of $2.76 / 100,000$ and 1.60/100,000 was recorded, respectively. Among females over 45 years of age suicide rates progressively decreased, while rates in the other age groups remained fairly stable. Conclusion. The present analysis documents a rise in suicides among young men, and highlights the need for agespecific suicide prevention programmes. 


\section{Introduction}

Suicide rates vary in different countries and at different times (La Vecchia et al., 1994). In most Western countries recent rates of overall deaths by suicide are stable or slightly declining. However, in some areas suicide rates have risen for males, especially young men (Cantor, 2000; Lubin et al., 2001), with a significant decline of female suicides (Charlton, 1995; Zacharakis et al., 1998). In contrast with this general trend suicides are on the increase among young females in other countries, for example New Zealand and Norway, (Rygnestad, 1992; Deavoll et al., 1993). According to World Health Organization, world-wide suicide trends have shown a progressive change in age distribution: the proportion of young people committing suicide rose from $44 \%$ in 1950 to 53\% in 1995 (World Health Organization, 2000).

In Italy the analysis of age-specific suicide trends showed an overall increase in suicide deaths of about 35\% for males and over 15\% for females from 1975 to 1987 (D’Avanzo et al., 1993). More recent, analyses have focused on specific research hypotheses, such as the influence of climate on suicidal behaviour (Preti, 1997; Preti, 1998), possible diurnal variations in suicide (Preti and Miotto, 2001), the relationship between unemployment and suicide (Preti and Miotto, 1999) and the possible association between new antidepressants and suicide trends (Barbui et al., 1999). However, recent overall deaths by suicide have not been 
analysed by gender and age. The aim of this study is therefore to update age-specific and age-standardised suicide mortality rates to 1996 and to describe the distribution of suicides in Italy in the last decade by methods.

\section{Materials and methods}

National data on numbers of suicide deaths according to the Ninth Revision of the Italian International Classification of Diseases (ICD-IX) in each sex and age-group and estimates of the Italian resident population were collected from the Central Institute of Statistics (ISTAT) from 1986 to 1996 . No information is available from ISTAT after 1996. From these data, age-specific and agestandardised death certification rates for all suicides were computed. Standardisation was done by the direct method on the basis of the Italian population of the 1991 census year. Calculations were done using STATA 4.0 (StataCorp, 1995)

ISTAT data on suicide methods were extracted according to ICDIX, and include the following categories: $950=$ poisoning by solid or liquid substances; 951 and 952 = poisoning by gas; $953=$ hanging; 954 = submersion; 955 = firearms and explosives; $956=$ cutting and piercing instruments; 957 = jumping from high places; $958=$ other non-specified method. 


\section{Results}

Standardised suicide rates in Italy from 1986 to 1996 are presented in Table 1. Among males the rate decreased by 0.72 per 100,000 and among females by 1.02 per 100,000 (Table 1 ).

Table 1 Suicides in Italy 1986-1996

\begin{tabular}{llllll}
\hline \multirow{2}{*}{ Year } & \multicolumn{2}{l}{ Males } & & \multicolumn{2}{l}{ Females } \\
\cline { 3 - 3 } \cline { 5 - 6 } \cline { 5 - 6 } & No. & $\begin{array}{l}\text { Standardised } \\
\text { rate per 100,000 }\end{array}$ & & No. & $\begin{array}{l}\text { Standardised } \\
\text { rate per 100,000 }\end{array}$ \\
\hline 1986 & 3,293 & 12.54 & 1,398 & 5.00 \\
1987 & 3,263 & 12.29 & & 1,253 & 4.43 \\
1988 & 3,095 & 11.52 & 1,287 & 4.49 \\
1989 & 3,124 & 11.44 & 1,218 & 4.19 \\
1990 & 3,181 & 11.50 & 1,221 & 4.15 \\
1991 & 3,206 & 11.42 & 1,247 & 4.20 \\
1992 & 3,339 & 11.89 & 1,204 & 4.07 \\
1993 & 3,516 & 12.37 & 1,181 & 3.94 \\
1994 & 3,411 & 11.87 & 1,125 & 3.72 \\
1995 & 3,430 & 11.80 & 1,139 & 3.72 \\
1996 & 3,458 & 11.82 & 1,231 & 3.98 \\
\hline
\end{tabular}

The age-specific rates of suicide in males are presented in Figure 1. The highest rates were among people over 65 years of age, and rates were progressively lower in the other age groups. Among males over 45 years of age rates progressively decreased in the eleven years considered, while among subjects below 15 years they remained stable. In the 15-24 and 25-44 age groups suicide 
rates rose, with overall increases of 2.76/100,000 and $1.60 / 100,000$, respectively.

The age-specific rates of suicide among females are presented in Figure 2. The rates were highest in people over 65 years of age and were progressively lower in the other age groups. Among females over 45 years of age rates progressively decreased in the eleven years considered, while rates in the other three age groups remained fairly stable.

The percentage of suicides committed by males increased from $70.2 \%$ in 1986 to $73.7 \%$ in 1996 , and the percentage for people below 45 years of age rose $6.5 \%$.

The most frequent methods of suicide were hanging and jumping (Table 2). Over the 11 years examined suicide by hanging increased by slightly less than $10 \%$ and suicide by gassing rose nearly three times. All other methods decreased during the study period. 
Suicide trends in Italy from 1986 to 1996

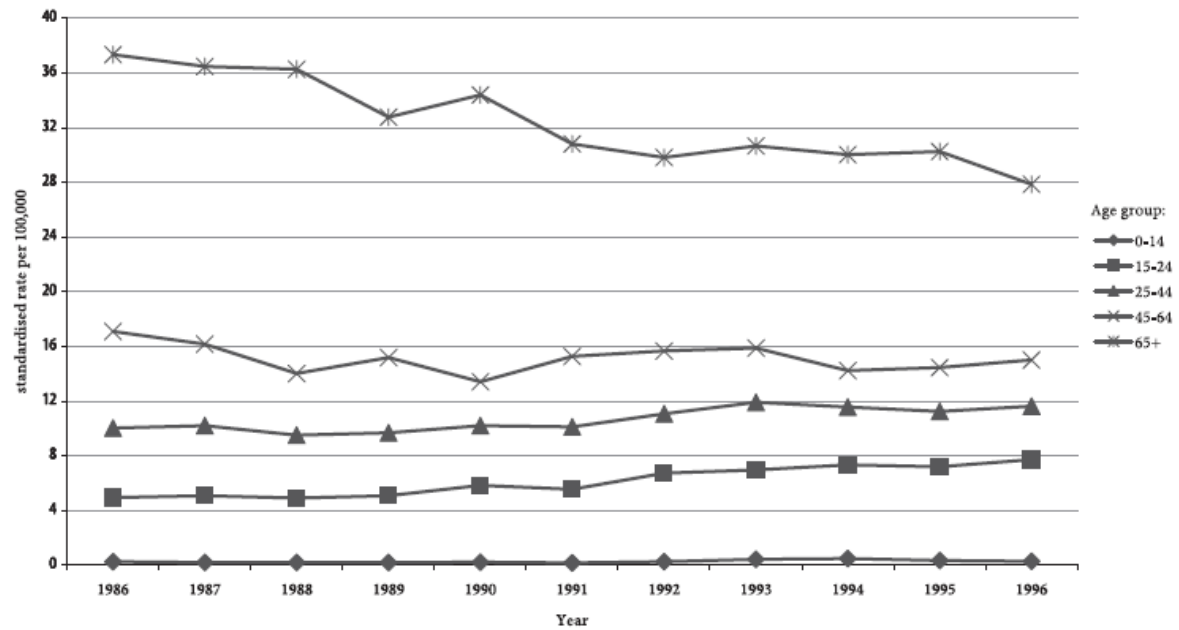

Figure 1. Age-specific male suicide rates in Italy, 1986-1996

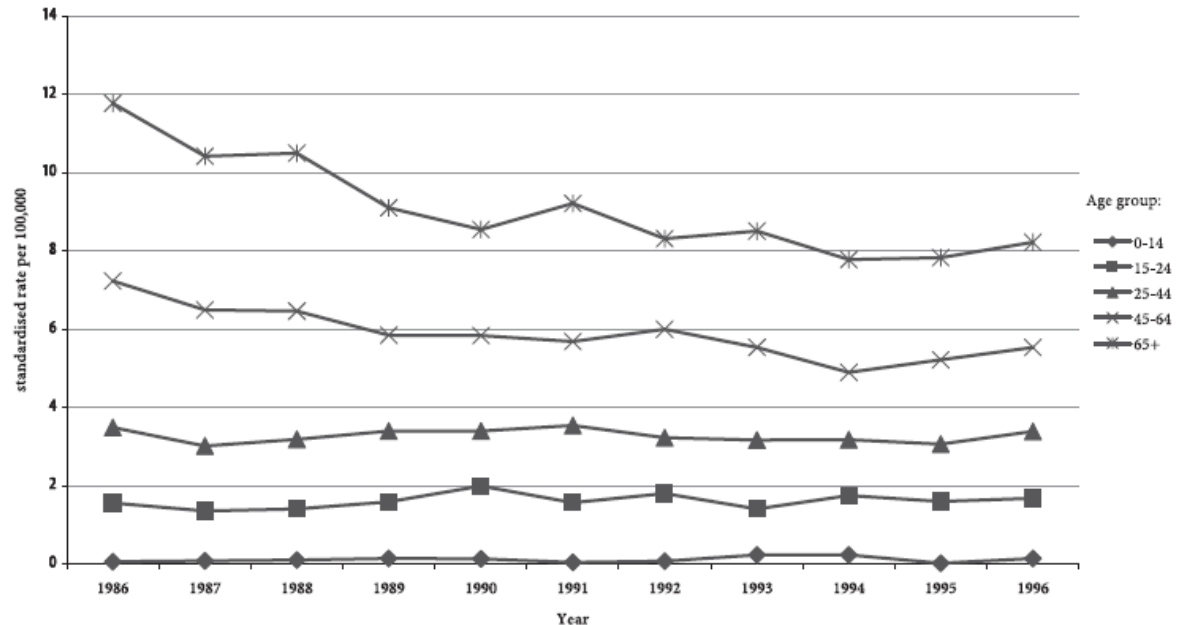

Figure 2. Age-specific female suicide rates in Italy, 1986-1996 


\section{Chapter 1}

Table 2 Distribution of suicides by method in Italy, 1986-1996

\begin{tabular}{lllllllll}
\hline Year & $\begin{array}{l}\text { Poisoning } \\
\%\end{array}$ & $\begin{array}{l}\text { Poisoning by gas } \\
\%\end{array}$ & $\begin{array}{l}\text { Hanging } \\
\%\end{array}$ & $\begin{array}{l}\text { Submersion } \\
\%\end{array}$ & $\begin{array}{l}\text { Firearms } \\
\%\end{array}$ & $\begin{array}{l}\text { Cutting and piercing } \\
\%\end{array}$ & $\begin{array}{l}\text { Jumping } \\
\%\end{array}$ & $\begin{array}{l}\text { Other } \\
\%\end{array}$ \\
\hline 1986 & 6.16 & 3.17 & 35.58 & 9.95 & 14.73 & 1.51 & 1.88 & 23.70 \\
1987 & 4.91 & 3.28 & 38.35 & 8.52 & 14.77 & 3.18 & 25.07 \\
1988 & 5.34 & 3.83 & 36.92 & 8.69 & 13.90 & 2.08 & 3.21 \\
1989 & 5.61 & 3.80 & 37.19 & 7.71 & 13.86 & 1.36 & 25.35 & 3.88 \\
1990 & 4.88 & 8.15 & 36.00 & 6.79 & 13.17 & 1.43 & 25.76 & 3.68 \\
1991 & 4.98 & 8.89 & 34.62 & 7.59 & 13.88 & 2.00 & 24.10 & 3.11 \\
1992 & 4.82 & 8.51 & 34.87 & 7.81 & 13.82 & 2.07 & 24.26 & 3.83 \\
1993 & 4.51 & 8.64 & 36.47 & 6.28 & 15.07 & 1.89 & 23.40 & 3.73 \\
1994 & 4.17 & 7.69 & 40.14 & 6.30 & 14.28 & 1.63 & 22.18 & 3.59 \\
1995 & 4.22 & 8.78 & 39.96 & 5.65 & 13.92 & 1.62 & 21.27 & 4.57 \\
1996 & 4.30 & 8.53 & 41.27 & 6.61 & 12.48 & 1.39 & 21.48 & 3.84 \\
\hline
\end{tabular}




\section{Discussion}

The present analysis showed that in the last decade the rise in suicide deaths observed in Italy up to 1987 reached a plateau. Suicides remained substantially stable from 1986 to 1996, and in 1996 the overall suicide mortality was around 12 per 100,000 for males and 4 per 100,000 for females; these rates were similar to figures for other Western countries (World Health Organization, 2000).

Monitoring suicide rates in Italy is particularly important since it was suggested that the progressive closure of psychiatric hospitals and the implementation of community psychiatric care would produce high rates of homelessness and suicide (Jones and Poletti, 1985). However, this was not based on epidemiological evidence. Williams et al. (1986) showed that five years after the Italian psychiatric reform there was no correlation between the suicide rate and the decrease in the number of psychiatric hospital beds. In the last ten years the downsizing of psychiatric hospitals has continued; our analysis found no dramatic impact on overall suicides, in agreement with Williams et al. Furthermore, a national law issued in 1994 sped this process up by prescribing the final dismantlement of all psychiatric hospitals. Between 1995 and 2000 all remaining hospitals closed, and psychiatric patients were placed in the community. In this evolving context of care monitoring suicide deaths on a nation-wide scale and in selected 
areas and patient populations still seems essential for the evaluation of mental health services, in order to rule out any association between community care and suicide.

From 1950 to 1995 the age distribution of world-wide cases of suicide shifted, with a larger proportion of subjects under 45 years of age committing suicide (World Health Organization, 2000). Italian data are consistent with this figure: we observed a $6.5 \%$ rise in the number of young adults committing suicide in the eleven years considered. This can very likely be explained by the increasing rates among young males and the decreasing rates for elderly males and females. Young males between 15 and 24 years and young adult males between 25 and 44 years were the only two age groups where suicide rates have risen in Italy in these eleven years. Female rates for the same age groups remained substantially stable. It is difficult to explain this phenomenon, which has been described in many other Western countries (Cantor, 2000). Risk factors for suicide include familial and social variables, environmental and individual variables (van Heeringen, 2001). Among the latter, psychological and psychiatric disorders seem to play a central role. Approximately $10 \%$ of mentally ill people die by suicide, compared to $0.015-0.05 \%$ of the general population (Tanney, 1992). Specific psychiatric disorders associated with suicide are depression, schizophrenia, substance 
abuse and borderline personality disorder. In Italy some data have been published suggesting that the hospital incidence for schizophrenia and other major psychoses is on the increase: from 1984 to 1994 first-admission rates for schizophrenia and paranoia rose progressively, as did those for affective psychosis, mania and major depression (Preti and Miotto, 2000). Obviously, these data might reflect changes in the organisation of mental health care in Italy, but might also indicate some changes in the true incidence of psychoses, as suggested for example for mood disorders in some countries. Thus, the increasing suicide rate in young people in Italy might be partly related to recent trends in the incidence of specific psychiatric disorders.

In Italy the distribution of cases of suicide by method showed a slight decline in suicides by all methods except hanging and gassing. Hanging accounted for more than $40 \%$ of cases in 1996, thus being the main method, and suicides by gassing increased of nearly three times. This finding is in contrast with trends in England and Wales, where a marked reduction in suicide by gassing was recorded after the detoxification of the domestic gas supplies (Gunnell et al., 2000). The "poisoning" category includes suicides by drug overdose. In Italy in 1988 a new generation of antidepressant drugs, the selective serotonin reuptake inhibitors (SSRI), were introduced; these are safer in overdose than the old antidepressants, thus potentially reducing the risk of suicide. 
Barbui et al. (1999) analysed the increasing use of SSRI from 1988 to 1994 and detected no improvement in overall suicide rates. However, they did not stratify suicides according to method. The present analysis showed that suicides by poisoning slightly declined in the eleven years considered, possibly suggesting that the increasing use of SSRI might has had a positive impact on suicide by poisoning.

In conclusion, the present analysis confirms that overall male and female suicide rates remained stable from 1986 to 1996 in Italy, but that there was a rise among young men, highlighting the need for age-group specific suicide prevention programmes. 
Suicide trends in Italy from 1986 to 1996

\section{Acknowledgements}

We are grateful to Prof. Carlo La Vecchia for his helpful comments and suggestions on previous versions of the manuscript. 


\section{References}

Barbui C, Campomori A, D’Avanzo B, Negri E, Garattini S. Antidepressant drug use since the introduction of SSRI: national trends, regional differences, and impact on suicide rates. Social Psychiatry and Psychiatric Epidemiology, 1999; 34: 152-156.

Cantor C. Suicide in the Western World. In: Hawton K, Van Heeringen $\mathrm{K}$ (eds). The International Handbook of Suicide and Attempted Suicide. Chichester: Wiley; 2000: pp 467-487.

Charlton J. Trends and patterns in suicide in England and Wales. International Journal of Epidemiology, 1995, 24(Suppl 1): S45S52.

D’Avanzo B, La Vecchia C, Negri E, Saraceno B. Suicide mortality in Italy: an update from 1955 to 1987 . Revue d'Epidémiologie et Santé Publique, 1993; 41: 454-460.

Deavoll BJ, Mulder RT, Beautrais AL, Joyce PR. One hundred years of suicide in New Zealand. Acta Psychiatrica Scandinavica, 1993; 87: 81-85. 
Jones K, Poletti A. Understanding the Italian experience. British Journal of Psychiatry, 1985; 146: 341-347.

Gunnell D, Middleton N, Frankel S. Method availability and the prevention of suicide - a re-analysis of secular trends in England and Wales 1950-1975. Social Psychiatry and Psychiatric Epidemiology, 2000; 35: 437-443.

La Vecchia C, Lucchini F, Levi F. World-wide trends in suicide mortality, 1955-1989. Acta Psychiatrica Scandinavica, 1994; 90: 53-64.

Lubin G, Glasser S, Boyko V, Barell V. Epidemiology of suicide in Israel: a nationwide population study. Social Psychiatry and Psychiatric Epidemiology, 2001; 36: 123-127.

Preti A. The influence of seasonal change on suicidal behaviour in Italy. Journal of Affective Disorders, 1997; 44: 123-130.

Preti A. The influence of climate on suicidal behaviour in Italy. Psychiatry Research, 1998, 78: 9-19. 
Preti A, Miotto P. Suicide and unemployment in Italy, 1982-1994. Journal of Epidemiology and Community Health, 1999; 53: 694701.

Preti A, Miotto P. Increase in first admissions for schizophrenia and other major psychoses in Italy. Psychiatry Research, 2000; 94: 139-152.

Preti A, Miotto P. Diurnal variations in suicide by age and gender in Italy. Journal of Affective Disorders, 2001; 65: 253-261.

Rygnestad T. Sucide in Norway. Changes in the $20^{\text {th }}$ century with special emphasis on the development during the last 20 years. Tidsskr Nor Laegeforen, 1992; 112: 38-42.

StataCorp. Stata Statistical Software: Release 4. College Station, TX: Stata Corporation; 1995

Tanney BL. Mental disorders, psychiatric patients and suicide. In: RW Maris, AL Berman, JT Maltsberger, RI Yufit (eds). Assessment and Prediction of Suicide. New York: Guilford Press; 1992: pp 277320. 
Van Heeringen C. Suicide in adolescents. International Clinical Psychopharmacology, 2001, 16(Suppl 2): S1-S6.

World Health Organization. Mental and Behavioural Disorders. Figures and facts about suicide. WHO/MNH/MBD/99.1. Geneva: Department of Mental Health, Social Change and Mental Health, World Health Organisation; 2000.

Williams P, De Salvia D, Tansella M. Suicide, psychiatric reform, and the provision of psychiatric services in Italy. Social Psychiatry, 1986; 21: 89-95.

Zacharakis CA, Madianos MG, Papadimitriou GN, Stefanis CN. Suicide in Greece 1980-1995: patterns and social factors. Social Psychiatry and Psychiatric Epidemiology, 1998; 33: 471-476. 


\section{Chapter 2. Suicide in Italian}

adolescents: mortality trends among people aged 15-19 from 1972 to $2008^{1}$

${ }^{1}$ The present study has been reported in a previous version as: Campi $R$, Barbato A, D'Avanzo B, Guaiana G, Bonati M. Suicide in Italian Children and Adolescents. Journal of Affective Disorders 2009; 113: 291-295. 
Suicide in Italian adolescents: mortality trends among people aged 15-19 from 1972 to 2008

\section{Summary}

Background: Data and statistics on suicide mortality in several countries have been published and discussed over the last few decades but gaps in knowledge are present in the epidemiology of suicide among Italian youths. Methods: Suicide mortality data for the years 1973-2008 were obtained from the Italian Central Institute of Statistics (ISTAT). Age-standardized mortality rates were calculated and examined for trends over time. Results: suicide rates in Italian adolescents overall increased in males and decreased in females from 1972 to 2008. Between 2002 and 2008, suicide has consistently been the third leading cause of death in Italian adolescents (people aged 15 to 19) males, after road accidents and tumors, and the fourth or fifth in females, after road accidents, tumors, and cardiovascular diseases (ISTAT, 19722008). Limitations: Routine suicide mortality data have several weaknesses; these are especially, related to the level of accuracy in the certification of violent causes of death. Conclusion: A national research programme to study suicidal behaviour and risk factors in children and adolescents is essential. The permanent monitoring of the situation, exploring gender and interpersonal issues with the aim to plan protective initiatives in an appropriate manner, is also fundamental. 


\section{Introduction}

Suicide in adolescents is a one of the leading cause of death of young people worldwide (Gunnell at al, 2003) and has been defined as a preventable tragedy (Greydanus, 2009). Around 200,000 youth and young adults commit suicide every year in the world (Greydanus, 2007). In the last years, several authors raised concern about increasing suicide rates in adolescents (Van Heeringen 2001, Pelkonen and Marttunen, 2003), but a careful examination of published data on temporal trends of youth suicide in last thirty years in Europe showed conflicting results (Mittendorf-Rutz, 2004). The different pattern across countries can be partly related to the different periods of time studied, particularly when an event is rare, and trends can be influenced even by small variations. Comparison is made difficult also by different age grouping: collapsing the age group 15-19 with that 20-24 can be misleading (Zacharakis, 2005), since the two age groups have been observed to show different rates.

In European countries, either increasing, decreasing and stable trends are represented both in men and women. On a whole, between 1980 and 1995 (Mittendorfer-Rutz et al, 2004), there were several countries with increases in men and stable or decreases in females, and a few countries with stable rates in both sexes. In England and Wales, the increase in males was confirmed 
in analyses conducted on longer periods (McClure 2001, Hawton 2005), however a more recent study showed falling trends of suicide rate in the whole of United Kingdom (Windfuhr et al 2008). In the US, a decrease in males and females was observed in the period 1992-2001 (Bridge et al 2005, Gould et al 2003), and in Canada stable trends between 1979 and 1999 were reported (Cheung et al, 2005).

Various causes are mentioned for changing trends, but evidence supporting preventive strategies is scant (McClure 2001, Greenberg et al 2003, Gould et al 2003), and suggests that the phenomenon is locally characterised. A better understanding of the problem and enhanced possibilities for prevention needs to be based on local epidemiological surveillance and research (World Health Organization, 2001), and on sufficiently long periods of time.

The aim of this study is to analyze suicide rates in Italy among males and females aged 15-19 years, from 1972 to 2008.

\section{Materials and methods}

Data on suicide in Italy have been routinely collected and published by the Italian Central Institute of Statistics (ISTAT). Mortality data were published in the Causes of Death Statistics Yearbooks. At present, no data for suicides are available after 
2008 according to age and sex. We considered as suicides the events classified from E950 to E959 in the diseases list of the Ninth Revision of the International Classification of Diseases (ICD9; World Health Organization, 1978) until 2003. Since 2004, ISTAT switched the classification to ICD-10 (World Health Organization, 1992). We then considered as suicides the events classified from X60 to X84 in the diseases list of the ICD-10 (World Health Organization, 1992). Unfortunately, no data is available on 2004 and 2005 from ISTAT, as they have not been released yet.

Suicide numbers and population data were used to compute sexspecific rates per 100,000 population for the age 15 to 19 each year between 1972 and 2008, for each sex.

A statistical model using ordinary least squares linear regression was employed, based on the model developed by Preti and Miotto (Preti et al, 2000), who analyzed hospital admission for psychoses in Italy. The model was used in the present study to test for changes over time in suicide rates. Rates were the dependent variable and years were the independent variable. Linear regression analysis of suicide over 35 years (1972-2003, 20062008) was performed, with two missing data (year 2004 and 2005). A two-tailed t-test was also performed to test for the hypothesis of a significant slope. Data were analyzed using SPSS for Windows version 19. 
Suicide in Italian adolescents: mortality trends among people aged 15-19 from 1972 to 2008

\section{Results}

Trends of suicide rates in people aged 15-19 years from 1972 to 2008 are shown for the two sexes, in Figure 1.

Suicide rates of males and females aged 15-19

1972-2008

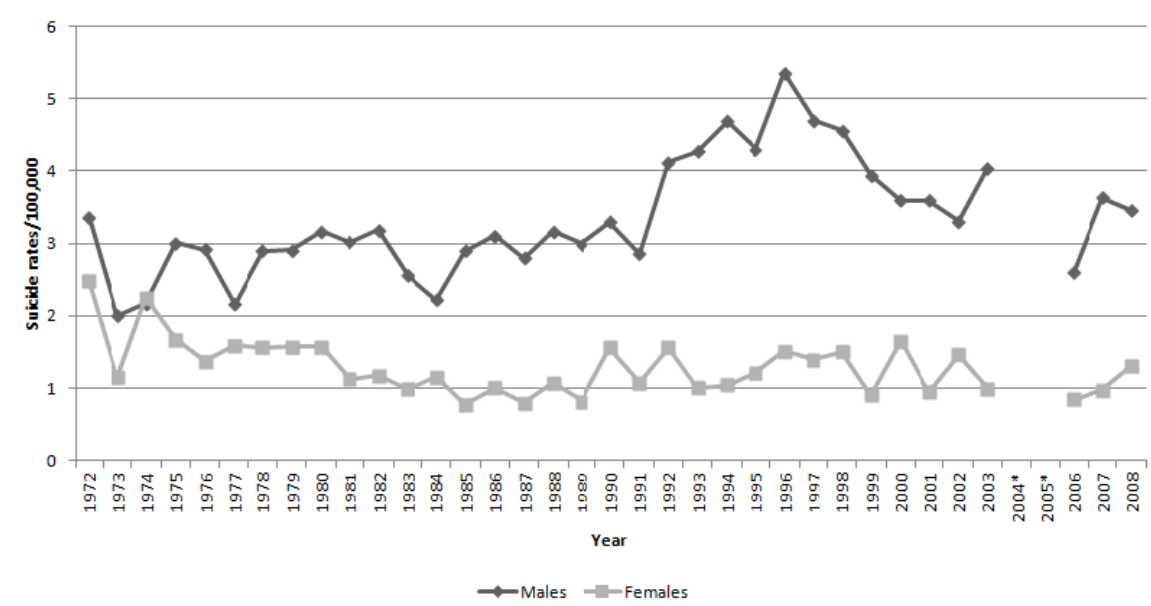

*missing data

Figure 1.

An increase across the entire period was apparent for males, whereas in females a tendency to decrease was observed between 1974 and 1989, and afterwards the rates remained substantially stable. A peak was observed in 1996 among males, when rates reached 5.35/100,000 (corresponding to 96 suicides), and among females in 1972, with a rate of 2.48/100,000 (47 suicides), then suicide rates declined in males after 1996, until 2005, and then 
they increased until 2008. In females, suicide rates oscillated between 0.99 and 1.31 from 2003 to 2008. In 2008, suicide deaths were 53 in males and 19 in females, corresponding to rates of 3.45 and 1.31 per 100,000 population, respectively.

Rates among males were higher than rates among females throughout the whole period examined, except in 1974. The ratio between male and female rates was 1.4 in 1972 and 2.63 in 2001, with a steady increase across the period observed.

Linear regression model for suicide rates showed a significant linear trend both for males (slope $=0.043$; 95\% C.I. $=0.021,0.065$; S.E. $=0.11$; adjusted $R$ square $=0.301 ; F=15.653 ; p=0.0001$ ) and for females (slope $=-0.015 ; 95 \%$ C.I. $=-0.027,-0.004 ;$ S.E. $=0.06$; adjusted $\mathrm{R}$ square=0.153; $\mathrm{F}=7.5120 ; \mathrm{p}=0.012$ ). According to the model, suicide rates significantly increased in males and significantly decreased in females, although less sharply than in males. The extrapolation of least square regression lines for suicide rates in males and females aged 15 to 19 years, respectively, is shown in Figure 2 and 3. 
Suicide in Italian adolescents: mortality trends among people aged 15-19 from 1972 to 2008

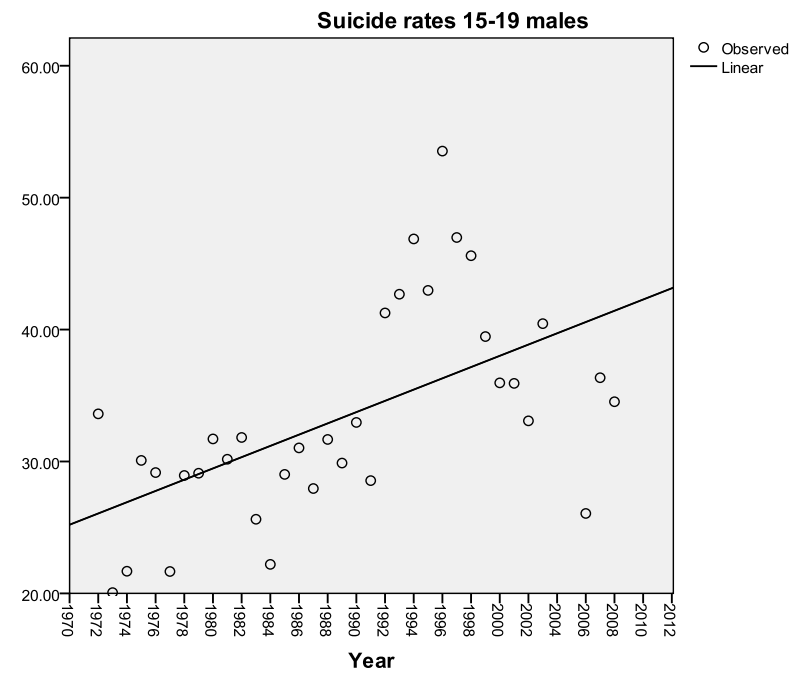

Figure 2. Linear regression models for suicide rates among males aged 15 to 19 years.

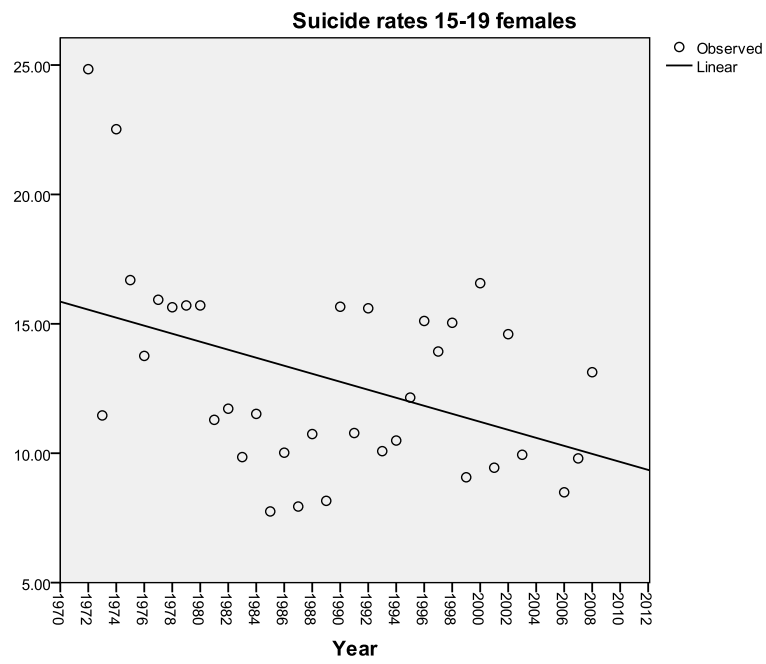

Figure 3. Linear regression models for suicide rates among females aged 15 to 19 years. 


\section{Discussion}

This is one of the few studies of suicide rates in a Mediterranean country. Usually, suicide research has been conducted in Englishspeaking countries. The risk factors and prevalence estimates from Anglo-Saxon culture cannot be extended to Southern European countries, since they have a different cultural background (Scocco et al, 2008).

In summary this study found that suicide rates in Italian adolescents overall increased in males and decreased in females from 1972 to 2008. Between 2002 and 2008, suicide has consistently been the third leading cause of death in Italian adolescents (people aged 15 to 19) males, after road accidents and tumors, and the fourth or fifth in females, after road accidents, tumors, and cardiovascular diseases (ISTAT, 1972-2008).

The continuing increase in suicide rates among males may reflect the increase in adolescent psychopathology. Indeed, there has been an increase in hospital admissions for mental illness among adolescents between 1999 and 2008 (ISTAT, 1999-2008), particularly for externalizing disorders (ISTAT, 1999-2008). This may reflect an increase in psychopathology in adolescents. Availability of Pediatric Mental Health Services and antidepressant prescription, can play a role in the development of adolescent mental illness. It appears that antidepressants 
prescribing in children and adolescents is substantially lower in Italy than in the United States and other European countries (Clavenna et al, 2007). This factor needs to be further investigated, as lower antidepressant prescribing may be associated with less optimal treatment of depression, which may in turn increase the risk of suicide. We observed, in line with other countries (Bridge et al, 2006), that males commit suicide with higher rates compared to females, as with adults.

However, under-reporting of suicide rates, particularly in Catholic countries has been identified as a possible confounding factor in the assessment of the impact of suicide. This can be a possible limitation of the data source.

There is a need for a more thorough investigation of circumstances and triggers of suicide in young people, particularly interpersonal issues, and for studies examining the relationship between socioeconomic status and adolescent suicide, as Italy has a paucity of studies investigating determinants of suicides. The need of such studies is still high and should be a priority of governments and researchers. Suicide rates are on the rise among Italian young males, unlike adults. In Italy, the other age-strata showed a downward trend, particularly after the 90s, both in males and in females (Guaiana et al, 2005). All the age strata examined showed such trend. Elderly suicide markedly decreased from 1985 to 2008 (ISTAT, 1972-2008). These data should even 
more urgently point the attention of health care providers and policymakers to target interventions to improve mental health of Italian adolescents.

If we compare the picture of suicide in adolescents 15-19 years in the European countries, the findings are heterogeneous. Italy shows lower rate of adolescent suicide compared to other European countries with a similar gender profile (Bridge et al, 2006). Mittendorfer-Rutz and colleagues (Mittendorfer-Rutz et al, 2004) observed that among seventeen Western and Eastern European countries between 1980 and 1995, seven showed significantly increased suicide rates in males, four stable rates, four significantly decreased rates, and two non-significant increases. In females, significant increases were reported in four countries. Bulgaria and Italy were the two countries showing increasing rates in males and decreasing in females. The problem is therefore worrisome in some countries but less in others, and it strongly calls for more accurate local surveillance aiming at identifying protective factors and areas of vulnerability. Unlike other countries (McClure 2001), in Italy the pattern in men and women aged 15-19 contrasts the general pattern of adults and elderly. Although the picture of mutual influences between genetic, biological and environmental factors on suicide risk is extremely complicated and possibly different according to the 
various phases of life (Gunnell et al, 2005), several environmental factors are consistently reported to be associated in ecological and descriptive studies, including:

Substance abuse and media influence (Bursztein et al, 2009) should be regarded as frequent co-factors.

Economic determinants. In fact, suicide rates are higher in the economically developed Northern Italy than the more deprived South (Pompili et al, 2009).

Higher rate of divorce and family discord, as well as bullying and peer victimization (Bursztein et al, 2009). Italy is experiencing an increase in family instability, with an increase in separation and divorce rates (ISTAT, 2011).

Increase in impulsivity and aggression (Bursztein et al, 2009), which can be considered as a modulator of suicidal behaviour. Italy has seen an increase in hospital admissions for conduct disorders in children and adolescents (ISTAT, 1999-2008). Some authors argue that Italian society is going into a time of social trouble, where the sense of sharing common values is fading and social relationships are becoming less cohesive (CENSIS, 2010; CENSIS, 2011). This led to an increase in violence with a "dysregulation of drives" (CENSIS; 2011) that may be involved in the increase in impulsivity and aggression which, in turn, leads to a higher likelihood of suicide. 


\section{Conclusions}

The trend of increasing suicide rates for young males and females in Italy is worrisome and warrants further attention and more research, both at epidemiological and at observational level. Adolescent suicide is preventable (Greydanus et al, 2009) if we carry out a careful assessment of the risk factors and the determinants involved. Researchers can have an important role to guide policymaker and clinicians to the best assessment and treatment strategies in order to avoid this preventable tragedy. Also, it will be important to set up a national register of suicides for Italian adolescents. 


\section{References}

Bailly D. Benefits and risks of using antidepressants in children and adolescents. Expert Opinion in Drug Safety, 2008; 7: 9-27.

Biddle L, Brock A, Brookes ST, Gunnell D. Suicide rates in young men in England and Wales in the 21st century: time trend study. British Medical Journal, 2008; 336: 539-542.

Bridge JA, Barbe RP, Brent DA. Recent trends in suicide among U.S. adolescent males, 1992-2001. Psychiatric Services, 2005; 56: 522.

Bridge JA, Goldstein TR, Brent DA. Adolescent suicide and suicidal behavior. Journal of Child Psychology and Psychiatry, 2006; 47: 372-394.

Bursztein C, Apter A. Adolescent suicide. Current Opinion in Psychiatry, 2009; 22: 1-6.

Cheung A.H. and C.S. Dewa. Current trends in youth suicide and firearms regulations. Canadian Journal of Public Health, 2005; 96: 131-135. 
CENSIS. Rapporto Annuale sulla Situazione Sociale del Paese. Rome: CENSIS, 2010.

CENSIS. La crescente sregolazione delle pulsioni. Rome: CENSIS, 2011.

Clavenna A, Rossi E, De Rosa M, Bonati M. Use of psychotropic medications in Italian children and adolescents. European Journal of Pediatrics, 2007; 166: 339-347.

Clavenna A, Andretta M, Pilati P, Dusi M, Gangemi M, Gattoni MB, Lombardo G, Zoccante L, Mezzalira L, Bonati M. Antidepressant and antipsychotic use in an Italian pediatric population. BMC Pediatrics, 2011; 11: 40.

Gibbons RD, Brown CH, Hur K, Marcus SM, Bhaumik DK, Erkens JA, Herings RM, Mann JJ. Early evidence on the effects of regulators' suicidality warnings on SSRI prescriptions and suicide in children and adolescents. American Journal of Psychiatry, 2007; 164: $1356-1363$.

Gould MS, Greenberg T, Velting DM, Shaffer D. Youth suicide risk and preventive interventions: a review of the past 10 years. 
Journal of the American Academy of Child and Adolescent Psychiatry, 2003; 42: 386-405.

Greydanus DE, Calles J Jr. Suicide in children and adolescents. Primary Care: Clinical Office Practice, 2007; 34: 259-273.

Greydanus DE, Bacopoulou F, Tsalamanois E. Suicide in adolescents: a worldwide preventable tragedy. Keio Journal of Medicine, 2009; 58: 95-102.

Guaiana G., M. Andretta, L. Corbari, M. Mirandola, A. Sorio, B. D'Avanzo, C. Barbui. Antidepressant drug consumption and public health indicators in Italy, 1955-2000. Journal of Clinical Psychiatry, 2005; 66: 750-755.

Gunnell D, Lewis G. Studying suicide from the life course perspective: implications for prevention. British Journal of Psychiatry, 2005; 187: 206-208.

Gunnell D, Middleton N. National suicide rates as an indicator of the effect on suicide on premature mortality. Lancet, 2003; 362: 961-962. 
Hawton K, James A. Suicide and deliberate self harm in young people. British Medical Journal, 2005; 330: 891-894.

ISTAT. Cause di Morte. Rome: ISTAT, 1972-2008.

ISTAT. Separazioni e divorzi in Italia. Rome: ISTAT, 2011.

ISTAT. Ospedalizzazione per Disturbi Psichici 1999-2008. Rome: ISTAT, 1999-2008.

McClure GMG. Suicide in children and adolescents in England and Wales 1970-1998. British Journal of Psychiatry, 2001; 178: 469474.

Mittendorfer-Rutz E, Wasserman D. Trends in adolescent suicide mortality in the WHO European Region. European Child and Adolescent Psychiatry, 2004; 13: 321-331.

Pelkonen M, Marttunen M. Child and Adolescent suicide. Epidemiology, risk factors, and approaches to prevention. Pediatric Drugs, 2003; 5: 243-265. 
Pompili M, Masocco M, Vichi M, Lester D, Innamorati M, Tatarelli R, Vanacore N. Suicide among Italian adolescents: 1970-2002. European Child and Adolescent Psychiatry, 2009; 18: 525-533.

Preti A, Miotto P. Increase in first admissions for schizophrenia and other major psychoses in Italy. Psychiatry Research, 2000; 94: 139-152.

Scocco P, De Girolamo G, Vilagut G, Alonso J. Prevalence of suicide ideation, plans, and attempts and related risk factors in Italy: results from the European Study on the Epidemiology of Mental Disorders-World Mental Health Study. Comprehensive Psychiatry, 2008; 49: 13-21.

Van Heeringen C. Suicide in adolescents. International Clinical Psychopharmacology, 2001; 16 (Suppl 2): s1-s6.

Windfhur K, While D, Hunt I, Turnbull P, Lowe R, Burns J, Swinson N, Shaw J, Appleby L, Kapur N and the National Confidential Enquiry into suicide and homicide by people with mental illness. Suicide in juveniles and adolescents in the United Kingdom. Journal of Child Psychology and Psychiatry, 2008; 11: 1155-1165. 
World Health Organization. International Classifications of Disease (9th. Edition - Clinical Modification). Geneva: World Health Organization, 1978.

World Health Organization. International Classifications of Disease (10th. Edition). Geneva: World Health Organization, 1992.

World Health Organization. World Health Report 2001, Mental Health: New Understanding New Hope. Geneva: World Health organization, 2001.

Zacharakis C.A., V. Hadjivassilis, M.G. Madianos, G.N. Papadimitriou, C.N. Stefanis. Suicide in Cyprus 1988-1999. European Psychiatry, 2005; 20: 110-114. 


\section{Chapter 3. Suicide and}

\section{antidepressant prescribing in Italy,}

1955-2000

Published as: Guaiana G, Andretta M, Corbari L, Mirandola M, Sorio A, D’Avanzo B, Barbui C. Antidepressant drug consumption and public health indicators in Italy, 1955-2000. Journal of Clinical Psychiatry, 2005; 66: 750-755. 


\section{Summary}

Objective: This study investigated the impact of the increasing consumptions of selective serotonin reuptake inhibitors (SSRIs) and newer antidepressants on the following public health indicators: a) suicide rates; b) proportion of completed suicides by poisoning with solid or liquid substances; c) admissions for depression, and proportion of admissions for depression that were first admissions. Methods: Data on antidepressants dispensed in Italy from 1983 to 2000 were obtained from the Italian Ministry of Health, while data on suicide deaths were obtained from the Italian National Institute of Statistics. Results: In Italy from 1983 to 2000 the use of tricyclic antidepressants remained substantially stable and the use of SSRIs and newer agents dramatically increased. In contrast, suicide rates for males decreased from 1955 to 1974, and subsequently increased, reaching a peak in 1985 and then declining. In females, suicide rates remained substantially stable until 1978. A subsequent increase occurred up to 1985, followed by a steady decline. Suicide by poisoning dropped by nearly 50\% from 1986 to 2000 . Admissions to hospital for depression showed an erratic pattern; however, no decline was observed. No change was observed in the rate of first admissions for depression. Conclusion: Despite a reduction in suicides by poisoning, the analysis of long-term 
trends in suicide did not suggest that increases in antidepressant prescribing lie behind recent reductions in population suicides. Furthermore, in Italy newer antidepressants had no impact on the total number of admissions for depression, nor on the proportion of all admissions that were first admissions. 


\section{Introduction}

Over the last years antidepressant (AD) prescribing has markedly increased in many developed countries, mainly after the introduction of selective serotonin reuptake inhibitors (SSRIs) in the early 1990s (Isacsson et al, 1999; Lawrenson et al, 2000; Middleton et al, 2001; Ciuna et al, 2004; Olfson et al, 2002). This might be the reflection of better recognition and prescribing for depression (Henriksson et al, 1995; Rich et al, 1997), and might therefore have relevant public health implications. In particular, it is expected a reduction in the rates of completed suicides and a reduction in the number of suicides by poisoning, as a consequence of better recognition and treatment of subjects with depressive symptoms, and because newer ADs are rarely lethal in overdose (Taylor et al, 2003). In addition, it is expected a decrease in the number of subjects hospitalized for depression, given that SSRIs and newer ADs should theoretically be associated with better patient adherence and therefore lower relapse rates.

In the present study we investigated the relationship between the increasing consumptions of SSRIs and newer ADs on the following public health indicators: a) suicide rates; b) proportion of completed suicides by poisoning; c) admissions for depression, and proportion of admissions for depression that were first admissions. 


\section{Materials and Methods}

Data source

This study was carried out in Italy, a country with nearly sixty million inhabitants. National data on numbers of suicide deaths according to the Ninth Revision of the Italian International Classification of Diseases (ICD-IX) in each sex and age-group, and estimates of the Italian resident population, were collected from the National Institute of Statistics (ISTAT) from 1955 to 2000. Data after 2000 are not yet available. ISTAT data on suicide methods were extracted according to ICD-IX, and include the following categories: $950=$ poisoning by solid or liquid substances; 951 and 952 = poisoning by gas; 953 = hanging; $954=$ submersion; 955 = firearms and explosives; 956 = cutting and piercing instruments; 957 = jumping from high places; $958=$ other non-specified method. Hospital-discharge data were collected from ISTAT, as published in the health-care statistics yearbook (ISTAT, 2004) for the corresponding period. We extracted the total number of admissions for depression, and the proportion of admissions for depression that were first admissions, up to 1998. Data after 1998 are not yet available.

Data on AD prescriptions were collected by an independent source for pharmaceutical market intelligence (IMS Health). In Italy it gathers data from 251/256 (98\%) Italian wholesalers; 
these data are then extrapolated for the whole country. IMS Health provides prescribing information to manufacturers, health care providers and to the Italian Ministry of health, but it is not itself involved in the production or sales of drugs. IMS-data on drug sales included in this analysis were obtained from the Italian Ministry of health, which supports their use for research purposes. For each agent, it records the number of packages sold. From 1983 to June 2000, pharmacological agents from the N06A group of the anatomical therapeutic chemical (ATC) classification system were extracted and included in the analysis.

\section{Data analysis}

Sex- and age-standardized death rates for all suicides were computed. Standardization was done by the direct method on the basis of the Italian population of the 2001 census year (D'Avanzo et al, 1993; Doll et al, 1982).

For each $\mathrm{AD}$, the number of packages sold was converted into defined daily doses (DDDs) per 1,000 inhabitants per day (DDD/1,000/day). The DDD is the international unit of drug utilisation approved by the World Health Organisation for drug use studies (World Health Organization Collaborating Centre for Statistics Methodology, 2003) . The DDD is a theoretical unit of measurement defined as the assumed average maintenance daily 
dose for a drug, used for its main indication in adults. The DDD/1,000/day indicates how many people per 1,000 of the population have in theory received a standard dose (i.e. the DDD) of a particular medication or category of medication daily.

For each year, the total number of admissions for depression was divided by the Italian resident population, and figures per 100,000 inhabitants were calculated. Finally, the proportion of admissions for depression that were first admissions was calculated.

\section{Data presentation}

Since statistical methods for assessing possible relationships between $\mathrm{AD}$ use and public health indicators are highly controversial and sometimes based on unproven assumptions (Moncrieff, 2003; Gunnell et al, 2004), a descriptive approach to data presentation was employed.

\section{Results}

Antidepressant drug prescribing

The analysis of AD prescribing revealed that, while the use of tricyclic antidepressants and that of other old agents (mianserin, trazodone, ade-methionine) remained substantially stable or slightly declined from 1983 to 2000 (Figure 1), the use of SSRIs and newer agents (venlafaxine, mirtazapine, reboxetine) dramatically increased, and accounted for 10.33 DDDs/1,000/day 
in 2000 (Figure 1). Overall, AD use increased from 4.94 DDDs/1,000/day in 1983 to 16.61 DDDs/1,000/day in 2000 .

\section{Public health indicators}

Standardized suicide rates from 1955 to 2000 are presented in Figure 1. Suicide rates for males decreased from 1955 to 1974, and subsequently increased, reaching a peak in 1985. After 1985 rates declined, from 14.12 to 10.98 per 100,000 in 2000 . In females, suicide rates remained substantially stable until 1978. A subsequent increase occurred, followed by a steady decline from 5.42 to 3.54 from 1985 to 2000 . Breaking down rates by age, a consistent decrease in suicides was observed in males and females over 65 (Figure 2 and 3). In addition, there was a mild trend towards decline in males and females aged 45-64, and a slight rise in suicide rates for young men since 1970s. The most frequent methods of suicide were hanging, jumping and firearms (Table 1). While the proportion of suicides by these methods was substantially stable, suicide by poisoning dropped by nearly $50 \%$ from 1986 to 2000. 


\begin{tabular}{lllllllll}
\hline Year & Poisoning & $\begin{array}{l}\text { Poisoning } \\
\text { by gas }\end{array}$ & Hanging & Submersion & Firearms & $\begin{array}{l}\text { Cutting, } \\
\text { piercing }\end{array}$ & Jumping & Others \\
& & & & & & & & \\
& \% & \% & \% & \% & \% & \% & $\%$ & $\%$ \\
\hline $\mathbf{1 9 8 6}$ & 6.16 & 3.18 & 37.58 & 9.96 & 14.73 & 1.51 & 23.70 & 3.18 \\
$\mathbf{1 9 8 7}$ & 4.92 & 3.28 & 38.35 & 8.52 & 14.77 & 1.88 & 25.07 & 3.21 \\
$\mathbf{1 9 8 8}$ & 5.34 & 3.83 & 36.92 & 8.70 & 13.90 & 2.08 & 25.35 & 3.88 \\
$\mathbf{1 9 8 9}$ & 5.62 & 3.80 & 37.20 & 7.72 & 13.86 & 1.36 & 26.76 & 3.68 \\
$\mathbf{1 9 9 0}$ & 4.88 & 8.16 & 36.01 & 6.79 & 13.18 & 1.43 & 25.44 & 4.11 \\
$\mathbf{1 9 9 1}$ & 4.99 & 8.89 & 34.62 & 7.59 & 13.88 & 2.00 & 24.10 & 3.93 \\
$\mathbf{1 9 9 2}$ & 4.82 & 8.52 & 34.87 & 7.81 & 13.82 & 2.07 & 24.26 & 3.83 \\
$\mathbf{1 9 9 3}$ & 4.51 & 8.64 & 36.48 & 6.28 & 15.07 & 1.89 & 23.40 & 3.73 \\
$\mathbf{1 9 9 4}$ & 4.17 & 7.70 & 40.15 & 6.30 & 14.28 & 1.63 & 22.18 & 3.59 \\
$\mathbf{1 9 9 5}$ & 4.22 & 8.78 & 39.97 & 5.65 & 13.92 & 1.62 & 21.27 & 4.57 \\
$\mathbf{1 9 9 6}$ & 4.30 & 8.53 & 41.27 & 6.61 & 12.48 & 1.39 & 21.48 & 3.94 \\
$\mathbf{1 9 9 7}$ & 4.07 & 6.95 & 43.20 & 6.30 & 13.34 & 1.34 & 21.09 & 3.71 \\
$\mathbf{1 9 9 8}$ & 3.51 & 6.26 & 42.76 & 5.88 & 14.39 & 1.55 & 20.74 & 4.91 \\
$\mathbf{1 9 9 9}$ & 4.10 & 5.93 & 41.85 & 5.69 & 14.92 & 1.63 & 21.75 & 4.13 \\
$\mathbf{2 0 0 0}$ & 3.82 & 5.86 & 41.82 & 5.48 & 14.95 & 1.68 & 22.18 & 4.21 \\
\hline
\end{tabular}

Table 1. Distribution of suicides by methods in Italy, 1986-2000

Finally, admissions to hospital for depression, available from 1986 to 1998, showed an erratic pattern (Figure 4); however, no decline was observed. The proportion of all admissions that were first admissions remained substantially stable.

\section{Discussion}

Undoubtedly, the availability of SSRIs and newer ADs has increased the therapeutic options available for patients with depressive disorders. Their tolerability profile, different from that of tricyclic and related ADs, makes these agents particularly suitable in a wide range of situations where conventional ADs are not appropriate. In addition, they are less toxic when taken in overdose and might increase patient adherence to treatment 
(Masand et al, 1999). Although these advantages might be observed in individual patients, it is relevant to establish and monitor whether there are positive consequences in terms of public health measures.

A dramatic rise in SSRI and newer AD prescribing was accompanied by a drop in suicides by poisoning in Italy. Although a causal relationship between these two phenomena cannot be established by means of the present ecological analysis, this is a relevant finding in terms of public health, whose impact on overall suicide rates remains difficult to establish. In Italy suicide rates have been declining in males and females over-65, but not in young people. Interestingly, according to recent cross-sectional analyses of $\mathrm{AD}$ prescribing conducted in selected areas of Italy (Barbui et al, 2003; Percudani et al, 2004), males and females over-65 account for the majority of $\mathrm{AD}$ prescriptions, thus suggesting a possible impact of $\mathrm{AD}$ prescribing in this age group. However, in late-life suicide rates were already declining before the introduction, and before a dramatic rise in prescriptions, of SSRIs and newer ADs.

This analysis has two main limitations. First, AD sales data allow to estimate the consumption of drugs, but cannot provide information on their real use. Since a relevant proportion of the medicines prescribed for people with chronic conditions are not 
taken (Jones, 2003), great caution is required in assuming that $\mathrm{AD}$ prescriptions correspond to AD utilisation. Second, the naturalistic design of this analysis is subject to the ecological fallacy, and therefore no causal relationships can be established. In contrast with most ecological analyses investigating the relationship between $\mathrm{AD}$ prescribing and suicide, the present study looked at long-term trends. This is a crucial factor because the possibility that suicide rates were already declining before the dramatic rise in $\mathrm{AD}$ prescriptions has to be considered (Levi et al, 2003). Focusing on 10-15 years only, in fact, might give the wrong impression of an association between AD prescribing and suicide rates, while, in reality, the outcome of interest (decreasing suicide rates) might have preceded the exposure variable (AD prescribing). Carlsten and colleagues (Carlsten et al, 2001) to overcome this problem, carried out a time-series analysis using a 2 -slope model to compare suicide rates in Sweden before and after the introduction of the SSRIs. This analysis found that $\mathrm{AD}$ sales increased in men from 4.2 DDD/1,000 inhabitants/day during 1977-1979 to 21.8 in 1995-1997 and in women from 8.8 to 42.4 DDD/1,000 inhabitants/day between the same periods. In the two census periods, suicide rates decreased in men by $30.9 \%$ and in women by $34.0 \%$. Similarly, In the United Kingdom declines in suicide preceded increases in prescribing, and rises in AD prescribing since 1991 in different age and sex groups did not 
consistently coincide with clear changes in previous suicide trends (Gunnell et al, 2004).

Other analyses found contrasting results. Hall and colleagues examined the association between changes in antidepressant prescribing in Australia from 1991 to 2000 and changes in suicide rates (Hall et al, 2003). Between 1991 and 2000 the suicide rate markedly decreased in old men and women and increased in young adults, especially young men, yielding a substantially stable total suicide rate. The analysis of AD consumption in the same period showed that exposure to ADs was higher for women than men in all age groups and increased markedly for both men and women over the study period, with the largest increases among older adults. A significant negative association was observed between $\mathrm{AD}$ consumption and suicide in women but not in men. Among both men and women the largest declines in suicide occurred in the age groups with the highest exposure to AD across the study period (Hall et al, 2003). Similarly, Isacsson analysed national statistics on suicide, alcohol consumption, unemployment and use of ADs for 1978-1996 in Sweden, and for 1990-1996 in Denmark, Norway and Finland (Isacsson, 2000). Suicide rate decreased by $19 \%$ in parallel with the increased use of $\mathrm{AD}$ in Sweden, Denmark, Norway and Finland. Moreover, in Sweden there was no demographic group with regard to age, gender or 
county in which the suicide rate decreased in the absence of an increased use of ADs. However, in women under 30 and over 75 years of age, and in four of the 23 counties, suicide rates remained unchanged despite an increased consumption of ADs. Another nationwide analysis of suicide mortality in Finland from 1990 to 1995 was carried out by Ohberg and colleagues (Ohberg et al, 1998) with the aim of exploring suicide mortality by various methods. Over the study period the total suicide mortality decreased from 30.3 per 100,000 inhabitants to 27.2 per 100,000 inhabitants. In the same period the total consumption of $\mathrm{AD}$ agents more than doubled from 9.3 DDD units in 1990 to 21.8 in 1995 (Ohberg et al, 1998).

Grunebaum and colleagues (Grunenbaum et al, 2004), who investigated the relationship between antidepressant prescribing and suicide rates in the United States, showed that the decline in the national suicide rate appeared to be associated with greater use of non-tricyclic ADs. However, only 15 years (1985-1999) were analysed, and no data were reported on trends in suicide before 1985. According to other analyses, suicide rates were already declining before 1985 in the United States, especially in females (Levi et al, 2003).

In addition to suicide rates, admissions to hospital is another public health measure that could theoretically have been affected by the introduction of SSRIs and newer ADs. We observed no changes in the 13-year period considered. Helgason and 
colleagues (Helgason et al, 2004) who carried out a similar analysis in Iceland, a country with only 286,000 inhabitants, found that despite sales of ADs increased from 8.4 DDD/1,000/day in 1975 to 72.7 in 2000, suicide rates did not show any definite trend, and rates for outpatient visits and hospital admissions progressively increased.

\section{Conclusions}

In conclusion, despite a reduction in suicides by poisoning, the analysis of long-term trends in suicide did not suggest that increases in antidepressant prescribing lie behind recent reductions in population suicides. This relationship deserves further and more accurate investigation, for example by looking at the distribution of SSRI prescribing according to age and sex. Furthermore, in Italy SSRIs and newer ADs had no impact on the total number of admissions for depression, nor on the proportion of all admissions that were first admissions. 


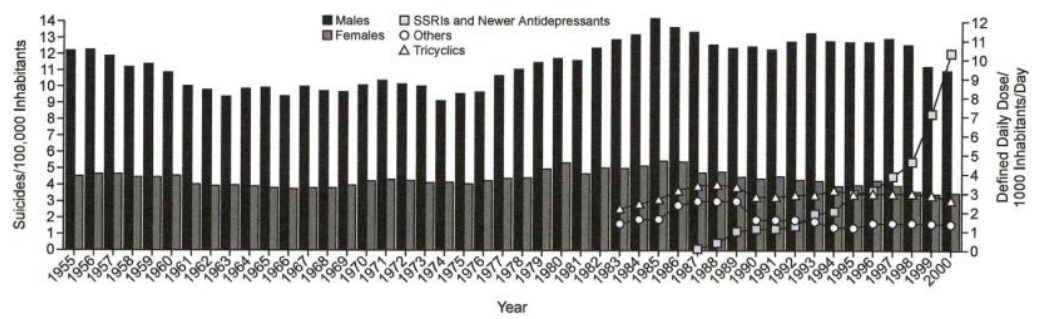

Drug prescription data are from IMS Health, London, England. Abbreviation: SSRI = selective serotonin reuptake inhibitor.

Figure 1. Suicide rates per 100.000 inhabitants (bars) and antidepressant drug prescribing in Italy

Legend: SSRI = selective serotonin-reuptake inhibitors.

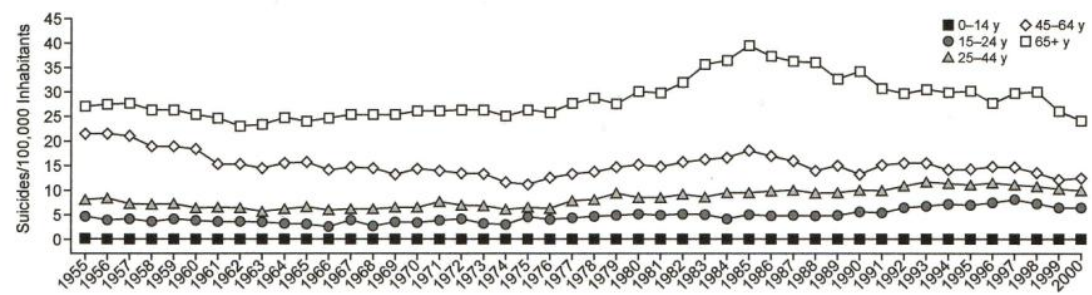

Figure 2. Age-specific male suicide rates in Italy, 1955-2000

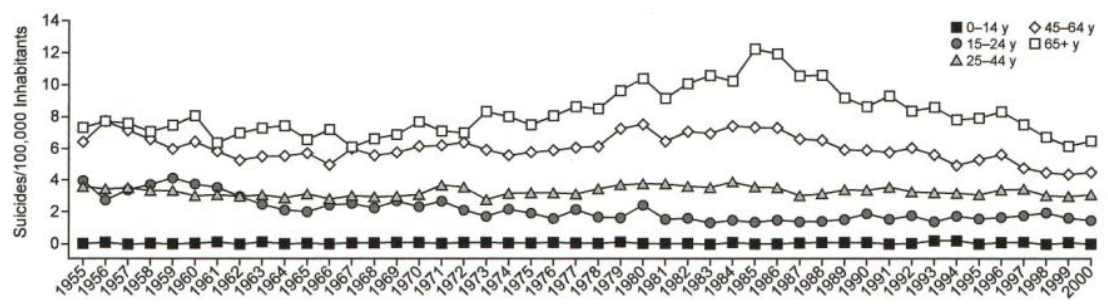

Figure 3. Age-specific female suicide rates in Italy, 1955-2000 
Chapter 3

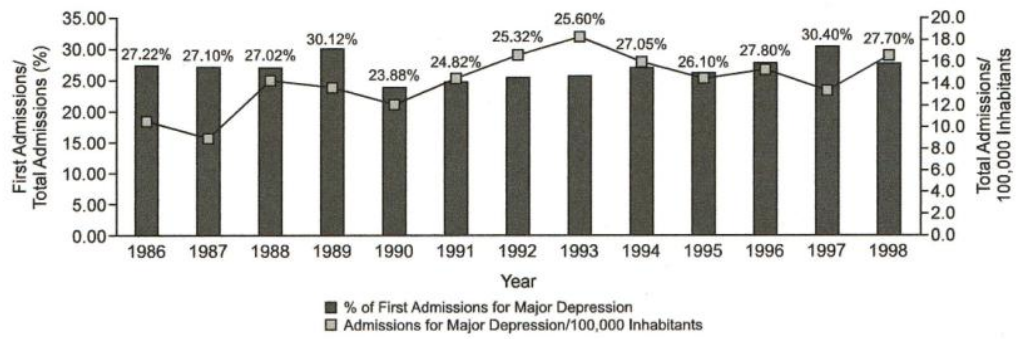

Figure 4. Admissions for depression in Italy from 1986 to 1998, and proportion of first admissions 


\section{References}

Barbui C, Broglio E, Costa Laia A, D’Agostino S, Enrico F, Ferraro L, Fiorio E, Miletti F, Pietraru C, Poggio L, Tognoni G. Cross-sectional database analysis of antidepressant prescribing in Italy. Journal of Clinical Psychopharmacology, 2003; 23: 31-34.

Carlsten A, Waern M, Ekedahl A, Ranstam J. Antidepressant medication and suicide in Sweden. Pharmacoepidemiology and Drug Safety, 2001;10: 525-530.

Ciuna A, Andretta M, Corbari L, Levi D, Mirandola M, Sorio A, Barbui C. Are we going to increase the use of antidepressants up to that of benzodiazepines? European Journal of Clinical Pharmacology, 2004; 60: 629-634.

D’Avanzo B, La Vecchia C, Negri E, Saraceno B. Suicide mortality in Italy: an update from 1955 to 1987. Revue d'Epidemiologie et Santé Publique, 1993; 41: 454-460.

Doll R, Smith PG. Comparisons between registries: agestandardised rates. IARC Science Publications, 1982; 42: 671-675. 
Grunebaum MF, Ellis SP, Li S, Oquendo MA, Mann JJ. Antidepressants and suicide risk in the United States, 1985-1999. Journal of Clinical Psychiatry, 2004; 65: 1456-1462.

Gunnell D, Ashby D. Antidepressant and suicide: what is the balance of benefit and harm. British Medical Journal, 2004;329: 34-38.

Hall WD, Mant A, Mitchell PB, Rendle VA, Hickie IB, McManus P. Association between antidepressant prescribing and suicide in Australia, 1991-2000: trend analysis. British Medical Journal, 2003; 326: 1008-1012.

Helgason T, Tomasson H, Zoega T. Antidepressants and public health in Iceland. British Journal of Psychiatry, 2004; 184:157-162

Henriksson S, Boethius G, Hakansson J, Isacsson G. Indications for and outcome of antidepressant medication in a general population: a prescription database and medical record study, in Jamtland county, Sweden 1995. Acta Psychiatrica Scandinavica, 2003; 108: 427-431. 
Isacsson G, Boethius G, Henriksson S. Selective serotonin reuptake inhibitors have broadened the utilisation of antidepressant treatment in accordance with recommendations. Findings from a Swedish prescription database. Journal of Affective Disorders, 1999; 53: 15-22.

Isacsson G. Suicide prevention-a medical breakthrough? Acta Psychiatrica Scandinavica, 2000; 102: 113-117.

ISTAT. Annuario delle Statistiche Sanitarie. Rome: ISTAT; 2004.

Jones G. Prescribing and taking medicines. Concordance is a fine theory but it is mostly not being practised. British Medical Journal, 2003; 327: 819.

Lawrenson RA, Tyrer F, Newson RB. The treatment of depression in UK general practice: selective serotonin reuptake inhibitors and tricyclic antidepressants compared. Journal of Affectiver Disorders, 2000; 59: 149-157.

Levi F, La Vecchia C, Lucchini F, Negri E, Saxena S, Maulik PK, Saraceno B. Trends in mortality from suicide, 1965-99. Acta Psichiatrica Scandinavica, 2003; 108: 341-349. 
Masand PS, Gupta S. Selective serotonin-reuptake inhibitors: an update. Harvard Review of Psychiatry, 1999; 7: 69-84.

Middleton N, Gunnell D, Whitley E. Secular trends in antidepressant prescribing in the UK, 1975-1998. Journal of Public Health Medicine, 2001; 23: 262-267.

Moncrieff J. Antidepressant prescribing and suicide: Analysis is misleading. British Medical Journal, 2003; 327:288.

Ohberg A, Vuori E, Klaukka T, Lonnqvist J. Antidepressants and suicide mortality. Journal of Affective Disorders, 1998; 50: 225233.

Olfson M, Marcus SC, Druss B, Elinson L, Tanielian T, Pincus HA. National trends in the outpatient treatment of depression. JAMA, 2002; 287: 203-209.

Percudani M, Barbui C, Fortino I, Petrovich L. Antidepressant drug use in Lombardy Italy: a population-based study. Journal of Affective Disorders, 2004; 83: 169-175. 
Rich CL, Isacsson G. Suicide and antidepressants in south Alabama: evidence for improved treatment of depression. Journal of Affective Disorders, 1997; 45: 135-142.

Taylor D, Paton C, Kerwin R. The South London and Maudsley NHS Trust 2003 prescribing guidelines. London: Martin Dunitz, 2003.

World Health Organization Collaborating Centre for Drug Statistic Methodology. Guidelines for ATC Classification and DDD Assignment. Oslo: World Health Organization Collaborating Centre for Drug Statistic Methodology, 2003. 


\section{Chapter 4. Antidepressant drugs prescribing and suicide in Emilia- Romagna region (Italy), 1999-2008}

Published as: Guaiana G. Antidepressant Prescribing and Suicides in Emilia-Romagna Region (Italy) from 1999 to 2008: An Ecological Study. Clinical Practice \& Epidemiology in Mental Health, 2011; 7: 120-122. 


\section{Summary}

Anti-depressant (AD) prescribing rose in several countries worldwide over the last 20 years. Some concerns have been raised over the fact that AD use, mainly Selective Serotonin Reuptake Inhibitors (SSRI) may increase the risk of suicide. AD consumption and suicide rates data in Emilia-Romagna region, Italy have been extracted from regional government databases on AD prescribing and suicide rates, from 1999 to 2008. A statistical model using ordinary least squares linear regression was employed. The overall suicide rates decreased during the period under examination, in spite of the observed exponential increase in use of ADs. Despite the doubling in prescribing of SSRI and newer ADs in recent years, there continues to be no negative impact on suicide rates in Emilia Romagna. 


\section{Introduction}

Anti-depressant (AD) prescribing rose in several countries worldwide over the last 20 years (Isacsson et al, 2008), mainly after the introduction of Selective Serotonin Reuptake Inhibitors (Isacsson et al, 2008; Guaiana et al, 2005). This increase may be the result of better treatment and recognition of depression (Isacsson et al, 2008). There is some evidence that treating more depressed patients with AD might prevent suicide (Isacsson et al, 1994). However, some concerns have been raised over the fact that $\mathrm{AD}$ use, mainly Selective Serotonin Reuptake Inhibitors (SSRI) may increase the risk of suicide (Healy et al, 2005). Ecological studies showed some evidence that more widespread $\mathrm{AD}$ use corresponds to a decrease in suicide rates (Isacsson et al, 2008), although this finding is disputed (Isacsson et al, 2010). A meta-analysis published in 2009 (Stone et al, 2009) showed that the risk in suicidality associated with use of antidepressants strongly depends on age, with a higher risk in adults aged 25 years of age or under, a reduced risk of suicidality among people aged 65 and older, and a possibly protective effect in adults aged 25 to 64 years.

The aim of this study is to investigate the trend in AD prescribing and deaths by suicide in Emilia Romagna, a large Italian region, 
with a view to understanding how the pattern of AD sale is related to suicide.

\section{Materials and methods}

Emilia-Romagna is a northern Italian region with a population of about 4.4 million people (ISTAT, 1998-2007). It has an area of $22446 \mathrm{~km}^{2}$.

Data concerning suicide rates based on ICD-IX classification (E950-E959) (World Health Organization, 1978), were collected by the SALUTER database (Salute Emilia Romagna, www.saluter.it - accessed February 21 2011). This is the official internet site for the Regional Government-funded statistical office on healthrelated statistics for Emilia-Romagna region. The rates were agestandardized per 100000 population by the statistical office, with the direct method, based on the 1998 resident population. Rates for males and females were extracted. Data are available from 1999 to 2008. No data have been released after 2008 .

AD prescribing data were collected from the official governmentfunded CREVIF database (CREVIF Database, www.crevif.it accessed February 21 2011). This office collects data on all medication prescribed by the Italian National Health Service in Emilia-Romagna region. Every year the CREVIF issues a report outlining the Defined Daily Doses (DDD)/1000 population/day (DDDM) for each category or subcategory of medication, which is 
available on-line (CREVIF database). Data were not divided by age or sex. The DDD is the international unit of drug utilisation approved by the World Health Organisation for drug use studies (World Health Organization Collaborating Centre for Drug Statistic Methodology, 2003). The DDD is a theoretical unit of measurement defined as the assumed average maintenance daily dose for a drug, used for its main indication in adults. The DDDM indicates how many people per 1,000 of the population have in theory received a standard dose (i.e. the DDD) of a particular medication or category of medication daily. The ADs were aggregated by CREVIF into three categories: SSRI (fluoxetine, fluvoxamine, citalopram, escitalopram, sertraline, paroxetine), Tryciclic ADs (TCA), and Others (Mianserin, Trazodone, Mirtazapine, Venlafaxine, Reboxetine, Duloxetine). Data were available from 1999 to 2008. There is no data after 2008 .

A statistical model using ordinary least squares linear regression was employed, based on the model developed by Preti and Miotto (Preti et al, 2000). The model was used in the present study to test for changes over time in suicide rates. Rates were the dependent variable and years were the independent variable. Linear regression analysis of rates over 10 years (1999-2008) was performed. A two-tailed t-test was also performed to test for the hypothesis of a significant slope. 
SPSS for Windows version 19 has been used to perform all the calculations.

\section{Results}

Results on AD prescribing and suicides are shown on Figure 1.

The analysis of AD drug prescribing revealed that there has been a marked increase in the use of SSRI. The DDDM for SSRI increased from 1.9 in 1999 to 31.9 in 2008, more than 15-fold increase. DDDM for TCA, on the other hand, slightly decreased from 1.9 in 1999 to 1.5 in 2008. A nearly 5-fold increase in the prescription of other ADs has also been observed between 1999 and 2008, with a DDDM increasing from 1.5 in 1999 to 7.3 in 2008. Standardized suicide rates decreased in males from 16.70 in 1999 to 12.69 in 2008. In females, standardized suicide rates decreased from 6.15 in 1999 to 4.61 in 2008. The Linear Regression Model showed that there has been a slow but progressive decrease in suicide rates for males (slope $=-0.440,95 \%$ Confidence Interval $=-0.581$ to -0.299 , Standard Error $=0.061$, Adj $R^{2}=0.850, F=51.99, p=0.0001$ ) and for females $($ slope $=-0.199,95 \%$ Confidence Interval $=-0.340$ to 0.057, Standard Error=0.061, Adj $R^{2}=0.567, F=10.50, p=0.012$ ). 


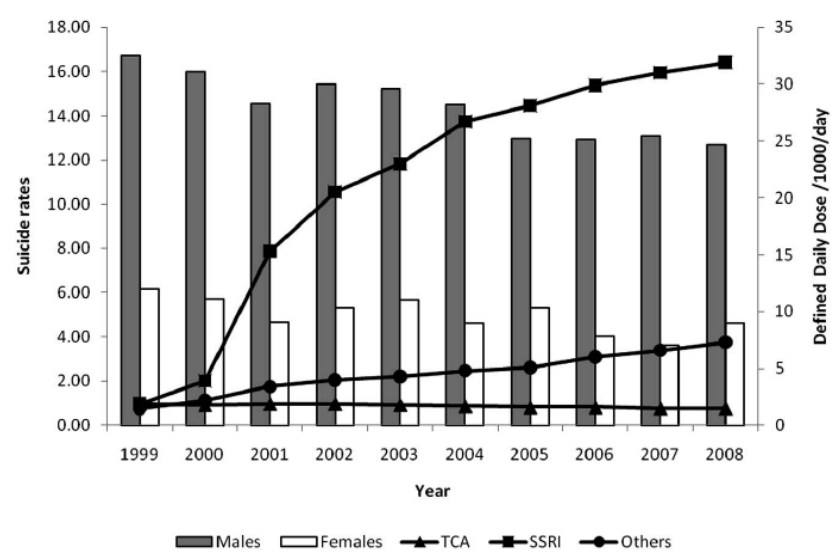

Fig. (1). Suicide rates per 100.000 inhabitants (bars) and antidepressant drug consumption (lines) in Emilia-Romagna 1999-2008

\section{Discussion}

The main finding of this study is that the overall suicide rates decreased during the period under examination, in spite of the observed exponential increase in use of ADs.

Our analysis showed that despite the doubling in prescribing of SSRI and newer ADs in recent years, there continues to be no negative impact on suicide rates in Emilia Romagna. If this findings were consistent to Healy's and colleagues' (Healy et al, 2005), prediction of an increase in suicide by SSRI, there would have been a marked increase in suicide rates, which did not happen. Also, Khan and colleagues showed that SSRI do not induce suicide more than other AD or even placebo (Khan et al, 2003). Our findings are more in line with the data examined by Isaacson and colleagues for Europe and worldwide (Isacsson et al 2008), 
where suicide rates showed an opposite trend to AD prescribing. If we consider the trend of suicides in Italy we notice that there has been a decrease in rates even before the appearance of SSRI in the Italian market. Guaiana and colleagues (Guaiana et al, 2002) found that there was an overall decline in suicide rates in Italy from 1986 to 1996, both in males and in females. However, suicides rates markedly declined among elderly of both sexes and increased in males aged 15-24 and 25-44. When suicide rates were compared to antidepressant prescribing in Italy, it appeared that there has been an overall steady decline in suicide rates, between 1955 and 2000, which preceded the exponential increase in AD prescribing (Guaiana et al, 2005). This decrease may be linked to earlier treatment and detection of mental disorders. Vichi and colleagues also examined suicide rates in Italy between 1980 and 2002 (Vichi et al, 2010). They concluded that the decline in suicide rates is possibly a consequence of the decrease in the incidence of mental disorders as a result of the development of an integrated and community-based mental health system, which in turn may have led to decreased suicide rates. AD prescribing may be part of this picture, as earlier detection of mental disorder may have to an increase in AD prescribing. Mental illness in general and depression in particular are a strong predictor of suicide (Cavanagh et al, 2003). Earlier detection of depression by community mental health services might have led to increased 
treatment with $\mathrm{AD}$ that, in turn, led to a decrease in suicide rates. This hypothesis, however suggestive, remains speculative.

This study suffers from some obvious limitations: first of all, the naturalistic design makes it prone to the ecological fallacy, as no clear casual relationship can be established. Also, data on DDDM and suicides were not divided by age or sex. It is possible that the negative trend in suicide rates can be only applied to certain age groups, including the elderly. It appears that people over 65 account for the majority of AD prescribing in Italy (Barbui et al, 2003) and suicides in Italy seem to decline mostly in people aged 65 or more (Guaiana et al, 2005). It can be possible that the decrease in suicide rates observed in Emilia-Romagna applies mainly to people aged 65 or older, although we do not have data to confirm or refute this hypothesis. Also, we assumed that all ADs are prescribed and used for depression. This is not entirely true, as ADs are increasingly used for anxiety disorders as well, also in Italy (Ciuna et al, 2004). Anxiety disorders are at least as prevalent as depression. Both types of disorders are highly comorbid. Our database does not make it possible to find out the specific disease that required the prescription of the AD. However, since anxiety and depression are closely intermingled, the former being often an indicator of the severity of the latter and vice versa (Brown et al, 1996), this limitation does not invalidate our main 
Antidepressant drugs prescribing and suicide in Emilia-Romagna region (Italy), 1999-

conclusions. Finally, data on AD sale does not capture actual AD consumption. It is definitely possible that people who are prescribed AD do not take them regularly or at all.

\section{Conclusions}

In spite of the limitations, we can say that an increase an $\mathrm{AD}$ prescribing (particularly SSRI) has not been paralleled by an increase in suicide rates in Emilia-Romagna region of Italy. Further studies will be required to refute or corroborate this finding. 


\section{List of abbreviations}
$\mathrm{AD}=$ antidepressants
DDD = Defined Daily Dose
DDDM = Defined Daily Dose $/ 1000 /$ day

SSRI = Selective Serotonin Reuptake Inhibitors

TCA = Tricyclic Antidepressants

\section{Conflict of interest}

The author has not transmitted any conflict of interest.

\section{Acknowledgements}

The author would like to thank Dr. Marnin Heisel for the assistance in the preparation of the manuscript. 


\section{References}

Barbui C, Broglio E, Costa Laia A, D’Agostino S, Enrico F, Ferraro L, Fiorio E, Miletti F, Pietraru C, Poggio L, Tognoni G. Cross-sectional database analysis of antidepressant prescribing in Italy. Journal of Clinical Psychopharmacology, 2003; 23: 31-34.

Brown C, Schulberg HC, Madonia MJ, Shear MK, Houck PR. Treatment outcomes for primary care patients with major depression and lifetime anxiety disorders. American Journal of Psychiatry, 1996; 153: 1293-1300.

Cavanagh JTO, Carson AJ, Sharpe M, Lawrie M. Psychological autopsy studies of suicide: a systematic review. Psychological Medicine, 2003; 33: 395-405.

Ciuna A, Andretta M, Corbari L, Levi D, Mirandola M, Sorio A, Barbui C. Are we going to increase the use of antidepressants up to that of benzodiazepines? European Journal of Clinical Pharmacology, 2004; 60: 629-634.

Guaiana G, D'Avanzo B, Barbui C. Update of suicide trends in Italy from 1986 to 1996. Soc Psychiatry and Psychiatric Epidemiology, 2002; 37: 267-270. 
Guaiana G, Andretta M, Corbari L, Mirandola M, Sorio A, D’Avanzo B, Barbui C. Antidepressant drug consumption and public health indicators in Italy, 1955 to 2000. Journal of Clinical Psychiatry, 2005; 66: 750-755.

Healy D, Aldred G. Antidepressant drug use and the risk of suicide. International Review of Psychiatry, 2005; 17: 163-172.

Isacsson G, Bergman U, Rich C. Antidepressant, depression and suicide: an analysis of the San Diego study. Journal of Affective Disorders, 1994; 32: 277-286.

Isacsson G, Rich C. Antidepressant medication prevents suicide: a review of ecological studies. European Psychiatric Review, 2008; 1: 24-26.

Isacsson G, Rich C, Jureidin J, Raven M. The increased use of antidepressants has contributed to the worldwide reduction in suicide rates. British Journal of Psychiatry, 2010; 196: 429-433.

ISTAT. Annuario Statistico Italiano. Rome: ISTAT, 1998-2007. 
Khan A, Khan S, Kolts R, Brown WA. Suicide rates in clinical trials of SSRIs, other antidepressants and placebo: analysis of FDA reports. American Journal of Psychiatry, 2003; 160: 790-792.

Preti A, Miotto P. Increase in first admissions for schizophrenia and other major psychoses in Italy. Psychiatry Research, 2000; 94: 139-152.

Stone M, Laughren T, Jones ML, Levenson M, Holland PC, Hughes A, Hammad TA, Temple R, Rochester G. Risk of suicidality in clinical trials of antidepressants in adults: analysis of proprietary data submitted to US Food and Drug Administration. British Medical Journal, 2009; 339: b2880.

Vichi M, Masocco M, Pompili M, Lester D, Tatarelli R, Vanacore N. Suicide mortality in Italy 1980-2002. Psychiatry Research, 2010; 175: 89-97.

World Health Organization Collaborating Centre for Drug Statistic Methodology. Guidelines for ATC Classification and DDD Assignment. Oslo: World Health Organization Collaborating Centre for Drug Statistic Methodology, 2003. 
World Health Organization. The Ninth Revision of the International Classification of Diseases and Related Health Problems (ICD-9). Geneva: World Health Organization, 1978. 


\section{Chapter 5. Antidepressant}

prescribing, suicide and hospital admissions for depression in Veneto region (Italy), 2000-2005

Published as: Guaiana G, Andretta M, Griez E, Biancosino B, Grassi L. Sales of antidepressants, suicides and hospital admissions for depression in Veneto Region, Italy, from 2000 to 2005: an ecological Study. Annals of Clinical Psychiatry, 2011, 10: 24. 


\section{Summary}

Background. Increased prescription of antidepressants has been consistently associated with a decrease in suicide rates in several countries. The aim of this study is to explore antidepressant consumption, suicide rates and admission for depression in Veneto Region, Italy, in order to see whether the same pattern could be replicated. Methods. Data from the Italian Minister of Health (admissions for depression), the Pharmacy Service of a Local Health Unit (antidepressants prescribing) and from the Epidemiological System of Veneto Region (suicide rates) were collected, from 2000 to 2005, for Veneto Region. Results. Suicide rates did not show any marked increase but were stable in males and females. Antidepressant prescribing increased exponentially over the period examined, whilst admissions for depression markedly decreased. The trend for exponential increase in antidepressant prescribing in Veneto Region has been shared with other countries. Conclusions .It is possible that the increase in antidepressant prescribing might be associated with an earlier treatment of depression, thus decreasing the likelihood of aggravation of depression. 


\section{Introduction}

Antidepressant prescribing rose in several countries worldwide over the last 20 years, mainly after the introduction of Selective Serotonin Reuptake Inhibitors (Isacsson et al, 2008; Guaiana et al, 2005). This increase may be the result of better treatment and recognition of depression (Rich et al, 1997). However, some concerns have been raised over the fact that antidepressant use may increase the risk of suicide (Healy et al, 2005). Ecological studies showed some evidence that more widespread antidepressant use corresponds to a decrease in suicide rates (Isacsson et al, 2008), although this finding is disputed (Isacsson et al, 2010). Some studies show that treating more depressed patients with antidepressant might prevent suicides (Isacsson et al, 1994). Moreover, a meta-analysis by Barbui and colleagues (Barbui et al, 2009) on observational studies, showed that use of SSRI is associated with a reduced risk of suicide in adults with depression, particularly in people aged 65 or over. Other than suicide and antidepressant prescribing, the pattern of hospital admissions for depression can be another valid indicator to explore trends in the prevalence of depression and to shed some light on the relationship between suicide rates and depression. In one of the few ecological studies on the topic, Vyssoki and colleagues found that increased hospital admissions for depression was linked to a decrease in suicide rates in Austria 
between 1989 and 2008 (Vyssoki et al, 2011). These findings are in line with Roy (Roy et al, 1999), who found that patients who commit suicide at their first attempt had fewer admissions for depression. It appears that hospital admissions may have a protective effect on suicide rates. Hospital admissions rates can also be considered a proxy for depression severity (Goldberg et al, 2001; Pope et al, 2000) and can offer some insight on the trend of severely depressed people over time. Evidence shows that depression is a major cause of suicide (Cheng, 1995), and that severe depression is associated with higher suicide risk (Hardy, 2009). The time trend of hospital admissions for depression has been investigated in several studies (Guaiana et al, 2005; Walsh, 1998; Shajahan et al, 1998). Shajahan and colleagues (Shajahan et al, 1998) found that admissions for depression declined in women and increased in men between 1980 and 1995 in Scotland; on the other hand Walsh (Walsh, 1998) found that there was no change in admissions in men in Ireland between 1975 and 1995. Guaiana and colleagues (Guaiana et al, 2005) found that admissions in Italy did not decline between 1986 and 1998. Analyzing combined trends for hospital admissions for depression, suicide and antidepressant prescribing, can offer some insight on the impact of antidepressant prescribing on admissions for depression and suicide rates. This analysis has been carried out for some 
European countries (Guaiana et al, 2005; Isacsson et al, 2010). However, only few studies focused on selected regions of a country. Italy is a diverse country with some differences between the North and the South (ISTAT, 2000-2005). Trends in the whole of Italy may not be representative of a specific region.

Veneto is a north-east Italian region with a population of about 5 million people (ISTAT, 2000-2005). It has an average yearly numbers of suicides of 327 (Milan, 2008). Half of suicides occur in people aged 52 or older (Milan, 2008). Males account for three quarters of suicides (Milan, 2008). The most used method is hanging (Milan, 2008).

The aim of this study is to examine the trend in admissions for depression, antidepressant prescribing and suicide in this large Italian Region, with a view to investigating how the pattern of antidepressant sale is related to suicide and admissions for depression, considered a proxy for depression severity.

\section{Materials and methods}

Data on admissions for depression were collected by the Italian Health Ministry Internet data base on Hospital discharges (Scheda di Dimissione Ospedaliera: SDO).

The official data base is freely available on the Internet (http://www.ministerosalute.it/programmazione/sdo/sdo.jsp), and includes data from 2000 to 2005. For every patient 
discharged from an Italian hospital, an official discharge form (the SDO) needs to be completed and sent to the Ministry of Health. The SDO includes demographic data (age, sex, region of discharge) and ICD-9-CM discharge diagnosis. Data were selected for the Veneto region and for the following ICD-9-CM diagnostic codes: 296.20 to 295.26 (Major Depression single episode), 296.30 to 296.36 (Major Depression recurrent episode), 296.82 (Atypical depressive syndrome), 298.0 (Depressive psychosis), 300.4 (Neurotic depression), 311 (Depressive disorder, not otherwise classified). Data on age were grouped in the following age bands: 0-14 years of age, 15-64, 65 and over. There is no specific validation study of the SDO. However, the Italian Ministry of Health runs its own validation audit and it publishes the result in their annual report (Italian Ministry of Health, 2000-2005). A raw rate of admission per 100,000 population was calculated for each age-band and sex, for each year, as well as an age-standardized total rate of admissions for depression per 100,000 population, for each year and sex. The standard population is the 2011 Census population.

We also collected data on psychiatric bed availability in Veneto Region from 2000 to 2005, from the ISTAT statistical yearbook (ISTAT, 2000-2005). 
Data on AD prescriptions were collected by the Pharmacy service of one of the Local Health Unit (LHU) in Veneto, from 2000 to 2005. No data is available after 2005. Data were available for 12 out of 21 LHU. Population of 12 LHU refers to all inhabitants of LHU with no further restrictions. The distribution of classes of ages and gender is almost the same for the 12 LHU and Veneto Region as a whole (percentage of children aged 0-14 years: 13.8\% vs $13.9 \%$, percentage of old people over 65 years: $19.8 \%$ vs 19.5\%, percentage of female: 51.2 vs 51.1). Furthermore, prescriptions of antidepressant in $12 \mathrm{LHU}$ is very similar to that of Veneto Region (in 2005 number of boxes of antidepressant prescribed are 0.46 vs 0.44 ). Based on these assumptions, sample of 12 LHU can be considered as representative of the whole Veneto Region. For each AD, the number of packages sold was converted into defined daily doses (DDDs) per 1,000 inhabitants per day (DDD/1,000/day). The DDD is the international unit of drug utilisation approved by the World Health Organisation for drug use studies (World Health Organization Collaborating Centre for Drug Statistic Methodology, 2003). The DDD is a theoretical unit of measurement defined as the assumed average maintenance daily dose for a drug, used for its main indication in adults. The DDD/1,000/day indicates how many people per 1,000 of the population have in theory received a standard dose (i.e. the DDD) of a particular medication or category of medication daily. 
Data on numbers of suicide deaths according to the Ninth Revision of the Italian International Classification of Diseases (ICD-IX) in each sex and age-group and estimates of the resident population in Veneto were collected from the Regional Epidemiological System (Sistema Epidemiologico Regione Veneto: SER), which is the local government-funded regional statistical office, from 2000 to 2005 . Data were age-standardized by the SER for each sex.

A statistical model using ordinary least squares linear regression was employed, based on the model developed by Preti and Miotto (Preti et al, 2000). The model was used in the present study to test for changes over time in suicide rates and admission rates for depression. Rates were the dependent variable and years were the independent variable. Linear regression analysis of rates over 6 years (2000-2005) was performed. A two-tailed t-test was also performed to test for the hypothesis of a significant slope.

A Spearman $\rho$ correlation coefficient per each sex and aged-strata across the time period examined (2000-2005) has been calculated for $\mathrm{AD} \mathrm{DDD}$ and admissions for depression rates. We also calculated a Spearman $\rho$ correlation coefficient for AD DDD and suicides rates for each sex, between 2000 and 2005 and a Spearman $\rho$ correlation coefficient for admissions for depression and suicide rate, for each sex, between 2000 and 2005 . 
SPSS for Windows version 19 has been used to perform all the calculations.

\section{Results}

\section{Hospital admissions for depression and psychiatric beds}

We performed a separate analysis of admissions for each age band and sex, for the years 2000 to 2005. The pattern of admission for the age-band 0-14 males is quite erratic with a drop in 2001 and a steady increase from 2002 to 2005. Females aged 0 to 14 also showed an erratic pattern with a decline in admissions from 2000 to 2001, followed by a drop in 2002, a peak in 2004 and another decline in 2005. It is very likely that this erratic pattern reflects the small numbers of admissions. The linear regression model showed no significant trend both for males (slope $=-0.036,95 \%$ Confidence Interval $=-0.312$ to 0.384 , Standard Error $=0.125, \mathrm{Adj}$ $\mathrm{R}^{2}=-0.225, \mathrm{~F}=0.082, \mathrm{p}=0.788$ ) and for females (slope $=-0.069$, 95\% Confidence Interval $=-0.544$ to 0.406 , Standard Error $=0.171$, Adj $\left.R^{2}=0.201, F=0.162, p=0.708\right)$.

The 15-64 age band showed, instead, a consistent trend toward reduction in admission between 2000 and 2005, for males (slope= -1.465 , 95\% Confidence Interval $=-1.837$ to -1.093 , Standard Error $=0.134$, Adj $R^{2}=0.960, F=119.642, p=0.0001$ ) and, to a higher degree, for females (slope $=-6.379$, 95\% Confidence Interval $=-7.291$ to -5.466 , Standard Error $=0.329$, Adj $R^{2}=0.987$, 
$\mathrm{F}=376.559, \mathrm{p}=0.0001)$. People aged 65 or older showed a downward trend, too. Admissions for males over 65 increased from 2000 to 2001 and then steadily decreased (slope= -8.994, 95\% Confidence Interval $=-15.247$ to -2.741 , Standard Error $=$ 2.252, Adj $\left.R^{2}=0.749, F=15.948, p=0.016\right)$. Females admissions showed a decreasing trend from 2000 to 2005 (slope $=-22.508$, 95\% Confidence Interval $=-30.518$ to -14.497 , Standard Error $=$ 2.885, Adj $\mathrm{R}^{2}=0.923, \mathrm{~F}=60.861, \mathrm{p}=0.001$ ) .

The total age-standardized admission rates for depression for each sex is shown on table 1.

\begin{tabular}{lrc}
\hline & MALES & FEMALES \\
\hline $\mathbf{2 0 0 0}$ & 20.92 & 46.52 \\
$\mathbf{2 0 0 1}$ & 21.42 & 44.96 \\
$\mathbf{2 0 0 2}$ & 20.94 & 42.26 \\
$\mathbf{2 0 0 3}$ & 20.51 & 38.94 \\
$\mathbf{2 0 0 4}$ & 20.33 & 37.51 \\
$\mathbf{2 0 0 5}$ & 19.54 & 35.13 \\
\hline
\end{tabular}

Table 1. Age-standardized admission rate per 100,000 population for depression for each sex, 2000-2005

Overall, the admissions for depression declined both in males and in females from 2000 to 2005. 
The number of beds in the Veneto region changed from a maximum of 796 in 2000 to a minimum of 733 in 2003. The number of beds rose again up to 763 in 2004 and 757 in 2005.

\section{Antidepressant drugs prescribing}

The analysis show that antidepressants (AD) consumption in Veneto Region increased exponentially from 2000 to 2005, both for males and for females (see Figure 1).

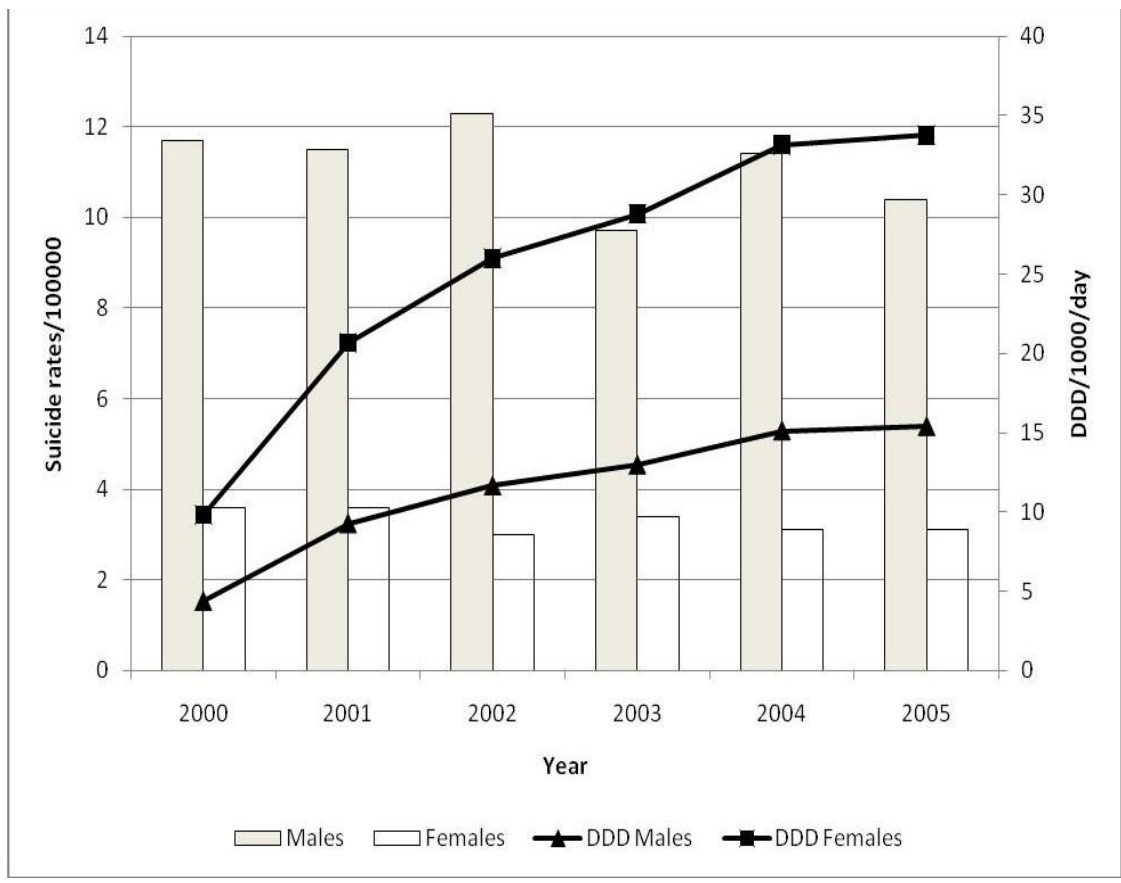

Figure 1. Suicide rates (bars) and antidepressant prescribing (line) among males and females in Veneto from 2000 to 2005 
If we break down the data by age (see Table 2), we notice that there is an increased use of antidepressants as we move to the higher age-band. This finding is consistent among males and females for all the years examined. AD prescribing is at least double in males and females over 65, compared to people aged 15-64 years. If we look at the prescribing trend, we can find that in the 0-14 age band, AD consumption steadily increased between 2000 and 2005, both in males and in females. Looking at the 15-64 age band, we find out that $A D$ prescription increased exponentially from 2000 to 2005, with an almost identical trend in males and females. Males, however, were prescribed less DDD than females. The 65 and over age band shows the same trend as the 15-64 years old, with an exponential increase in AD DDD, with almost identical trends for males and females, and males prescribed less DDD than females. 


\begin{tabular}{rcccrrr}
\hline & \multicolumn{3}{c}{ MALES } & \multicolumn{4}{c}{ FEMALES } \\
\hline $\mathbf{2 0 0 0}$ & $\mathbf{0 - 1 4}$ & $\mathbf{1 5 - 6 4}$ & $\mathbf{6 5 +}$ & $\mathbf{0 - 1 4}$ & $\mathbf{1 5 - 6 4}$ & $\mathbf{6 5 +}$ \\
$\mathbf{2 0 0 1}$ & 0.05 & 3.63 & 12.51 & 0.02 & 7.60 & 22.73 \\
$\mathbf{2 0 0 2}$ & 0.11 & 8.76 & 20.85 & 0.11 & 18.56 & 39.75 \\
$\mathbf{2 0 0 3}$ & 0.22 & 12.34 & 28.06 & 0.28 & 25.99 & 54.39 \\
$\mathbf{2 0 0 4}$ & 0.31 & 14.60 & 31.35 & 0.4 & 30.43 & 60.94 \\
$\mathbf{2 0 0 5}$ & 0.35 & 15.12 & 30.61 & 0.53 & 31.73 & 59.62 \\
\hline
\end{tabular}

Table 2 - DDD/1000/day for AD divided by age and sex

\section{Suicides}

Suicide rates per 100,000 population in Veneto showed some minor changes in males over the period examined, with a maximum of 12.3 in 2002 and a minimum of 9.7 in 2003. The rate of suicide did not change markedly in females, oscillating between a maximum of 3.6/100,000 in 2000 and 2001 and 3.1/100,000 in 2004 and 2005 (see Figure 1). The linear regression model did not yield a statistically significant result, both for males (slope= $0.269,95 \%$ Confidence Interval $=-0.863$ to 0.326 , Standard Error= 0.214 , Adj $\mathrm{R}^{2}=0.103, \mathrm{~F}=1.572, \mathrm{p}=0.278$ ) and for females (slope= $0.103,95 \%$ Confidence Interval $=-0.242$ to 0.036 , Standard Error= 0.05, Adj $R^{2}=0.393, F=4.235, p=0.109$ ). 


\section{Correlation}

The Spearman $\rho$ correlation coefficients for AD DDD and admission rates for depression are shown on Table 3.

\begin{tabular}{ll}
\hline $\begin{array}{l}\text { Admissions for depression and } \\
\text { DDD Males aged 0-14 }\end{array}$ & $\rho=-0.08(\mathrm{NS})$ \\
\hline $\begin{array}{l}\text { Admissions for depression and } \\
\text { DDD Females aged 0-14 }\end{array}$ & $\rho=-0.3(\mathrm{NS})$ \\
\hline $\begin{array}{l}\text { Admissions for depression and } \\
\text { DDD Males aged 15-64 }\end{array}$ & $\rho=-1(\mathrm{p}<0.01)$ \\
\hline $\begin{array}{l}\text { Admissions for depression and } \\
\text { DDD Females aged 15-64 }\end{array}$ & $\rho=-1(\mathrm{p}<0.01)$ \\
\hline $\begin{array}{l}\text { Admissions for depression and } \\
\text { DDD Males aged 65+ }\end{array}$ & $\rho=-0.94(\mathrm{p}<0.05)$ \\
\hline $\begin{array}{l}\text { Admissions for depression and } \\
\text { DDD Females aged 65+ }\end{array}$ & $\rho=-0.89(\mathrm{p}<0.05)$ \\
\hline \multicolumn{2}{c}{$\mathrm{NS}=$ not significant }
\end{tabular}

Table 3 - Spearman $\rho$ correlation coefficients and $p$ values for AD DDD and admissions rates for depression.

It appears that there is a high inverse correlation between antidepressant prescribing and admissions for depression for the age strata 15-64 and 65+, both in males and in females. No significant correlation was found between antidepressant prescribing and admissions for depression in the age-strata 0-14, for both sexes.

The Spearman $\rho$ correlation coefficients for AD DDD and agestandardized suicide rates are shown on Table 4 . There is no 
correlation between suicide rates and AD DDD between 2000 and 2005 , for both sexes.

\begin{tabular}{ll}
\hline $\begin{array}{l}\text { AD DDD and Suicide rates } \\
\text { Males }\end{array}$ & $\rho=-0.66(\mathrm{NS})$ \\
\hline $\begin{array}{l}\text { AD DDD and Suicide rates } \\
\text { Females }\end{array}$ & $\rho=-0.61(\mathrm{NS})$ \\
\hline & $\mathrm{NS}=$ not significant
\end{tabular}

Table 4 - Spearman $\rho$ correlation coefficients and $p$ values for AD DDD and suicide rates.

The Spearman $\rho$ correlation coefficients for total admissions for depression and age-standardized suicide rates for each sex are shown on Table 5. There is no correlation between suicide rates and admissions for depression between 2000 and 2005, for both sexes.

\begin{tabular}{ll}
\hline $\begin{array}{l}\text { Total admissions and Suicide } \\
\text { rates Males }\end{array}$ & $\rho=0.66(\mathrm{NS})$ \\
\hline $\begin{array}{l}\text { Total admissions and Suicide } \\
\text { rates Females }\end{array}$ & $\rho=0.62(\mathrm{NS})$ \\
\hline
\end{tabular}

$$
\text { NS= not significant }
$$

Table 5 - Spearman $\rho$ correlation coefficients for admissions for depression and suicide rates, for each sex. 


\section{Discussion}

The present study aimed at assessing trends in hospital admissions for depression, considered as a proxy for depression severity and to relate these trends with antidepressant prescription and suicide rates in the region of Veneto between 2000 and 2005. Additionally suicide rates would be analyzed in order to assess a possible link between antidepressant use and suicide. Essentially, we found a marked decline in admissions for depression, with no major change in psychiatric bed availability, an exponential increase in antidepressant prescribing and no change in suicide rates. Also the study shows that the trend of suicide rates does not correlate with the changes in admission rates for depression. It also appears that the increase in $\mathrm{AD}$ prescribing does not correlate with changes in suicide rates. It may be possible that the relationship between $\mathrm{AD}$ prescribing and suicide rates may work only for some age strata. Elderly use antidepressants far more than younger people. This finding is confirmed for the whole of Italy (Barbui et al, 2003). Unfortunately, we have no information on suicide rates divided by age. It appears that antidepressants are very effective to prevent suicide among elderly (Barbui et al, 2009). We also have no data on the proportion of Selective Serotonin Reuptake Inhibitors (SSRIs) on the total of AD prescribed. However, we can say that it 
is likely that the majority of antidepressant prescribed in Veneto are SSRIs and newer AD. The study by Guaiana and colleagues (Guaiana et al, 2005) showed that SSRIs and newer AD had an exponential increase in prescription, whilst the prescription of older Tricyclic AD did not change. Also, other two recent studies done in different Italian regions (Trifirò et al, 2007; Castelpietra et al, 2008) showed that the prevalence of SSRI use markedly increased. The first and most striking finding is the sharp decline of hospital admissions for depression. This decrease affected both the age strata 16-64 and 65+ age band, as well males and females. The data relating to the $0-14$ age strata are not reliable due to the small numbers involved. This findings is at odds with that of Vyssoki and colleagues (Vyssoki et al, 2011), who found that an increase in hospital admissions for depression is paralleled with a decrease in suicide rates. There are several possible explanations to the finding in the 16-64 and 65+ ages bands. In theory, less hospital admissions may just reflect a decrease in the general prevalence of depression, or a decrease in recognition of depression, or both. There is not any evidence to suggest either of both. On the contrary, worldwide data have repeatedly documented an increase in the incidence and/or awareness of depression both amongst the general population and amongst medical practitioners (Isacsson et al, 2010). Moreover, both trends would be at odds with our second finding of a impressive increase in antidepressant prescription in the same region at the 
same time. Another possibility is that the observed decrease in hospital admission merely reflects a decrease in beds availability. This however does not seem to be the case as the number of beds did not decline. A most likely explanation of the observed decline in hospital admission for depression between 2000 and 2005 is that depression became better diagnosed, and therefore better treated. This notion becomes particularly salient when considering our next finding of an approximately fivefold increase in antidepressant use in the same period. It is best plausible that the observed increase in antidepressant prescribing reflects a better effort in recognizing depression and therefore an earlier and more effective treatment. The benefits of early intervention have been widely documented (Kupfer et al, 1989), resulting in the shortening of the depressive episode. If, as mentioned above, hospital admission is a valid indicator of depression severity (Goldber et al, 2001; Pope et al, 2000), then it is arguable that the decrease in hospital admissions is directly linked to an increase in effective prescription of antidepressants. It is of note that a worldwide increase in the prescription of antidepressants have been observed over the last 10-15 years (Isacsson et al, 1994). There have been some reports showing that admissions for depression increased or did not change (Guaiana et al, 2005; Walsh, 1998; Shajahan et al 1998). Shajahan and colleagues 
(Shajahan et al 1998) reported that admissions increased in men, in Scotland. They hypothesize that this can be due to increased recognition of depression or increase in health seeking behavior of men. The study of Shajahan refers to an earlier timeframe (1980-95). It is possible to hypothesize that in the late ' 90 , there has been an increased awareness of depression, possibly leading to an increase in the number of the people treated with antidepressants, which eventually led to an overall decrease in depression severity and therefore in admissions for depression. The increased awareness for depression may likely have happened in Primary Care. It appears that General Practitioner prescribe more and more $\mathrm{AD}$ in some European regions (Vyssoki et al, 2011). To corroborate this hypothesis, Munoz-Arroyo and colleagues (Munoz-Arroyo et al, 2006) found that prescription of antidepressant by General Practitioner doubled in Scotland from 1992 to 2000. Also, the studies by Walsh (Walsh, 1998) and Guaiana and colleagues (Guaiana et al, 2005), examining admissions in Ireland and in Italy, respectively, referred to an earlier timeframe. Our hypothesis is that there has been a time lag between increased prescription of antidepressants and reduction in admissions for depression. In Italy, antidepressant prescribing increased exponentially only since 1995 (Guaiana et al, 2005). We hypothesize that it may have taken some years to see some effect on depression and admissions for depression. Also, it is of interest to note that the decrease in admissions for depression is not 
associated with change in suicide rate, as we found no correlation between admissions for depression and suicide rates, for both sexes. Our final finding is that overall suicide rates remained unchanged during the period under examination, in spite of the observed exponential increase in use of antidepressants. If antidepressant were associated with an increase in suicide rates, as pointed out by Healy and colleagues (Healy et al, 2005), there would have been an increase in suicide rates, which did not happen. Vichi and colleagues examined suicide rates in Italy between 1980 and 2002 (Vichi et al, 2010). They concluded that the decline in suicide rates is possibly a consequence of the decrease in the incidence of mental disorders as a result of the development of an integrated and community-based mental health system, which in turn may have led to decreased suicide rates, by early detection of mental disorders, including depression. AD prescribing may be part of this picture, as earlier detection of mental disorder may have led to an increase in $\mathrm{AD}$ prescribing. Our findings are more in line with the data examined by Isaacson and colleagues (Isacsson et al, 2010; Isacsson et al, 1994), and Barbui and colleagues (Barbui et al, 2009) where suicide rates showed an opposite trend to antidepressant prescribing. Also, Khan and colleagues (Khan et al, 1003) showed that SSRIs do not induce suicide more than other AD or even 
placebo. Whatsoever, our study failed to find any argument suggesting that an increase in antidepressant use is associated with increased risk of suicide.

The present study suffers from some limitations. First we assumed that all antidepressants are prescribed and used for depression. This is not entirely true, as antidepressants are increasingly used for anxiety disorders as well, also in Italy (Ciuna et al, 2004). Anxiety disorders are at least as prevalent as depression. Both types of disorders are highly comorbid. Our database does not make it possible to find out the specific disease that required the prescription of the antidepressant. However, since anxiety and depression are closely intermingled, the former being often an indicator of the severity of the latter and vice versa (Brown et al, 1996), this limitation does not necessarily invalidate our main conclusions. Secondly, data on antidepressant prescribing are not covering the entire Veneto Region, but only some of the LHUs. We assumed that the data can be extended to the whole region but we cannot rule out a possible bias in data collection. Also, the study cover a relative limited period of time, only six years. Nevertheless, clear trends can be found. Thirdly, we cannot exclude the possibility that that the downward trend in hospital admissions for depression in Veneto and in Italy could be part of a broader picture where admissions for mental health problems as a whole are decreasing. Moreover, the DDD only reflects prescription and not current usage. It is not possible to 
take for granted that all people who receive a prescription will use it. It must also be said that the reliability of data on admissions, suicides and DDD may be questioned, as it happens for any large scale data collection. Another point to consider is that suicide is not only linked to depression but also to schizophrenia, bipolar disorder and substance misuse (Hor et al, 2010; McIntyre et al, 2008; Vijaykumar et al, 2011). Our data do not include admissions for those conditions. Data may have been different if we had included admissions for those mental disorders. Finally, the naturalistic design of this analysis is by definition subject to the ecological fallacy, and therefore no causal relationships can be definitely established.

\section{Conclusions}

In spite of these limitations, we conclude that the marked increase observed in sale of antidepressants has been attended by a striking decrease in hospital admissions for depression in the same period. The exponential change in antidepressant use was not accompanied by any relevant change in suicide rates. Further studies will be required to refute or corroborate these findings. 
Antidepressant prescribing, suicide and hospital admissions for depression in Veneto region (Italy), 2000-2005

\section{Competing interests}

The authors declare that they have no competing interest.

\section{Authors' contributions}

GG and MA participated in the design of the study. GG, BB, LG and EG devised the statistical model and contributed to the discussion section.

\section{Acknowledgements}

None. 


\section{References}

Barbui C, Broglio E, Laia AC, D’Agostino S, Enrico F, Ferraro L, Fiorio E, Miletti F, Pietraru C, Poggio L, Tognoni G. Cross-sectional database analysis of antidepressant prescribing in Italy. Journal of Clinical Psychopharmacology, 2003; 23:31-34.

Barbui C, Esposito E, Cipriani A. Selective serotonin reuptake inhibitors and risk of suicide: a systematic review of observational studies. Canadian Medical Association Journal, 2009; 180: 291297.

Brown C, Schulberg HC, Madonia MJ, Shear MK, Houck PR. Treatment outcomes for primary care patients with major depression and lifetime anxiety disorders. American Journal of Psychiatry, 1996; 153: 1293-1300.

Castelpietra G, Morsanutto A, Pascolo-Fabrici E, Isacsson G. Antidepressant use and suicide prevention: a prescription database study in the region Friuli-Venezia Giulia Italy. Acta Psychiatrica Scandinavica, 2008; 118: 382-388.

Cheng ATA. Mental illness and suicide. Archives of General Psychiatry, 1995; 52: 594-603 
Ciuna A, Andretta M, Corbari L, Levi D, Mirandola M, Sorio A, Barbui C. Are we going to increase the use of antidepressants up to that of benzodiazepines? European Journal of Clinical Pharmacology, 2004; 60: 629-634.

Goldberg JF, Harrow M, Whiteside JE. Risk for bipolar illness in patients initially hospitalized for unipolar depression. American Journal of Psychiatry, 2001; 158: 1265-1270.

Guaiana G, Andretta M, Corbari L, Mirandola M, Sorio A, D’Avanzo B, Barbui C. Antidepressant drug consumption and public health indicators in Italy 1955 to 2000. Journal of Clinical Psychiatry, 2005; 66: 750-755.

Hardy P. Severe depression: morbidity-mortality and suicide. Encephale, 2009; 35: (Suppl 7): S269-S271.

Healy D, Aldred G. Antidepressant drug use and the risk of suicide. International Review of Psychiatry, 2005; 17: 163-172.

Hor K, Taylor M. Suicide and schizophrenia: a systematic review of rates and risk factors. Journal of Psychopharmacology, 2010; 24(4 Suppl): 81-90. 
Isacsson G, Bergman U, Rich C. Antidepressant depression and suicide: an analysis of the San Diego study. Journal of Affective Disorders, 1994, 32: 277-286.

Isacsson G, Rich C, Jureidin J, Raven M. The increased use of antidepressants has contributed to the worldwide reduction in suicide rates. British Journal of Psychiatry, 2010; 196: 429-433.

Isacsson G, Rich C. Antidepressant medication prevents suicide: a review of ecological studies. European Psychiatric Review, 2008; 1: 24-26.

ISTAT: Annuario Statistico Italiano. Rome: ISTAT, 2000-2005.

Italian Ministery of Health: Rapporto Annuale sull'attività di ricovero ospedaliero. Rome: Ministero della Salute, 2000-2005.

Khan A, Khan S, Kolts R, Brown WA. Suicide rates in clinical trials of SSRIs other antidepressants and placebo: analysis of FDA reports. American Journal of Psychiatry, 2003; 160: 790-792. 
Kupfer DJ, Frank E, Perel JM. The advantage of early treatment intervention in recurrent depression. Archives of General Psychiatry, 1989; 46: 771-775.

McIntyre RS, Muzina DJ, Kemp DE, Blank D, Woldeyohannes HO, Lofchy J, Soczynska JK, Banik S, Konarski JZ. Bipolar disorder and suicide: research synthesis and clinical translation. Current Psychiatry Reports, 2008; 10: 66-72.

Milan G. I suicidi nel Veneto. Bollettino Informativo del Sistema Epidemiologico Regionale del Veneto, 2008; 3: 5-8.

Munoz-Arroyo R, Sutton M. Exploring potential explanations for the increase in antidepressant prescribing in Scotland using secondary analyses of routine data. British Journal of General Practice, 2006; 56: 423-428.

Pope GC, Ellis RP, Ash AS, Liu CF, Ayanian JZ, Bates DW, Burstin H, Iezzoni LI, Ingber MJ. Principal Inpatient Diagnostic Cost Group Model for Medicare Risk Adjustment. Health Care Financial Review, 2000; 3: 93-118.

Preti A, Miotto P. Increase in first admissions for schizophrenia and other major psychoses in Italy. Psychiatry Research, 2000; 94: 139-152. 
Rich CL, Isacsson G. Suicide and antidepressants in south Alabama: evidence for improved treatment of depression. Journal of Affective Disorders, 1997; 45: 135-142.

Roy AC. Depressed patients who suicide at their first attempt have had few admissions. Depression and Anxiety, 1999; 9: 75-77.

Shajahan PM, Cavanagh JT. Admission for depression among men in Scotland 1980-95: retrospective study. British Medical Journal, 1998; 316: 1496-1497.

Trifirò G, Barbui C, Spina E, Moretti S, Tari M, Alacqua M, Caputi AP, UVEC group, Arcoraci V. Antidepressant drugs: prevalence incidence and indication of use in general practice of Southern Italy during the years 2003-2004. Pharmacoepidemiology and Drug Safety, 2007, 16: 552-559.

Vichi M, Masocco M, Pompili M, Lester D, Tatarelli R, Vanacore N. Suicide mortality in Italy 1980-2002. Psychiatry Research, 2010; 175: 89-97. 
Vijayakumar L, Kumar MS, Vijayakumar V. Substance use and suicide. Current Opinion in Psychiatry, 2011; 24: 197-202.

Vyssoki B, Willeit M, Blüml V, Höfer P, Erfurth A, Psota G, Lesch OM, Kapusta ND. Inpatient treatment of major depression in Austria between 1989 and 2009: Impact of downsizing of psychiatric hospitals on admissions, suicide rates and outpatient psychiatric services. Journal of Affective Disorders, 2011; 133: 9396.

Walsh D. Admissions for depression have not increased among men in the Republic of Ireland. British Medical Journal, 1998; 317: 1158.

World Health Organization Collaborating Centre for Drug Statistic Methodology: Guidelines for ATC Classification and DDD Assignment. Oslo: World Health Organization Collaborating Centre for Drug Statistic Methodology, 2003. 


\section{Chapter 6. Admissions for Personality Disorders in Italy and}

suicide. Are Personality Disorders a determinant of suicide? 


\section{Part 1. Admissions for Personality Disorders in Italy from 1988 to 1998}

Published as: Guaiana G, Barbui C. Admissions for personality disorders in Italy from 1988 to 1998. Clinical Practice and Epidemiology in Mental Health , 2006; 2:20. 


\section{Summary}

Background. PDs affect a substantial proportion of the population. Trends in admissions for PDs in Italy from 1988 to 1998 were analyzed. Methods. We used the yearly data from the Italian Central Institute of Statistics. Results. The total number of admissions for PDs almost trebled from 1988 to 1998, as well as the proportion of all psychiatric admissions that were for PDs. Whilst there has been a marked increase in the absolute number of first admissions, the proportion of all first psychiatric admissions that were for PDs showed a steady but modest increase, ranging from $5.7 \%$ to $7.6 \%$. Conclusions. In terms of public health, these findings highlight the need of developing policies to tackle the increasing needs of care of PD patients. 


\section{Introduction}

PDs affect a substantial proportion of the population. While community surveys estimated that between 4.4 and $13 \%$ of individuals have a PD (Coid, 2003), surveys carried out in outpatient psychiatric settings estimated that nearly one third of psychiatric patients were diagnosed with one specific PD, and up to fifty percent received a general diagnosis of PDs (Zimmerman, 2005). Despite these figures, it remains unclear whether the burden of PDs on modern mental health services has been increasing. In North West Wales, a survey showed that PDs accounted for $9 \%$ of total admissions for psychiatric problems in 1996, while no PD patients were admitted 100 years ago (Healy, 2001). However, hospital admissions for PDs have never been examined during a time frame of substantial stability in terms of bed availability and conceptualization of PDs. To fill this gap, we analyzed trends in admissions for PDs in Italy from 1988 to 1998.

\section{Materials and methods}

In Italy, the Italian Central Institute of Statistics (ISTAT) routinely collects data from health authorities on hospital admissions. These data are published in the health-care statistics yearbooks for the corresponding period. Data collection is based on the ICD9-CM classification system. These figures were used to establish 
the total number of admissions for PDs and the proportion of all psychiatric admissions that were for PDs between 1988 and 1998. We additionally established the total number of first admissions for PDs and the proportion of all first psychiatric admissions that were for PDs. While the ISTAT system of data collection has always remained the same during the time frame considered in this analysis, a new system was implemented after 1998, and admission numbers were not recorded anymore. In recent years, ISTAT data have been shown to be useful for monitoring compulsory admissions (Guaiana et al, 2004), suicide rates (Guaiana et al, 2002) and other public health indicators (Guaiana et al, 2005).

\section{Results}

The total number of admissions for PDs almost trebled from 1988 to 1998; similarly, the proportion of all psychiatric admissions that were for PDs progressively increased, ranging from $5.3 \%$ to 8.9\% (Figure 1).

The analysis of first admissions for PDs revealed that whilst there has been a marked increase in the absolute number of first admissions, the proportion of all first psychiatric admissions that were for PDs showed a steady but modest increase, ranging from $5.7 \%$ to $7.6 \%$ (Figure 2 ). 


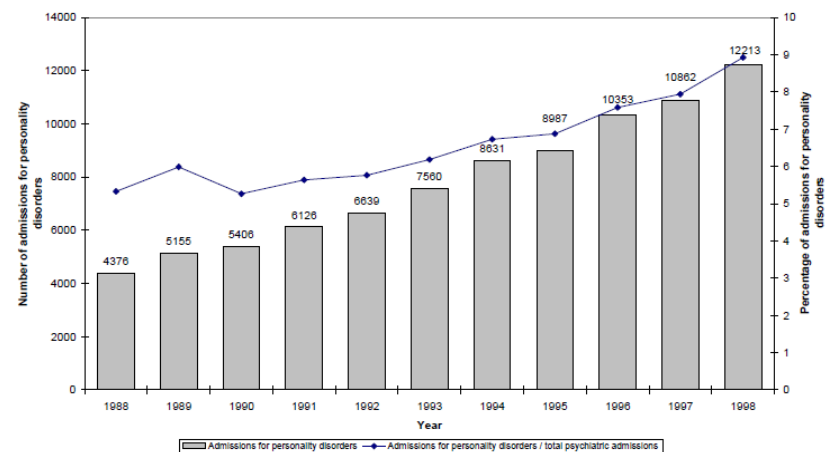

Figure I

Admissions for PDs. Number of admissions for personality disorders in Italy from 1988 to 1998, and proportion of all psychiatric admissions that were for personality disorders.

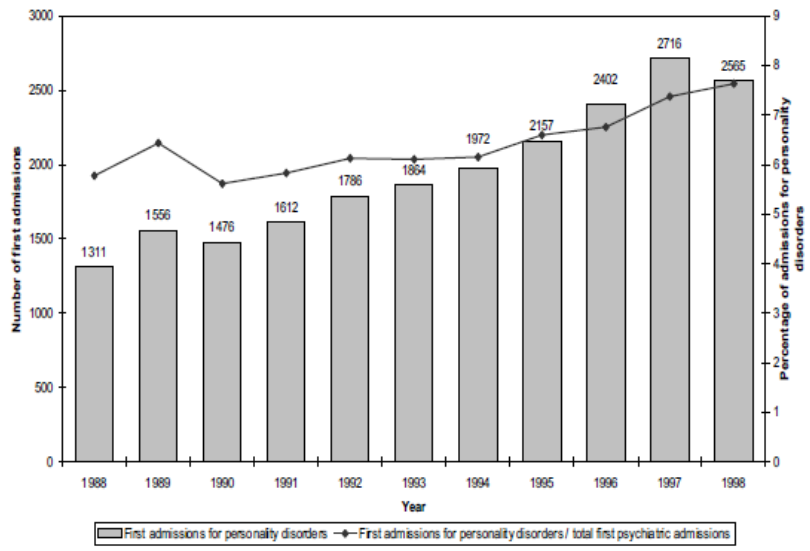

Figure 2

First admissions for PDs. Number of first admissions for personality disorders in Italy from 1988 to 1998 , and proportion of all first psychiatric admissions that were for personality disorders. 


\section{Discussion}

In Italy, the burden of PDs on modern mental health services has been increasing. In 1998, 9\% of all psychiatric admissions were for PDs.

A limitation of this analysis is the possible low quality of reporting by hospitals. Only clinical diagnoses of PDs are routinely collected, and no data are available to check the degree of coherence between this diagnostic information and research diagnoses of PDs. Given the difficulties of obtaining reliable diagnoses of some PDs (Paris, 2005), it is possible that the burden of PDs has been underestimated. In addition, the system work in such a way that no data are available on specific PDs, and therefore it remains unclear whether these increasing trends are mostly explained by the increasing burden of a specific PD, for example borderline personality disorder. Although we acknowledge these limitations, during the index years considered in this analysis the system of data collection has never changed. Likely, therefore, the possibility of low quality of reporting should not have affected the analysis of trends over the years. Another limitation is that we have no reliable data to establish whether these trends represent a genuine increase in hospital admissions or a greater awareness of the diagnosis. However, given that no major changes in the conceptualisation of PDs has occurred during the time frame 
considered in this analysis, it seems that these trends cannot be entirely attributed to a greater awareness of the illness.

\section{Conclusions}

In terms of public health, these findings highlight the need of developing policies to tackle the increasing needs of care of PD patients. Although to many clinicians PD remains a specialist subject, in many countries the possibility of developing specific facilities, in the public sector, seems unrealistic. Conversely, modern mental health services could probably develop specific skills for the psychological management of these patients, recognising that is almost impossible to be engaged in clinical psychiatry without coming across the problem of PDs. 


\section{List of abbreviations}

$\mathrm{PD}=$ Personality Disorder

PDs $=$ Personality Disorders

\section{Competing interests}

The authors declare that they have no competing interest.

\section{Authors' contributions}

CB conceived the study. GG implemented the idea, did the literature search and wrote the first draft of the article, mainly the Background, Methods and Results section. CB supervised the writing process and added the Discussion and Conclusion section.

\section{Acknowledgements}

None. 


\section{References}

Coid J. Epidemiology, public health and the problem of personality disorders. British Journal of Psychiatry, 2003; Suppl 44: S3-S10.

Guaiana G, Andretta M, Corbari L, Mirandola M, Sorio A, D’Avanzo B, Barbui C. Antidepressant drug consumption and public health indicators in Italy, 1955 to 2000. Journal of Clinical Psychiatry, 2005; 66: 750-755.

Guaiana G, Barbui C. Trends in the use of the Italian Mental Health Act, 1979-1997. European Psychiatry, 2004; 19: 444-445.

Guaiana G, D’Avanzo B, Barbui C. Update of suicide trends in Italy from 1986 to 1996. Social Psychiatry and Psychiatric Epidemiology, 2002; 37: 267-270.

Healy D, Savage M, Michael P, Harris M, Hirst D, Carter M, Cattell D, McMonagle T, Sohler N, Susser E. Psychiatric bed utilization: 1896 and 1996 compared. Psychological Medicine, 2001; 31: 779-790.

Paris J. The diagnosis of borderline personality disorder: problematic but better than the alternatives. Annals of Clinical Psychiatry, 2005; 17: 41-46. 
Zimmerman M, Rothschild L, Chelminski I. The prevalence of DSMIV personality disorders in psychiatric outpatients. American Journal of Psychiatry, 2005; 162: 1911-1918. 


\section{Part 2. Note: are personality}

\section{disorders a determinant of suicide?}




\section{Epidemiology and risk factors for suicide in personality disorders}

Krysinska and colleagues (Krysinska et al, 2006) reviewed the literature on the relationship between personality disorders and suicides. They mentioned that an analysis of 31 papers published from 1959 and 2001 (Bertolote et al, 2004) showed that personality disorders were found in $3.2 \%$ of suicides in the general population, but in $13.1 \%$ if multiple diagnoses were allowed. Also, Krysinska and colleagues referred to a review of psychological autopsy studies, published in 2004 (ArsenaultLapierre et al, 2004), where personality disorders accounted for about $14 \%$ of completed suicides. It appeared that personality disorders conferred a high suicide risk in males compared to females. Krysinska and colleagues also reported that psychological autopsy studies may not be as sensitive to Axis II pathology as for Axis I. So, it may be possible that personality disorders may be underestimated as contributors to completed suicides. Schneider and colleagues (Schneider et al, 2008) examined 263 suicides by psychological autopsy method and found that personality disorders were associated with a sevenfold suicide risk, across all clusters. If a person was suffering from more than one personality disorder in two different clusters, the risk was much higher (around 11 times higher than the general 
population). The authors concluded that: "Personality disorders modify the effects of socio-demographic variables and life events on suicide risk, with only marginal alterations following adjustment for substance use disorders or affective disorders" (Schneider et al, 2008).

If we examine the risk factors involved in suicide among people suffering from personality disorders, we can find that stressful specific life events may precipitate suicidal behavior (Krysinska et al, 2006). Events involving love and marriage, crime and legal problems, can increase risk particularly in people suffering from Schizotypal personality disorder, Avoidant personality disorder, Borderline personality disorder and Obsessive-Compulsive personality disorder (Yen et al, 2005). Also, financial and interpersonal problems can increase the likelihood of suicide attempts (Hekkinen et al, 1997). Another modulator for suicide behavior, particularly impulsive one, is the deficit in future-time thinking, related to hopelessness and impulsivity (MacLeod et al, 2004). There are several personality traits associated with suicidality, mainly impulsivity and harm-avoidance (Giegling et al, 2009). A study analyzing the Big Five personality traits, showed that lower agreeableness were associated with high suicide rates (McCann, 2010) Also, it appears that severity of personality disorders may be an aggravating factor at least for suicide attempts (Blasco-Fontecilla et al., 2009). 
Cluster B personality disorders are particularly associated with suicide (Pompili et al, 2004). It appears that patients with Borderline Personality Disorder represent a significant percentage of suicides, from 9 to 33\% (Pompili et al, 2004). Younger people are at higher risk (Pompili et al, 2004). There are few data on suicide among patients suffering from Narcissistic Personality Disorder (Pompili et al, 2004). On the other hand, people suffering from Antisocial Personality Disorder show a high risk of suicide; up to $72 \%$ of people with Antisocial Personality Disorder attempt suicide (Pompili et al, 2004).

People suffering from Cluster $\mathrm{C}$ personality disorders do not show any increase in suicide attempts (Chioqueta et al, 2004). Dependent Personality Disorder may be associated with an increased risk of suicide. However, if the variable risk is corrected with a lifetime history of depressive disorder, no increased risk has been found (Chioqueta et al, 2004). This finding is not surprising given the fact that Cluster $\mathrm{C}$ and personality disorders in general are associated with high levels of comorbidity with Major Depression and other Axis I disorders (Lenzenweger et al, 2007).

The issue of comorbidity between Axis II disorders and Axis I pathology is a very important one. an isolated personality disorder without comorbidity with Axis I disorders is a rare 
occurrence (Isometsä, 1996; Lenzeweger et al, 2007; Krysinska et al, 2006). Axis II conditions are frequently comorbid with mood and anxiety disorders (Lenzeweger et al, 2007). Such comorbidity markedly increases suicide risk (Cheng et al, 1997; Hawton et al, 2003), even in older people (Harwood et al, 2001). Also, comorbidity of Cluster B personality disorders with Bipolar Disorder can make an independent contribution to lifetime suicide risk (Garno et al, 2005). In particular, comorbidity between Borderline Personality Disorder and Major Depression, constitutes a serious risk for suicide attempts and increases its likelihood through increase in hopelessness and impulsivity (Soloff et al, 2000), or increase in psychoactive substance abuse (Isometsä et al, 1996). The problem of substance abuse in personality disorders is well-known. All personality disorders are associated with a much higher risk of substance abuse and dependence (Trull et al, 2010), with the highest comorbidity observed for Cluster B personality disorders (Trull et al 2010). Substance abuse and dependence can worsen or sometimes even induce impulsivity (Hopwood et al, 2011), which can increase risk for suicide attempts.

\section{Personality disorders and suicide. Analysis of Italian data}


Data from Italy (Guaiana et al, 2002; Chapter 1) showed that between 1986 and 1996 suicide rates increased up to 1987 and then decreased both in males and in females. On the other hand, it appears that admissions for personality disorders increased in Italy from 1988 to 1998 (Guaiana et al, 2006; Chapter 6, part 1), with a higher proportion of people with personality disorders admitted on total psychiatric admissions. A steady increase in first admissions for personality disorders has also ben observed in Italy in the same time period (Guaiana et al, 2006; Chapter 6, part 1). We concluded that the burden of personality disorders in Italy was increasing, and we recommended that policies should be developed to tackle this public health problem. At first sight, it may seem that, at a macroscopic level, the increased admissions in personality disorders are not paralleled by an increase in suicide. This seems counterintuitive, as it appears that personality disorders are associated with a higher risk of suicide. The evidence from studies at the microscopic levels points to the direction of a link between personality disorders and suicidal behavior. A recent observational-descriptive study conducted on hospital admissions at a hospital in Spain (Alberdi-Sudupe J et al, 2011) showed that people with personality disorders carry an Odds Ratio of 7.31 compared to people without them. Another study conducted in a German hospital (Ahrens et al, 1996) 
demonstrated that personality disorders carry a rate of suicidality almost as high as mood disorders. The authors concluded that suicidality is not only linked to mood disorders but also to personality disorders themselved. An epidemiological survey has been conducted in Italy on inpatient hospital psychiatry admissions, the PROGRES study (Gigantesco et al, 2007). Results from this survey showed that personality disorders carry an odds ratio of suicidal behavior of 2.72, compared with no personality disorders (Preti et al, 2010). However, the authors concluded that a diagnosis of personality disorder carries a lower predictive value than depressive symptoms and substance abuse. So, data from Italy confirm that the vulnerability to suicide in personality disorders may not operate only through personality itself but through comorbid conditions such as depression and substance abuse. It is well known, as examined above, that personality disorders carry a higher risk of comorbidity with mood disorders, which are associated with high suicide rate (Preti et al, 2010). The PROGRES study also showed that one fifth of the people admitted to hospital with a personality disorder had a psychotic symptom (Preti et al, 2009). The issue of comorbidity can offer a possible explanation to the apparent paradox of increasing admissions for personality disorders and decreasing suicide rates observed in Italy from 1988 to 1996. The data in Chapter 6, part 1 (Guaiana et al, 2006) are taken from a national database. No data on comorbidity is available. Given the high level of association 
between personality disorders and Axis I pathology, it is reasonable to hypothesize that the admissions for personality disorders recorded in the study by Guaiana and colleagues (Guaiana et al, 2006, Chapter 6, part 1) are not only related to the personality disorders themselves but possibly also related to the associated Axis I pathology. The PROGRES study confirmed this hypothesis at a microscopic level. In other chapters of this thesis (Chapter 4 and Chapter 5) it has been shown that early detection and treatment of depression may explain the decrease in suicide rates in Italy. It may be possible that depression is detected and promptly treated in people suffering from personality disorders, therefore decreasing the likelihood of suicide attempts or completed suicide.

\section{Conclusions}

How can epidemiological data inform the clinician on the best way to assess and manage suicidality in personality disorders? Personality disorders are associated with a higher risk of suicide attempts and completed suicide. Cluster B personality disorders are associated with the highest risk.

Suicidality in personality disorders is a very important variable. People suffering from personality disorders attempt and commit suicide more often than the general population. It is the 
comorbidity with Axis I disorders (particularly mood and anxiety disorders and substance abuse disorders) that markedly increase risk for suicide. Borderline Personality Disorder is associated with the highest risk of suicide. Careful assessment of suicidality should always been carried out, as it can have an impact on prognosis. It is imperative that careful exploration of Axis I pathology is carried out when dealing with a patient with personality disorders, as epidemiological data show that Axis I pathology, in Italy and elsewhere, may confer a higher risk of suicide. Further research is needed in order to improve efficacy of treatment interventions and reduce suicidality in individuals suffering from personality disorders, in particular focusing on the impact of treatment of comorbid Axis I conditions on suicidal behavior. 


\section{References}

Ahrens B, Haug HJ. Suicidality in hospitalized patients with a primary diagnosis of personality disorder. Crisis. 1996; 17: 59-63.

Alberdi-Sudupe J, Pita-Fernández S, Gómez-Pardiñas SM, IglesiasGil-de-Bernabé F, García-Fernández J, Martínez-Sande G, LantesLouzao S, Pértega-Díaz S. Suicide attempts and related factors in patients admitted to a general hospital: a ten-year cross-sectional study (1997-2007). BMC Psychiatry; 11: 51

Arsenault-Lapierre G, Kim C, Turecki G. Psychiatric diagnoses in 3275 suicides: a meta-analysis. BMC Psychiatry, 2004; 4: 37.

Bertolote JM, Fleischmann A, De Leo D, Wasserman D. Psychiatric diagnoses and suicide: revisiting the evidence. Crisis, 2004; 25: 147-155.

Blasco-Fontecilla H, Baca-Garcia E, Dervic K, Perez-Rodriguez MM, Saiz-Gonzalez MD, Saiz-Ruiz J, Oquendo MA, de Leon J. Severity of personality disorders and suicide attempt. Acta Psychiatrica Scandinavica, 2009; 119: 149-155. 
Cheng AT, Mann AH, Chan KA. Personality disorder and suicide. A case-control study. British Journal of Psychiatry, 1997; 170: 441446.

Chioqueta AP, Stiles TC. Assessing suicide risk in cluster C personality disorders. Crisis, 2004; 25: 128-133.

Garno JL, Goldberg JF, Ramirez PM, Ritzler BA, Bipolar disorder with comorbid cluster B personality disorder features: impact on suicidality. Journal of Clinical Psychiatry, 2005; 66: 339-345.

Giegling I, Olgiati P, Hartmann AM, Calati R, Möller HJ, Rujescu D, Serretti A. Personality and attempted suicide. Analysis of anger, aggression and impulsivity. Journal of Psychiatric Research, 2009, 43: 1262-1271.

Gigantesco A, Miglio R, Santone G, de Girolamo G, Bracco R, Morosini P, Norcio B, Picardi A, for the PROGRES group. The process of care in general hospital psychiatric units: a national survey in Italy. Australian and New Zealand Journal of Psychiatry, 2007, 41:509-518.

Guaiana G, D’Avanzo B, Barbui C. Update of suicide trends in Italy 1986-1996. Social Psychiatry and Psychiatric Epidemiology, 2002, 37: 267-270. 
Guaiana G, Barbui C. Admissions for personality disorders in Italy from 1988 to 1998. Clinical Practice and Epidemiology in Mental Health, 2006, 2:20.

Harwood D, Hawton K, Hope T, Jacoby R. Psychiatric disorder and personality factors associated with suicide in older people: a descriptive and case-control study International Journal of Geriatric Psychiatry, 2001; 15: 155-165.

Hawton K, Houston K, Haw C, Townsend E, Harriss L. Comorbidity of axis I and axis II disorders in patients who attempted suicide. American Journal of Psychiatry, 2003, 160: 1494-1500.

Hopwood CJ, Morey LC, Skodol AE, Sanislow CA, Grilo CM, Ansell EB, McGlashan TH, Markowitz JC, Pinto A, Yen S, Shea MT, Gunderson JG, Zanarini MC, Stout RL. Pathological personality traits among patients with absent, current, and remitted substance use disorders. Addictive Behaviors, 2011; 36: 10871090.

Isometsä ET, Henriksson MM, Heikkinen ME, Aro HM, Marttunen MJ, Kuoppasalmi KI, Lönnqvist JK. Suicide among subjects with 
personality disorders. American Journal of Psychiatry, 1996, 153: 667-673.

Lenzenweger MF, Lane MC, Loranger AW, Kessler RC. DSM-IV personality disorders in the National Comorbidity Survey Replication. Biological Psychiatry, 2007; 62: 553-564.

McCann SJ. Suicide, big five personality factors, and depression at the American state level. Archives of Suicide Research, 2010; 14: 368-374.

MacLeod AK, Tata P, Tyrer P, Schmidt U, Davidson K, Thompson S; POPMACT Group. Personality disorder and future-directed thinking in parasuicide. Journal of Personality Disorders, 2004; 18: 459-466.

Pompili M, Ruberto A, Girardi P, Tatarelli R. Suicidality in DSM IV cluster B personality disorders. An overview. Annali dell'Istituto Superiore di Sanità, 2004; 40: 475-483.

Preti A, Rucci P, Santone G, Picardi A, Miglio R, Bracco R, Norcio B, de Girolamo G; PROGES-Acute group. Patterns of admission to acute psychiatric in-patient facilities: a national survey in Italy. Psychological Medicine, 2009; 39:485-496. 
Preti A, Tondo L, Sisti D, Rocchi MB, De Girolamo G for the PROGRES-Acute group Correlates and antecedents of hospital admission for attempted suicide: a nationwide survey in Italy. European Archives of Psychiatry and Clinical Neuroscience, 2010; 260: 181-190.

Schneider B, Schnabel A, Wetterling T, Bartusch B, Weber B, Georgi K. How do personality Disorder modify suicide risk? Journal of Personality Disorders, 2008, 22: 233-245.

Soloff PH, Lynch KG, Kelly TM, Malone KM, Mann JJ. Characteristics of suicide attempts of patients with major depressive episode and borderline personality disorder: a comparative study. American Journal of Psychiatry, 2000; 157: 601-608.

Trull TJ, Jahng S, Tomko RL, Wood PK, Sher KJ. Revised NESARC personality disorder diagnoses: gender, prevalence, and comorbidity with substance dependence disorders. Journal of Personality Disorders, 2010; 24: 412-426.

Yen S, Pagano ME, Shea MT, Grilo CM, Gunderson JG, Skodol AE, McGlashan TH, Sanislow CA, Bender DS, Zanarini MC. Recent life events preceding suicide attempts in a personality disorder 
sample: findings from the collaborative longitudinal personality disorders study. Journal of Consulting and Clinical Psychology, 2005; 73: 99-105. 


\section{Chapter 7. An epidemiological}

investigation of suicides in Ticino

Canton (Switzerland) compared to

neighboring areas, 1999-2007 


\section{Summary}

Background. Suicide rate shows some variation among cultures. Ticino Canton in Switzerland and its neighboring areas in Italy (Provinces of Varese, Como and Verbano-Cusio-Ossola) form a Macro-Region (the "Regio Insubrica"), with some commonalities (e.g. Italian languages) and some differences (two different countries with two different political systems).

Aim. The aim of the present study is to explore suicide trends and rates in Ticino Canton compared to those from its neighboring Italian provinces, in order to explore cultural and system differences in suicide rates.

Methods. Data on suicide rates in Italy and Switzerland and sexand age-stratified data on the number and methods of deaths by suicide in Ticino Canton were collected from 1999 to 2007. Raw data were standardized by age, where possible.

Results. Ticino had a consistently higher suicide rate than neighboring Italian provinces of Varese and Como, but a lower suicide rate than Verbano-Cusio-Ossola.

Conclusions. Suicide rates can vary between Italy and Ticino canton because of differences in mental health systems, religion, impact of immigrants and remoteness. 


\section{Introduction}

Ticino Canton (or Ticino) is the southernmost Canton in Switzerland, and is unique in being the only Swiss Canton in which Italian is the sole official language and in which elements of both Italian and Swiss cultural influences are apparent (USTAT, 2000-2007). Ticino's population of 330,000 individuals represents approximately 7\% of the population of Switzerland (Mazzoleni, 2005). Ticino spans an area of approximately 2,800 square kilometers (USTAT, 2000-2007), and is surrounded on three sides by the Italian Provinces of Como, Varese, and VerbanoCusio-Ossola (VCO) to the Northwest, East, and Southwest, respectively (see Figure 1).

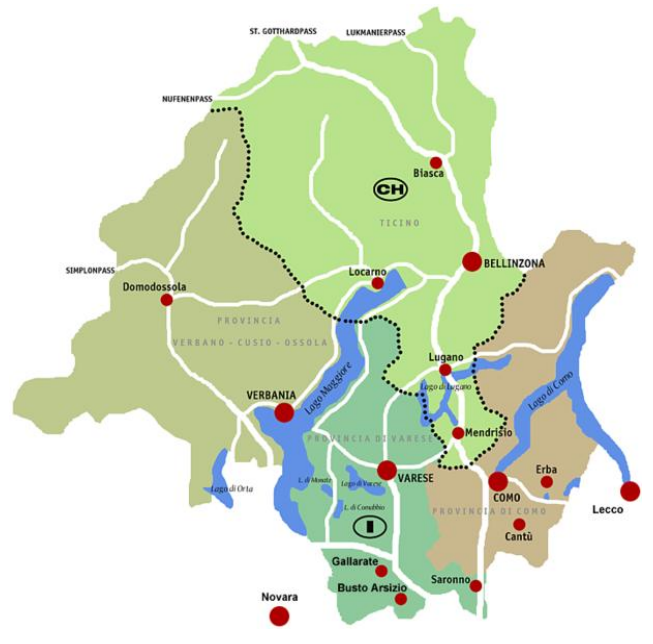

Figure 1. Map of Regio Insubrica

(Source: http://www.insubrinet.net/sect1 territorio.html) 
These Italian territories, together with Ticino, form a transnational macro-region called "Regio Insubrica" (Torricelli et al, 1997). This region has historically shared a common culture and language, despite spanning two nations (Mazzoleni et al., 2004). Although bordered by the Swiss Cantons of Uri and Valais to the North, Ticino has a certain degree of geomorphological isolation from other Swiss cantons, being situated entirely South of the Alps. . Ticino stands at the intersection of Northern and Southern European cultures and it's residents are proudly nationalistic, emphasizing cultural differences rather than similarities with their German-Swiss and Italian neighbors (Mazzoleni, 2005). According to Rudmin and colleagues (Rudmin, 2003), cultural variables can influence the epidemiology of suicide, accounting for as much as $25 \%$ of the variance of suicide rates. It appears that societies characterized by higher levels of individualism have higher suicide rates, especially for men (Rudmin, 2003), whereas societies with greater social cohesion have the lowest rates (Carlevaro, 1999; Rudmin, 2003). Carlevaro and colleagues (Carlevaro et al, 1999) previously compared suicide rates between Ticino and the rest of Switzerland from 1984 to 1995, relying upon police reports for data on suicides. They reported that Ticino had the lowest suicide rate in Switzerland, but did not compare those rates with neighboring Italian Provinces. 
The aim of the present study is thus to investigate suicide trends in Ticino Canton in order to explore potential cultural influences on differences in suicide rates between Ticino and its neighboring Italian provinces of Varese, Como and VCO.

\section{Materials and methods}

Population data and sex- and age-stratified mortality statistics for the number of deaths by suicide and methods used from 19992007 were collected from the Ticino Canton Statistical Office (USTAT), the official government-funded statistics office for Ticino Canton. Data are not yet available after 2007. Data on suicide methods were extracted according to the Tenth Revision of the International Classification of Diseases (ICD-10; World Health Organization, 1992, and included injury codes ranging from X60 to X84. Data on suicide methods were grouped into the following categories:

- Poisoning by chemical substances (ICD-10: X60-X66, X68, X69)

- Poisoning by gas (ICD-10: X67)

- Hanging (ICD-10: X70)

- Submersion (ICD-10: X71)

- Firearms (ICD-10: X72-X77)

- Cutting (ICD-10: X78, X79) 
- Jumping (ICD-10: X80-X82)

- Unspecified (ICD-10: X83, X84).

Raw data on the number of deaths by suicide were agestandardized using the direct method, based on Ticino's population according to the 2001 census. We standardized the suicide rates per 100,000 population members by sex, for every year in which data were available, and calculated total and sexspecific suicide rates by age stratum $(0-14,15-24,25-44,45-64$, $65+)$. An aggregate raw suicide rate per 100,000 inhabitants, from 1999 to 2007, was calculated for Ticino, in order to enable comparison with data from neighboring Italian regions.

Suicide mortality data for the Italian Provinces of Varese, Como, and VCO were obtained from the Central Institute of Statistics of Italy (ISTAT), for 1999-2007. Only aggregate data on raw suicide rates were available for the Italian provinces; stratification by sex was not possible.

\section{Results}

Deaths by suicide were examined over a 9-year period (19992007). In Ticino, suicide rates among men ranged from a minimum to 10.79 to a maximum of 22.03 per 100,000 population members. The suicide rates for women over the same period were far lower than for men, ranging from 3.64 to 11.17 per 100,000 
population members. Trends in suicide rates for males and females are shown in Figure 2.

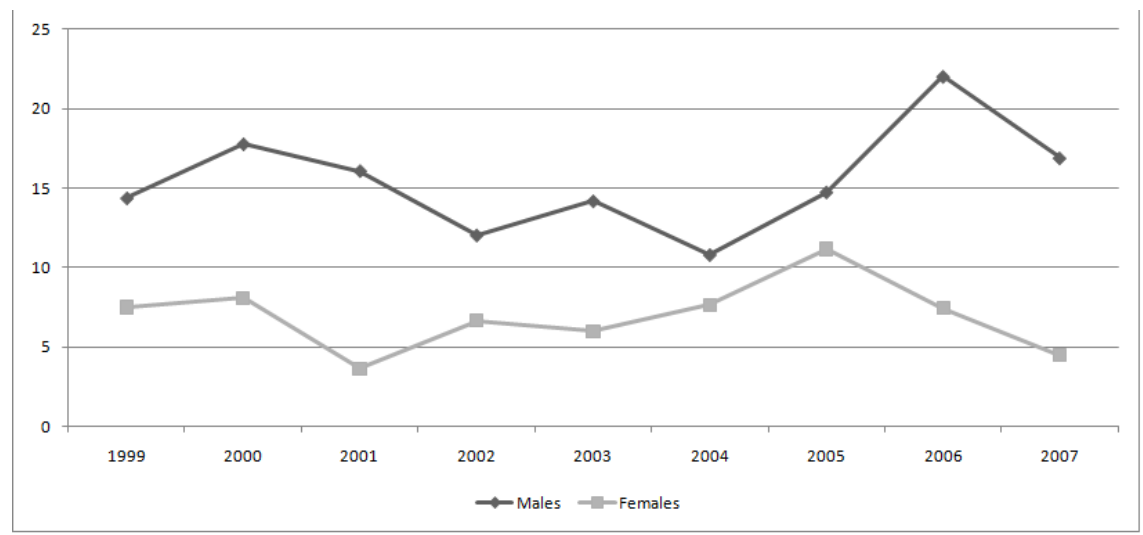

Figure 2. Standardized Suicide Rates Per 100,000 By Gender In Ticino Canton, Switzerland From 1999 To 2007

Sex differences emerged in methods of suicide among men and women in Ticino. Between 1999 and 2007, men employed hanging and firearms as a primary means of suicide, whereas women more commonly employed poisoning by chemical substances and jumping as their primary means of suicide, and infrequently used other methods of suicide. Cutting and poisoning by gas were very rarely used as methods of suicide, for both sexes. Men infrequently used submersion as a method of suicide. The most apparent difference in methods relates to the high prevalence of firearm use among men and the near absence 
of this method of suicide by women. Data on suicide methods employed appear in Table 1.

Stratifying Ticino's suicide mortality data by age revealed a trend towards an increase in suicide rates with increasing age, for both men and women. Older adults had the highest suicide rate in most years, both among men and women similar to the pattern of suicide in the United States (Heisel et al., 2005), exceptions notwithstanding. Age-stratified data on suicide rates in Ticino appear in Table 2 . 
Suicide rates in Ticino were consistently higher than in the Italian provinces of Varese and Como, but lower than in VCO for most years (see Table 3).

\begin{tabular}{|c|c|c|c|c|c|c|c|c|c|c|}
\hline & 1999 & 2000 & 2001 & 2002 & 2003 & 2004 & 2005 & 2006 & 2007 & \\
\hline \multicolumn{10}{|l|}{ MEN } & \\
\hline $\begin{array}{l}\text { Poisoning by } \\
\text { chemical } \\
\text { substances }\end{array}$ & 1 & 3 & 0 & 3 & 7 & 5 & 3 & 6 & 5 & \\
\hline $\begin{array}{l}\text { Poisoning by } \\
\text { gas }\end{array}$ & 2 & 0 & 0 & 0 & 1 & 0 & 0 & 1 & 0 & \\
\hline Hanging & 7 & 2 & 10 & 8 & 5 & 3 & 6 & 5 & 4 & \\
\hline Submersion & 0 & 0 & 0 & 0 & 0 & 0 & 0 & 0 & 1 & \\
\hline Firearms & 8 & 11 & 6 & 4 & 5 & 4 & 9 & 14 & 7 & \\
\hline Cutting & 0 & 1 & 0 & 0 & 0 & 2 & 1 & 0 & 1 & \\
\hline Jumping & 1 & 3 & 8 & 2 & 4 & 2 & 3 & 8 & 10 & \\
\hline Unspecified & 2 & 6 & 0 & 1 & 0 & 1 & 1 & 1 & 0 & \\
\hline Total & 21 & 26 & 24 & 18 & 22 & 17 & 23 & 35 & 28 & \\
\hline \multicolumn{11}{|l|}{ WOMEN } \\
\hline $\begin{array}{l}\text { Poisoning by } \\
\text { chemical } \\
\text { substances }\end{array}$ & 3 & 6 & 3 & 4 & 6 & 5 & 5 & 5 & 5 & \\
\hline $\begin{array}{l}\text { Poisoning by } \\
\text { gas }\end{array}$ & 0 & 1 & 0 & 0 & 0 & 0 & 1 & 0 & 0 & \\
\hline Hanging & 2 & 2 & 0 & 2 & 1 & 2 & 3 & 2 & 0 & \\
\hline Submersion & 1 & 1 & 0 & 1 & 0 & 1 & 2 & 0 & 1 & \\
\hline Firearms & 0 & 0 & 2 & 0 & 0 & 0 & 0 & 1 & 0 & \\
\hline Cutting & 0 & 0 & 0 & 0 & 0 & 0 & 0 & 0 & 0 & \\
\hline Jumping & 5 & 2 & 1 & 4 & 3 & 4 & 7 & 5 & 2 & \\
\hline Unspecified & 1 & 1 & 0 & 0 & 0 & 1 & 1 & 0 & 0 & \\
\hline Total & 12 & 13 & 6 & 11 & & & 13 & 19 & 13 & 8 \\
\hline
\end{tabular}

Table 1. Suicide Methods By Sex In Ticino From 1999 To 2007 Source: USTAT

NOTE: Data represent raw numbers of death by suicide. 


\begin{tabular}{|c|c|c|c|c|c|c|c|c|c|}
\hline \multicolumn{10}{|l|}{ Men } \\
\hline & 1999 & 2000 & 2001 & 2002 & 2003 & 2004 & 2005 & 2006 & 2007 \\
\hline $0-14$ & 0.00 & 0.00 & 0.00 & 0.00 & 0.00 & 0.00 & 0.00 & 0.00 & 4.39 \\
\hline $15-24$ & 12.16 & 20.18 & 12.63 & 0.00 & 12.54 & 12.69 & 18.77 & 6.18 & 24.32 \\
\hline $25-44$ & 6.33 & 19.26 & 12.69 & 21.09 & 4.21 & 6.33 & 19.01 & 23.39 & 10.70 \\
\hline $45-64$ & 25.14 & 20.04 & 17.37 & 12.26 & 17.01 & 16.51 & 16.34 & 36.80 & 18.12 \\
\hline $65+$ & 29.25 & 28.29 & 41.44 & 13.43 & 47.72 & 20.47 & 15.81 & 26.78 & 36.88 \\
\hline \multicolumn{10}{|c|}{ Women } \\
\hline & 1999 & 2000 & 2001 & 2002 & 2003 & 2004 & 2005 & 2006 & 2007 \\
\hline $0-14$ & 0.00 & 0.00 & 0.00 & 0.00 & 0.00 & 0.00 & 0.00 & 0.00 & 0.00 \\
\hline $15-24$ & 0.00 & 0.00 & 6.26 & 0.00 & 0.00 & 0.00 & 6.34 & 6.32 & 0.00 \\
\hline $25-44$ & 8.26 & 8.32 & 6.09 & 2.02 & 2.02 & 6.12 & 14.30 & 4.10 & 2.05 \\
\hline $45-64$ & 12.09 & 12.01 & 4.74 & 9.36 & 11.61 & 9.16 & 9.06 & 8.96 & 6.62 \\
\hline $65+$ & 9.11 & 11.92 & 0.00 & 17.33 & 11.41 & 16.51 & 18.87 & 15.82 & 10.32 \\
\hline
\end{tabular}

Source: USTAT 


\begin{tabular}{l|llll}
\hline & Ticino & Varese & Como & VCO \\
\hline $\mathbf{1 9 9 9}$ & 10.70 & 7.4 & 6.1 & 13.16 \\
$\mathbf{2 0 0 0}$ & 12.71 & 9.8 & 5.9 & 10.04 \\
$\mathbf{2 0 0 1}$ & 9.60 & 6.2 & 5.7 & 15.71 \\
$\mathbf{2 0 0 2}$ & 9.20 & 7 & 5.5 & 13.18 \\
$\mathbf{2 0 0 3}$ & 10.08 & 4.1 & 7.1 & 11.24 \\
$\mathbf{2 0 0 4}$ & 9.39 & 7.7 & 5.3 & 14.20 \\
$\mathbf{2 0 0 5}$ & 13.04 & 6.6 & 4.8 & 13.00 \\
$\mathbf{2 0 0 6}$ & 14.78 & 6.7 & 6.6 & 13.60 \\
$\mathbf{2 0 0 7}$ & 10.99 & 6.5 & 5 & 10.50 \\
\hline
\end{tabular}

Table 3. Unstandardized suicide rates /100,000 in Ticino, and the Italian Provinces of Varese, Como and Verbano-Cusio-Ossola 1999-2007

Source: ISTAT (Italian data), USTAT (data from Ticino)

$$
\text { VCO = Verbano-Cusio-Ossola }
$$




\section{Discussion}

Ticino's suicide rates fall in-between those of Northern and Southern Europe, reflecting its geographic position and cultural identity, which stands at the crossroads of two Middle-European and Southern European cultures (Mazzoleni, 2005). Suicide rates in Ticino are also generally lower than those in Germany, of roughly 20/100,000 for men and 10/100,000 for women (Baumert et al., 2008), and in France, of roughly 25-30/100,000 for men and 9/100,000 for women (see www.who.int/mental health/media/fran.pdf; Suicide rates in France 1950-2005; Retrieved September 23 2009). However, Ticino consistently has higher suicide rates than in Italy as a whole, both for men and for women (Guaiana et al., 2002).

An unexpected finding is that Ticino Canton has higher suicide rates than its neighboring Italian provinces. This finding is of particular relevance as Ticino shares cultural similarities with these Italian provinces, which together comprise the Regio Insubrica, including a shared Catholic background (ISTAT 20002007, USTAT 2000-2007). Ticino and the three Italian provinces of this macro-region further have a similar per capita income (ISTAT 2000-2007, USTAT 2000-2007); however, Ticino enjoys a lower unemployment rate (ISTAT 2000-2007, USTAT 2000-2007), and is both economically wealthier and more technologically advanced (Torricelli et al, 1997). One might expect that suicide 
rates would be higher in less economically rich territories (Lorant et al, 2005), yet our data suggest otherwise. We offer some hypotheses for this finding:

1. Differences in mental health systems: Mental health services are more community based in Italy (Piccinelli, 2002) and more hospital based in Ticino (USTAT 20002007). There is some evidence that well developed community mental health services are associated with lower suicide rates (Pirkola, 2009). It is possible that the higher emphasis on community based services in Italy might contribute to the lower suicide rate. There is some evidence that social fragmentation, more than poverty, is associated with higher suicide rates (Whitley et al, 1999). An emphasis towards more community based services might moderate suicide rates.

2. Religion. Ticino's population appears more secular than the Italian population (Mazzoleni, 2004), despite a common Catholic background (USTAT 2000-2007, ISTAT 2000-2007). Evidence suggests that religious affiliation may protect against death by suicide, especially among men (Gearing et al., 2009). Moreover, there is a higher proportion of Protestants in Ticino than in Italy (USTAT 2000-2007, ISTAT 2000-2007), and Protestant religious 
affiliation has been associated with higher suicide rates than among Catholics (Gearing et al., 2009).

3. Immigration. Approximately $25 \%$ of Ticino residents had immigrated to the region (USTAT 2000-2007), whereas only roughly $6 \%$ of residents of Varese and Como Provinces and $4 \%$ of VCO residents are immigrants (ISTAT 2000-2007). Immigrant status is associated with a higher risk for suicide (Kposowa et al., 2008), and immigrants tend to bring the suicide rate of their country of origin with them (Burvill, 1998). It is thus conceivable that the higher suicide rates in Ticino may be due in part to the effect of immigration from nations with higher suicide rates; however data were not available regarding the immigration status of people who died by suicide in Ticino or in the Italian Provinces.

4. Remoteness. Ticino is characterized by urbanized areas in the South of the Canton and rural/mountainous areas in the North (USTAT 2000-2007). Some evidence indicates that suicide rates tend to be higher among people living in rural or remote areas (Hawton et al., 2009), which may also explain the higher suicide rates in the Italian Province of VCO than in Varese and Como Provinces. VCO, like Ticino, is more rural than the other two Italian provinces, with more mountainous areas (Torricelli et al., 1997). Data were not available regarding urban or rural living settings 
of people who died by suicide in Ticino and in the Italian Provinces; therefore, this hypothesis is only speculative.

Ticino and its neighboring European regions can be further differentiated based on methods of suicide used. It is well-known that access to means is associated with risk for suicide and can increase the lethality of suicidal behavior (Cantor et al., 1998). Data from Ticino are consistent with this finding, as a significant proportion of those who died by suicide employed firearms. More people in Ticino and in Switzerland in general have access to firearms than elsewhere in Europe (Frei et al., 2006). Suicide by firearm is a problematic issue in the whole of Switzerland (Frei et al., 2006). Hanging has also been a method of choice in Ticino and in other countries, such as Italy (Guaiana et al., 2002).

This study's findings must be considered in the context of its limitations. A primary limitation is the relatively low number of recorded deaths by suicide in Ticino, ranging from 17 to 34 per year for men and 5 to 19 for women. Our findings are also limited by our not having conducted significance tests, given the ecological focus of this study.

\section{Conclusions}

Rates of suicide in Ticino fall in-between the low suicide rates of Southern European countries (like Italy) and the high suicide 
rates of Northern European territories and countries (such as Northern Switzerland, Germany and France). The culture and language of people in Ticino is similar to those of their Italian neighbors. It is possible that the higher suicide rates in Ticino reflect a poorer outcome of psychopathology in Ticino. The relatively small number of deaths by suicide in Ticino suggests the feasibility of conducting a psychological autopsy study in that region, facilitating identification of regional risk factors for suicide. This type of research can influence policy development and service planning, including a mental health plan soon to be implemented in Switzerland (Lehmann, 2004). 


\section{References}

Baumert J, Erazo N, Ruf E, Ladwig KH. Time trends in suicide mortality vary in choice of methods: an analysis of 145.865 fatal suicide cases in Germany 1991-2002. Social Psychiatry and Psychiatric Epidemiology, 2008; 43: 913-919.

Burvill PW. Migrant suicide rates in Australia and in country of birth. Psychological Medicine, 1998; 28: 201-208.

Cantor CH, Baume PJ. Access to methods of suicide: what impact? Australian and New Zealand Journal of Psychiatry, 1998; 32: 8-14.

Carlevaro T, Degrate A, Lungo A Molo-Bettelini C. Epidemiologie du suicide au Tessin 1984-1995. Swiss Archives of Neurology and Psychiatry, 1999; 150: 117-123.

Cavanagh JTO, Carson AJ, Sharpe M, Lawrie SM. Psychological autopsy studies of suicide: a systematic review. Psychological Medicine, 2003; 33: 395-405.

Frei A, Han A, Weiss MG, Dittmann V, Adjacic-Gross V. Use of army weapons and private firearms for suicide and homicide in the region of Basel, Switzerland. Crisis, 2006; 27:140-146. 
Gearing RE, Lizardi D. Religion and suicide. Journal of Religion and Health, 2009; 48: 332-341.

Guaiana G, Andretta M, Corbari L, Mirandola M, Sorio A, D’Avanzo B, Barbui C. Antidepressant drug consumption and public health indicators in Italy 1955 to 2000. Journal of Clinical Psychiatry, $2005 ; 66: 750-755$.

Guaiana G, D’Avanzo B, Barbui C. Update of suicide trends in Italy from 1986 to 1996. Social Psychiatry and Psychiatric Epidemiology, 2002; 37: 267-270.

Hawton K, Van Heeringen K. Suicide. Lancet, 2009; 373:13721381.

Heisel MJ, Duberstein PR. Suicide prevention in older adults. Clinical Psychology: Science and Practice, 2005; 12: 242-259.

ISTAT. Annuario Statistico Italiano. Rome: ISTAT, 2000-2007.

Kposowa AJ, McElvain JP, Breault KD. Immigration and suicide: the role of marital status duration of residence and social integration. Archives of Suicide Research, 2008; 12 : 82-92. 
Lehmann P. Strategie National visant a protèger promouvoir maintenir et retabilir la santé psychique de la population en Suisse. Berne: PNS, 2004.

Lorant V, Kunst AE, Huisman M, Bopp P, Mackenbach J on behalf of the EU Working Group on Socio-Economic Inequalities in Health. Socio-economic inequalities in suicide: a European comparative study. British Journal of Psychiatry, 2005; 187: 49-54.

Mazzoleni 0. Culture politiche e culture civiche a confronto Bellinzona: USTAT, 2004.

Mazzoleni O. Multi-level populism and Centre-Perifery Cleavage in Switzerland. In: Caramani D Meny Y (Eds). Challenges to consensual politics. Brussel: Peter Lang, pp 209-250, 2005.

Mazzoleni 0, Stanga M. Una periferia elvetica allo specchio dell'integrazione europea. Dati Statistiche e società, 2006; 3: 94108.

Piccinelli M, Politi P, Barale F. Focus on Psychiatry in Italy. British Journal of Psychiatry, 2002; 181: 538-544. 
Pirkola S, Sund R, Sailas E, Wahlbeck K. Community mental-health services and suicide rate in Finland: a nationwide small-area analysis. Lancet, 2009; 373: 147-153.

Rudmin FW, Ferrada-Noli M, Skolbekken JA. Questions of culture age and gender in the epidemiology of suicide. Scandinavian Journal of Psychology, 2003; 44: 373-381.

Schuler D, Rüesch P, Weiss C. La santè psychique en Suisse. Neuchatel: Observatoir Suisse de la Santé, 2007.

Torricelli GP, Scaramellini G, Thiede L. Atlante Socioeconomico della Regione Insubrica. Bellinzona: Casagrande, 1997.

USTAT. Annuario Statistico Ticinese Bellinzona: USTAT, 20002007.

Whitley E, Gunnell D, Dorling D, Smith GD. Ecological study of social fragmentation poverty and suicide. British Medical Journal, 1999; 319: 1034-1037.

World Health Organization. International Classifications of Disease (10th Edition) Geneva: World Health Organization, 1992. 
Conclusion 
In summary, the main findings of the study included in this thesis are:

1. Suicide rates in Italy are declining but mainly in the elderly. In young people, suicide rates are on the rise. It appears that social unease among young people is on the rise in Italy

2. Antidepressant prescribing exponentially increased in Italy over the last 20 years

3. Antidepressants can have an important role in preventing suicide, as they can improve depression, which is often linked to suicide. However, it appears that elderly mainly gained from antidepressant prescribing

4. We should not neglect the role of personality disorder in suicide, in particular when associated to a mood disorder, in Italy and elsewhere

5. Cultural factors may also play a role in suicide Although these results seem interesting, the studies have some limitations. First of all, the studies are all ecological and therefore subject to the ecological fallacy. The ecological fallacy is a fallacy based on the fact that groups of individuals are studied, rather than the individual themselves (Piantadosi et al, 1988). Data should be interpreted with caution, as serious errors can occur if researchers, clinicians and policymakers assume that data that apply to the group will pertain also to the individual (Piantadosi et 
al, 1988). In addition to the ecological fallacy, ecological studies may not show possible confounding factors for the data, may not be able to explore the issue of collinearity of some variables and cannot well analyze the relationship between exposure and effect, particularly if conducted in a time-trend fashion (Morgenstern, 1995). However, ecological studies can serve as useful hypothesisgenerative studies (Baldessarini et al, 2007), although some more stringent guidelines on their reporting may be necessary (Dufault et al, 2011). Ecologic studies are cheap to carry out and are suitable in analyzing exposure to a particular agent (Morgenstern, 1995). Several ecological studies in antidepressant prescribing and suicide have been published between 1999 and 2005 , a time where the debate on antidepressant prescribing and suicide was quite hot (Baldessarini et al, 2007).

Another limitation of the studies presented in this thesis is that data are extracted from official statistics at an aggregate level. Mistakes in data collection can indeed occur. In particular, suicide data are subject to under-reporting in several countries (Tollefsen et al, 2012). Under-reporting constitutes a major bias in the analysis of suicide deaths (Vichi et al, 2010). However, it appears that under-reporting of suicide in Italy may not occur.

How can these data be used for further studies? Ecological studies like the ones presented in this thesis, in spite of their limitations, 
can help generating hypotheses on a certain topic. These hypotheses should be verified by carrying out studies using different methodologies. Psychiatric Epidemiology needs some specific methodologies, as it inherited its study designs from general epidemiology (Prince et al, 2003). According to Prince and colleagues (Prince et al, 2003), Psychiatric Epidemiology faces some challenges, both general and specifically related to psychiatric epidemiology. General challenges include: identifying multiple levels of exposure, population-level risk factors and complex interventions. Challenges specific to the epidemiological investigation of mental disorder include: differentiating clinical versus non-clinical states, and identifying severity of the syndrome. It can be evident that suicide, thankfully being a rare event, can be difficult to study at the population level. Even more difficult and challenging is to find a relationship between suicide and its determinants. With these limitations in mind, research on suicide and antidepressant prescribing can take (and is some cases, has taken) several directions:

1. In order to investigate suicide, psychological autopsy studies can be carried out. Suicide is thankfully a rare event. In Ticino Canton, the area examined in Chapter 7, absolute number of suicides range from about 30 to 40 a year. The numbers may be suitable for some psychological autopsy study that may examine suicides more in detail. 
Cultural factors as well as organizational issues may be better explored. Psychological autopsy study may be limited by recall bias (Prince et al, 2003). There are several methodological challenges of psychological autopsy studies. Data collection and reliability is the main, which can be partially overcome by rigorous diagnostic interviews (Conner et al, 2011), although there is a high risk of bias (Pouliot et al, 2006). Also, the timing between death and interview can be a factor increasing bias (Pouliot et al, 2006). In spite of the limitations, psychological autopsy studies can shed some light on the determinants of suicide, including cultural ones.

2. Another possible step forward may involve evaluating antidepressant prescribing in different ages. It appears that the induction of suicide may be different if the patient is young, middle-aged or old. The studies included in this thesis, and data from the literature all point in the direction of a differential effect on suicide depending on age range. It appears that young people are more at risk of developing suicidal ideation and possibly to complete suicide. On the other hand, antidepressants may reduce suicidal ideation and suicidal risk among the elderly. The paper in chapter 5 showed that elderly have been prescribed more 
antidepressants from 2000 to 2005. It may be possible that the decrease in suicide rates in Italy may be attributed mainly to a decrease among elderly.

3. Some studies examined antidepressant prescribing in an Italian region (Friuli Venezia Giulia) using a prescription database, with individual-based data on antidepressant prescribing and suicide (Castelpietra et al, 2008). Unfortunately, this study did not allow a detailed analysis of suicide in different age groups. It will be of extreme importance to use individual-based data on a national level, with specified age bands. As a policy recommendation, it will be of vital importance to start and develop reliable national databases with data on antidepressant prescribing, suicide and admissions for mental disorder, so that the quality of data can be improved and the problems with ecological studies can be overcome.

4. Another possible direction can be to investigate how to translate the data from epidemiological studies into the bedside. This approach is called "Translational Epidemiology". Its psychiatric applications have been illustrated in a recent article (Weissman et al, 2011). Translational epidemiology is bidirectional, in that data from epidemiological studies in psychiatry can offer some 
interesting insights to basic scientist that work on the etiology and genetics of mental disorders (Weissman et al, 2011). It has been suggested that it is possible to enrich community surveys by adding DNA analysis or biomarkers to the standard epidemiological data. In the case of suicide, it may be useful to use this translational tools to investigate genetic of suicide as related to antidepressant prescribing by adding biomarkers to standard surveys.

Whatever the route pursued in the investigation of suicide and its relationship with antidepressant prescribing, further research will hopefully increase our understanding of the relationship between mental illness, its treatments and suicides, so that this tragic event can be more effectively prevented. 


\section{References}

Baldessarini RJ, Tondo L, Strombom IM, Dominguez S, Fawcett J, Licinio J, Oquendo MA, Tollefson GD, Valuck RJ, Tohen M. Ecological studies of antidepressant treatment and suicidal risks. Harvard Review of Psychiatry, 2007; 15: 133-145.

Castelpietra G, Morsanutto A, Pascolo-Fabrici E, Isacsson G. Antidepressant use and suicide prevention: a prescription database study in the region Friuli Venezia Giulia, Italy. Acta Psychiatrica Scandinavica, 2008; 118: 382-388.

Conner KR, Beautrais AL, Brent DA, Conwell Y, Phillips MR, Schneider B. The next generation of psychological autopsy studies. Part I. Interview content. Suicide and Life Threatening Behavior, 2011;41: 594-613.

Dufault B, Klar N. The quality of modern cross-sectional ecologic studies: a bibliometric review. American Journal of Epidemiology, 2011; 174: 1101-1107.

Morgenstern H. Ecologic studies in epidemiology: concepts, principles, and methods. Annual Review of Public Health, 1995;16: 61-81. 
Piantadosi S, Byar DP, Green SB. The ecological fallacy. American Journal of Epidemiology, 1988; 127: 893-904.

Pouliot L, De Leo D. Critical issues in psychological autopsy studies. Suicide and Life Threatening Behavior, 2006;36: 491-510.

Prince M, Stewart R, Ford T, Hotopf M (Eds). Practical Psychiatric Epidemiology. Oxford: Oxford University Press, 2003.

Tollefsen IM, Hem E, Ekeberg 0 . The reliability of suicide statistics: a systematic review. BMC Psychiatry, 2012. doi:10.1186/1471-244X-12-9

Vichi M, Masocco M, Pompili M, Lester D, Tatarelli R, Vanacore N. Suicide mortality in Italy from 1980 to 2002. Psychiatry Research, 2010; 175: 89-97.

Weissman MM, Brown AD, Talati A. Translational Epidemiology in Psychiatry: linking population to clinical and basic sciences. Archives of General Psychiatry, 2011; 68: 600-608. 


\section{Nederlanse Samenvatting}




\section{Een onderzoek naar het aantal zelfmoorden en het voorschrijven van antidepressiva in Italië en in het kanton Ticino in Zwitserland}

Dit proefschrift wil een bijdrage leveren aan de epidemiologische en farmaco-epidemiologische benadering van zelfmoord en het voorschrijven van antidepressiva. Het doel van dit proefschrift is de trends aan te geven in het aantal zelfmoorden in Italië en in het Kanton Ticino in Zwitserland en de relatie te onderzoeken tussen het aantal zelfmoorden en het voorschrijven van antidepressiva. Het eerste hoofdstuk (Hoofdstuk 1) schetst de omstandigheden. Het is een onderzoek naar zelfmoorden in Italië tussen 1986 en 1996. Het onderzoek is descriptief en maakt gebruik van de nationale database van het Italiaanse Nationale Bureau van Statistiek. Het onderzoek werd uitgevoerd met als doel de zelfmoord trends in Italië te onderzoeken naar aanleiding van een publicatie waarin zorgwekkende gegevens vermeld werden over het toenemende aantal zelfmoorden in Italië tussen 1975 en 1987. Gewoonlijk is het aantal zelfmoorden binnen de verschillende leeftijdsgroepen niet hetzelfde.

Hoofdstuk 2 van dit proefschrift onderzoekt zelfmoord bij kinderen en adolescenten om te zien of er een verschillend patroon kan worden waargenomen. Gebruik makend van dezelfde 
database als in Hoofdstuk 1 kijkt Hoofdstuk 2 vooral naar zelfmoord bij mensen tussen de 15 en 19 jaar oud in Italië tussen 1972 en 2008. Er zijn verschillende verklaringen gegeven voor zelfmoordtrends in Italië en elders. Een van de meest voorkomende verklaringen is het mogelijke verband tussen het voorschrijven van antidepressiva en zelfmoord. Zoals boven reeds aangegeven heeft dit onderwerp bij onderzoekers tot een verhit debat geleid.

Dit debat wordt nader besproken in Hoofdstuk 3. In dit hoofdstuk worden gegevens vermeld over het voorschrijven van antidepressiva en zelfmoord in Italië. De gegevens omvatten een lange periode. Zelfmoorden worden onderzocht van 1955 tot 2000 en het voorschrijven van antidepressiva van 1987 tot 2000. De database voor zelfmoorden is weer dezelfde als die gebruikt is in de Hoofdstukken 1 en 2, terwijl de gegevens over het voorschrijven van antidepressiva gehaald is uit de database van IMS Health, een private onderneming. Ook werd het aantal ziekenhuisopnames naar aanleiding van depressie onderzocht, weer met gebruikmaking van het Italiaanse Nationale Bureau voor de Statistiek (ISTAT). Een complete analyse van het aantal zelfmoorden moet ook kijken naar regionale verschillen. Italië is een land met duidelijke verschillen tussen de regio's. Het aantal zelfmoorden en het voorschrijven van antidepressiva kan verschillen van de ene regio naar de andere. Onderzoek naar de 
overeenkomsten en verschillen tussen de regio's kan enig inzicht verschaffen in de mogelijke oorzaken van zelfmoord.

Een regionale analyse van het aantal zelfmoorden en het voorschrijven van antidepressiva wordt gegeven in de hoofdstukken 4 en 5 van respectievelijk de Italiaanse regio's Emilia-Romagna en Veneto. De gegevens in hoofdstuk 4 werden verkregen uit de plaatselijke databases van de regio EmiliaRomagna van 1999 tot 2008.

Terwijl in de eerste drie hoofdstukken een pure beschrijvende benadering werd gebruikt, worden in Hoofdstuk 4 de gegevens geanalyseerd volgens een eenvoudig lineair regressief model. Hetzelfde model is gebruikt met betrekking tot de gegevens in Hoofdstuk 5. Ook hier werden gegevens over het voorschrijven van antidepressiva in de regio Veneto geanalyseerd in relatie tot het aantal zelfmoorden gedurende een periode van zes jaar (van 2000 tot 2005).

Hoofdstuk 5 bevat meer details over het voorschrijven van antidepressiva in vergelijk met de Hoofdstukken 3 en 4, omdat hier de data zijn opgesplitst naar leeftijd en geslacht. Het voorschrijven van antidepressiva werd geanalyseerd voor mensen in de leeftijdsgroepen van 0-14 jaar, 15-64 jaar en boven de 65 jaar. Antidepressant prescribing was analyzed in people aged 014, 15-64 and over 65. Dit geeft enig inzicht omdat zowel het 
gebruik van antidepressiva als het aantal zelfmoorden per leeftijdsgroep varieert. Het aantal opnames vanwege depressie werd ook onderzocht. Een van de hypotheses van dit proefschrift luidt dat als opnames voor depressie afnemen, er minder ernstige gevallen van depressie zijn, daar we opnames zien als een belangrijke aanwijzing voor de ernst van depressies. Depressie en andere As I stoornissen zijn zeker belangrijke oorzaken voor zelfmoord, maar ook persoonlijkheidsstoornissen zijn een belangrijke causale factor.

Hoofdstuk 6 gaat hier nader op in. Dit hoofdstuk is verdeeld in twee delen: deel 1 onderzoekt opname aantallen specifiek voor eerste en ook voor volgende opnames voor persoonlijkheidsstoornissen in heel Italië van 1988 tot 1998. Ook deze gegevens werden weer verkregen uit de ISTAT en hierop werd een beschrijvende methode toegepast. Ziekenhuisopnames voor persoonlijkheidsstoornissen kunnen in dit kader gezien worden als een aanwijzing voor de ernst van de depressie. Deel 2 van Hoofdstuk 6 bouwt verder op de resultaten van deel 1 door te kijken naar het bewijs voor het verband tussen zelfmoord en persoonlijkheidsstoornis. Hoofdstuk 6, deel 2 biedt een overzicht van dit onderwerp.

Tot zo ver gingen de diverse hoofdstukken over geestelijke gezondheidsproblemen en hun relatie tot zelfmoord. Terwijl dit een hele belangrijke reden voor zelfmoord is, moeten andere problemen niet vergeten worden. Cultuur is er een van. In het 
laatste hoofdstuk van dit proefschrift, Hoofdstuk 7, worden zelfmoordaantallen uit het kanton Ticino, in Zwitserland, weergegeven en vergeleken met aangrenzende provincies in Italië. Ticino is een Italiaans sprekend kanton in Zwitserland. Het kanton deelt elementen van zowel de Italiaanse als de Zwitserse cultuur. Het laatste hoofdstuk onderzoekt mogelijke oorzaken van zelfmoord door de lens van culturele en systeem verschillen.

De belangrijkste conclusies uit de verschillende onderzoeken in dit proefschrift zijn:

1. Het aantal zelfmoorden in Italië neemt af, maar vooral onder oudere mensen. Bij jonge mensen neemt het aantal zelfmoorden juist toe. Het lijkt erop dat onder jonge mensen in Italië het sociale ongemak toeneemt.

2. Het voorschrijven van antidepressieva is in de laatste 20 jaar in Italië exponentieel toegenomen.

3. Antidepressiva kunnen een belangrijke rol spleen in het voorkomen van zelfmoord omdat ze depressie kunnen verbeteren, een feit dat vaak in verband gebracht wordt met zelfmoord. Het lijkt er echter op dat hoofdzakelijk oudere mensen van het voorschrijven van antidepressiva profiteren.

4. We moeten de rol die persoonlijkheidsstoornissen bij zelfmoord spelen niet onderschatten, vooral niet als deze 
geassocieerd worden met een stemmingsstoornis, niet in Italië en niet elders.

5. Ook culturele factoren spleen waarschijnlijk een rol bij zelfmoord.

Alhoewel deze resultaten erg interessant lijken, zijn er toch beperkingen. Ten eerste zijn dit allemaal ecologische studies en dus vatbaar voor fouten die met dit soort studies samenhangen. Een andere beperking van deze studie is dat de gegevens verkregen werden uit officiële statistieken op geaggregeerd niveau. Er worden fouten gemaakt met het verzamelen van gegevens en bovendien worden zelfmoordgegevens in verschillende landen vaak onder-gerapporteerd. Onderrapportage geeft een belangrijke vertekening in de analyse van doding door zelfmoord.

Gegevens uit dit proefschrift kunnen gebruikt worden voor verder onderzoek dat gebruik maakt van de methode van psychologische, kritische analyse en vertalende epidemiologie. Ook kunnen meer gedetailleerde databases gebruikt worden om de gegevens uit dit proefschrift te bevestigen of te ontkrachten. 


\section{Acknowledgments}

This thesis represents the completion of years of work, of sleepless nights, of doubts and happiness, and relief. Since no person can live in isolation, this piece of work is the result of countless interactions with people who, directly or indirectly, helped me in completing it.

First and foremost I am very grateful to prof. Griez, who helped me sort out and tidy up the mess that was inhabiting my brain at the beginning of this journey. Your help and supervision have been invaluable!

It is often debated in epidemiology what proximate and remote causes of an event are. In my case, the remote cause for this thesis are definitely my parents, who instilled me the love for knowledge and the passion for study. Nothing could have been possible without their help and support during my years of school and university. Grazie Mamma e Grazie Papà, siete unici!!! The proximate cause of this thesis are the three people that share my house: Loen, my wife, Andrew and Christian, my children. Thanks to them, my life is solid and stable. Their daily warmth and contagious happiness makes my day, every day. 
Thanks to Leni Noteborn, who patiently explained to me again and again the long but necessary steps to complete this work and get to the defence! You have been very helpful! 


\section{Curriculum vitae}

Dr. Giuseppe Guaiana was born in Milan, Italy, on 21 September 1973. He completed high school from 1986 to 1991. He graduated in Medicine from the University of Milan, Italy in 1998. He then started his Residency in Psychiatry at the University of Eastern Piedmont in Novara, Italy. He moved to the United Kingdom in 2001 to complete his Residency Training in Psychiatry. He was Board Certified in Psychiatry in 2002, from Italy and United Kingdom. After certification, Dr. Guaiana took up an Assistant Professor (Clinical Lecturer) position at the University of Hull, United Kingdom, in 2003. He then moved to Switzerland, in 2005, where he worked as Attending Physician in Psychiatry at the Canton Psychiatric Hospital in Mendrisio, Ticino Canton, where he remained until June 2009. He obtained a Master of Science in Affective Neuroscience from Maastricht University in 2007.

Since July 1 2009, he has been Associate Professor of Psychiatry at the University of Western Ontario, working in the Psychosis Program (Saint Thomas) and in Mood and Anxiety (GAAMHS, London).

His research and clinical interests are in Psychiatric Epidemiology, Psychosis, Mood and Anxiety Disorders, Cognitive-Behavioral Therapy and Psychopharmacology. He taught and is teaching to 
Undergraduate Students in Psychology, to Medical Students and to Residents in Psychiatry. 


\section{Publication list}

\section{Peer Reviewed Publications}

Journal Articles

1. Guaiana G, Andretta M, Griez E, Biancosino B, Grassi L. Sales of antidepressants, suicides and hospital admissions for depression in Veneto Region (Italy) from 2000 to 2005: an ecological study. Annals of General Psychiatry, 2011. 10:14. Impact Factor: 1.53, Principal Author

2. Guaiana G. Suicides, Attempted Suicides and admissions for depression in Ticino Canton (Switzerland) 2000-2007. Minerva Psichiatrica, 2011, 52 (2): 101-106. Principal Author

3. Guaiana G, Morelli AC, Chiodo D. Group Cognitive Behavioral Therapy (Group) for Schizophrenia [protocol]. Cochrane Database of Systematic Reviews, 2012, DOI: 10.1002/14651858.CD009608. Principal Author

4. Guaiana G. Antidepressant prescribing and suicides in EmiliaRomagna Region (Italy) from 1999 to 2008: an ecological study. Clinical Practice and Epidemology in Mental Health, 2011, 7: 120-122. Principal Author 
5. Guaiana G, Gupta S, Chiodo D, Davies SJC. Agomelatine versus other types of antidepressive agents for major depression [Intervention protocol]. Cochrane Database of Systematic Reviews, 2010, Issue 11, Art. No.: CD008851. DOI: 10.1002/14651858. Principal Author

6. Guaiana G, Cipriani A, Barbui C. Hydroxyzine for Generalized Anxiety Disorder. Cochrane Database of Systematic Reviews, 2010, Issue 12, Art. No.: CD006815. DOI: 10.1002/14651858.CD006815.pub2. Principal Author

7. Campi R, Barbato A, D’Avanzo B, Guaiana G, Bonati M. Suicide in Italian children and adolescents. Journal of Affective Disorders, 2009, 113: 291-295. Coauthor

8. Guaiana G, Tyson P, Roberts K, Mortimer AM. Negative symptoms and not cognition predict social functioning among patients with schizophrenia. Swiss Archives of Neurology and Psychiatry, 2007, 158: 25-31. Principal Author

9. Guaiana G, Barbui C, Hotopf M. Amitriptyline for depression. The Cochrane Library, 2007 (3):CD004186. Principal Author

10. Guaiana G, Barbui C, Churchill R, Cipriani A, McGuire HF. Hydroxyzine for generalised anxiety disorder (protocol). Cochrane Database of Systematic Reviews, 2007, (4):CD006815. Principal Author 
11. Guaiana G, Barbui C. Admissions for personality disorders in Italy from 1988 to 1998. Clinical Practice and Epidemiology in Mental Health, 2006, 2:20. Principal Author

12. Guaiana G, Andretta M, Corbari L, Mirandola M, Sorio A, D’Avanzo B, Barbui C. Antidepressant drug consumption and public health indicators in Italy, 1955-2000. Journal of Clinical Psychiatry, 2005, 66:750-755. Principal Author

13. Barbui C, Guaiana G, Hotopf M. Amitriptyline for inpatients and SSRIs for outpatients with depression? Systematic review and meta-regression analysis. Pharmacopsychiatry, 2004, 37:93-97. Coauthor

14. Guaiana G, Barbui C. Trends in the use of the Italian Mental Health Act, 1986-1997. European Psychiatry, 2004, 19:444445. Principal Author

15. Guaiana G, Tyson P, Mortimer AM. The Rivermead Behavioural Memory Test can predict social functioning among schizophrenic patients treated with Clozapine. International Journal of Psychiatry in Clinical Practice, 2004, 8:245-249. Principal Author 
16. Guaiana G, Barbui C, Hotopf M. Amitriptyline versus other types of pharmacotherapy for depression. The Cochrane Library, 2003(2): CD004186. Principal Author

17. Guaiana G, D'Avanzo B, Barbui C. Update of suicide trends in Italy from 1986 to 1996. Social Psychiatry and Psychiatric Epidemiology, 2002, 37(6): 267-270. Principal Author

18. Guaiana G, Barbui C. Aspetti regolatori in Europa: revisione sistematica delle raccomandazioni sugli psicofarmaci. [A systematic review of the European Agency for the Evaluation of Medicinal Products (EMEA) recommendations on the conduct of clinical trials in psychiatry] Epidemiologia e Psichiatria Sociale, 2002, 11(1):28-34. Principal Author

19. Barbui C, Danese A, Guaiana G, Mapelli L, Miele L, Monzani E, Percudani M on behalf of the Study Group. Prescribing secondgeneration antipsychotics and the evolving standards of care in Italy. Pharmacopsychiatry, 2002, 6:239-243. Coauthor

20. Torre E, Zeppegno P, Usai C, Torre EM, Artioli P, Guaiana G, Olgiati P. Il Burnout: aspetti quantitativi e caratteristiche di personalità Una ricerca. [Burnout: quantitative aspects and personality styles: A study] Minerva Psichiatrica, 2001, 42(2): 83-89. Coauthor 
21. Torre E, Guaiana G, Marangon D, Migliaretti G, Rudoni M, Torre EM, Usai C, Zeppegno P. Suicide among young people: an epidemiological analysis in three Italian provinces. The European Journal of Psychiatry, 2001, 15(3): 180-188. Coauthor

22. Guaiana G, Barbui C. Ansia e insonnia: quali alternative alle benzodiazepine. Informazioni sui Farmaci, 2001, 25 (1): 1826. Principal Author

23. Barbui C, Guaiana G. La distimia in medicina generale Epidemiologia e trattamento farmacologico. Informazioni sui Farmaci, 2001, 25(2-3): 62-66. Coauthor

24. Barbui C, Guaiana G, Garattini S. Regulatory issues in Europe. Journal of Clinical Psychopharmacology, 2001, 21(6): 545548. Coauthor

25. Torre E, Zeppegno P, Imperatori F, Panella M, Artioli P, Guaiana G. Burnout, caratteristiche individuali, tipo psicologico: una ricerca. Rivista di Psichiatria, 2000, 35(4): 171-176. Coauthor

$\underline{\text { Case Reports }}$ 
1. Guaiana G, Salvioli C, Mariconda G. Methadone augmentation of clozapine in treatment-resistant schizophrenia without opiates addiction: a case report. Swiss Archives of Neurology and Psychiatry, 2009, 3:122-123. Principal Author

2. Guaiana G, Markova IS. Antipsychotic treatment improves outcome in Herpes Simplex Encephalitis: a case report. Journal of Neuropsychiatry and Clinical Neuroscience, 2006, 18:247. Principal Author

3. Guaiana G, Eyrek C, Mariconda G. Polydipsia with normal natremia induced by Valproic Acid. Australian and New Zealand Journal of Psychiatry, 2006, 40:815-816. Principal Author

4. Guaiana G, Robertson C, Mortimer AM. Efficacy of Transcranial Magnetic Stimulation in Panic Disorder: a case report. Australian and New Zealand Journal of Psychiatry, 2005, 39:1047. Principal Author

\section{$\underline{\text { Abstracts }}$}

1. Olgiati P, Guaiana G. Self-identity change in chronic schizophrenia. Abstract published for the International Congress for Schizophrenia Research, in Savannah, Georgia, US, on 5-6 April 2005. Coauthor 


\section{Non-Peer Reviewed Publications}

\section{$\underline{\text { Commentaries }}$}

1. Guaiana G. Past or current drug or alcohol use disorders increase the likelihood of a switch from depressive to manic, mixed or hypomanic states in patients with bipolar disorder. Evidence-Based Mental Health, 2010 Aug, 13:78. Principal Author

$\underline{\text { Invited commentary on personal experience with Autism }}$

1. Guaiana G, Guaiana ML. Possiamo cominciare la nostra storia dalla fine. Autismo Oggi, 2009, 17: 18-21. Principal Author 